


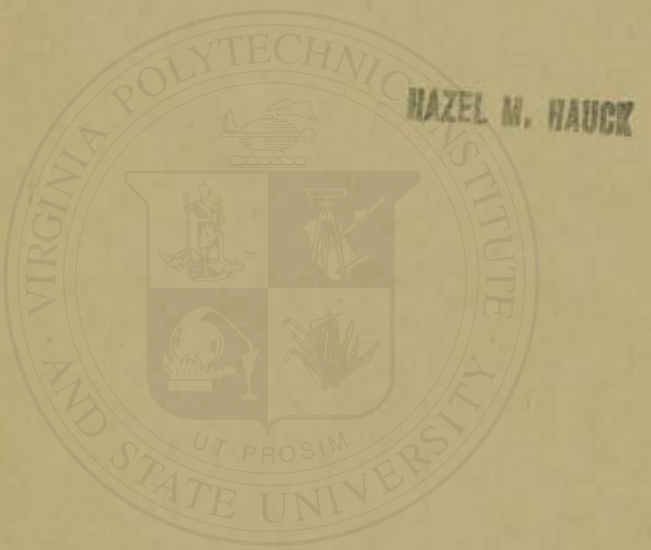


Hazel M. Hauck. 


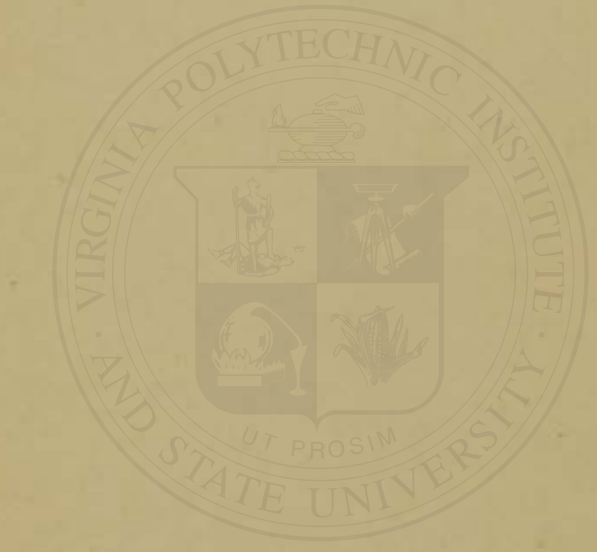




\section{FOOD, HEALTH AND GROWTH}

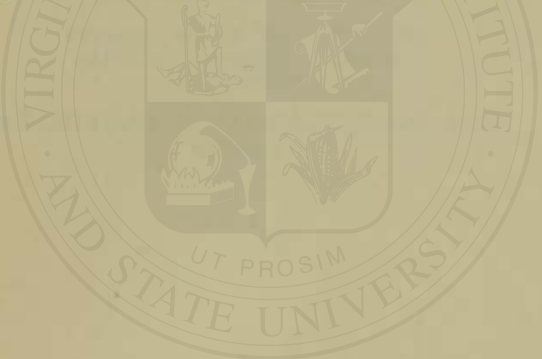




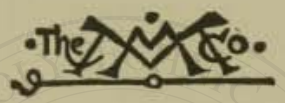

THE MACMILLAN COMPANY

SIEW YORK - BOSTON - CHICAGO - DALAS

ATLANTA - SAN ERANCISCO

MACMILLAN \& CO. Larrm

LONDON - BOMCRAY - CALCUTIA

MELL BOURNE

THB MACMILLAN CO. OP CANADA, Im. TORONTO 


\section{Food, Health and Growth}

A Discussion of the Nutrition of Children

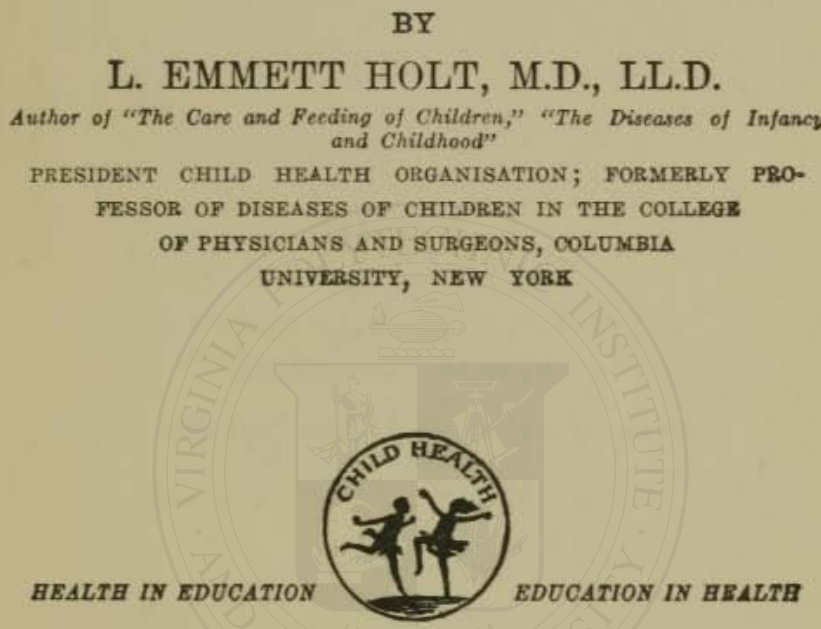

Selo 其ork

THE MACMILLAN COMPANY

1923

All rights reaerved 
PRINTED IN THE UNITED STATES OF AMFRICA
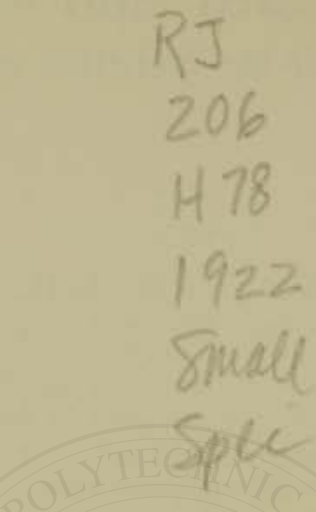

Cormuant, 1922, BY THE MACMILLAN COMPANY.

Set up and electrotyped. Published June, 1922.

Press of

J. J. Little \& Ives Company

New York, U. 8. A. 


\section{Dedicatted to}

RAY LYMAN WHBBR, M.D., LL.D. PRESIDENT LELAND STANFORT JUNIOR UNIVERSITY PHYSICIAN, EDUCATOR AND $\triangle D M I N I S T R A T O B$ 


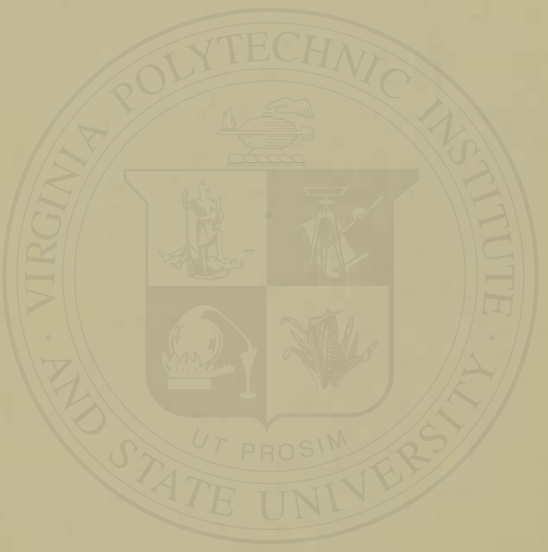




\section{PREFACE}

THis little volume contains the Lane Lectures given at the Medical School of the Leland Stanford Junior University in San Francisco in December, 1921. The lectures are published substantially as they were delivered.

The book is not therefore to be regarded as a text-book or even a systematic discussion of the aspects of nutrition which are here considered. But out of the wide range of topics relating to the nutrition of children certain ones have been chosen which seemed of special interest and importance at the present time, even though they are apparently not closely connected.

Everything relating to the subject of nutrition and especially the food and nutrition of children has acquired a new interest in the last few years and much new knowledge has been added. The effort has been made in these lectures to present some of this in such a simple form as to make it available to the student of nutrition and the general reader. vii 
viii

It has not been thought desirable to burden the text with references to the publications of the authors whose work is mentioned in these lectures. I must, however, express my special indebtedness to the Report of the British Medical Research Committee upon Accessory Food Factors (Vitamines).

The second and third lectures are based upon studies which have been carried on, chiefly at the Babies' Hospital during the past three years, jointly by the author and Helen L. Fales to whom acknowledgment is made for coöperation and assistance. The chemical work in connection with this study was done by Miss Fales, to whom I am also indebted for the tables of caloric food values in the Appendix. 


\section{CONTENTS}

LECTURH

I. Nutrition in Reilation to Growth, to Mrntal Progress and to Resistance to Disease . . . . . . . . . . . . 1

II. The Food Requirements of ChILdRen DURing the Entire Pertod of Growth . . . . 47

III. The Conditions Upon Which Are Based the Requirearents for Protein, fat, Carbohydrate and Minkral Salts. The PercentAGE of tHe Dimferent Food Constituents IN THE DIET OF CHILDEN . . . . . . 87

IV. Vitamtres . . . . . . . . . . 149

v. Practioal means by Which the nutrimon of Chindren May Be IMrpeoved . . . . . 208

VI. APPENDIX . . . . . . . . . 263

INDEX . . . . . . . . . . . 269 


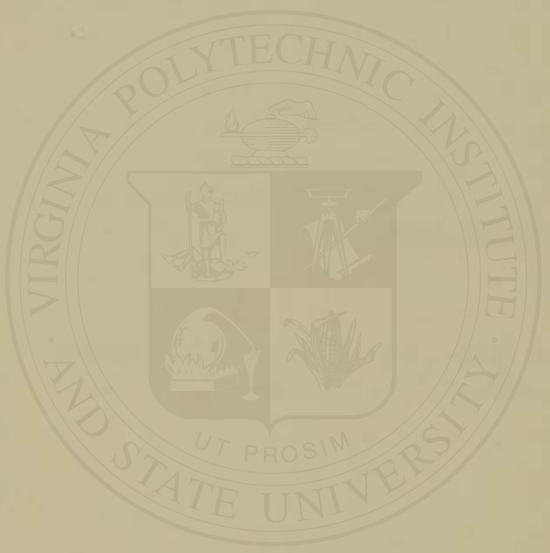




\section{ILLUSTRATIONS}

rooxe

1. Nutrition and Sehool Progress, Washington, D. C. 26

2. Weight and Sehool Progress, Detroit Boys . . 28

3. Annual Gain in Weight and Height for Both Sexes . . . . . . . . 53

4. Calories per Kilo. for Boys . . . . . 68

5. " " "6 " G Girls . . . to . . 68

6. Total Daily Calories for Boys . . . . . 74

7. "6 " " " Girls . . . . . . 74

8. " $"$ " $\quad 100$ Individual Observations 81

9. Proteins Reinforced by Addition of Amino-Acids 93

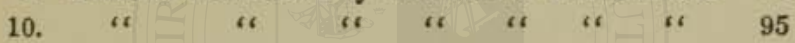

11. Grams Total Protein Taken Daily . . . . 101

12. Percentage of Animal and Vegetable Proteins . 104

13. Pereentage Distribution of Total Carbohydrate . 127

14. Growth with Diets Deficient in Mineral Salts . 136

15. Distribution of Calories Taken by Healthy Children . . . . . . . . 140

16. Distribution Total Calories-Boys . . . 143

17. " " 6 " "Girls . . . 143

18. " $"$ " 4 Per Kilo-Boys . 144

19. " " " " "-Girls . 144

20. Effect of Addition of Milk to Purified Foodstuffs 153

21. Growth on Diets Deficient in Vitamines . . . 156

22. Deficiency of Vitamine " $A$ " ' in Vegetable Oils . 160

23. Growth with Vitamine "B" from Different Plants . . . . . . . 170

24. Amounts of Foods Needed to Prevent Seurvy . 182 


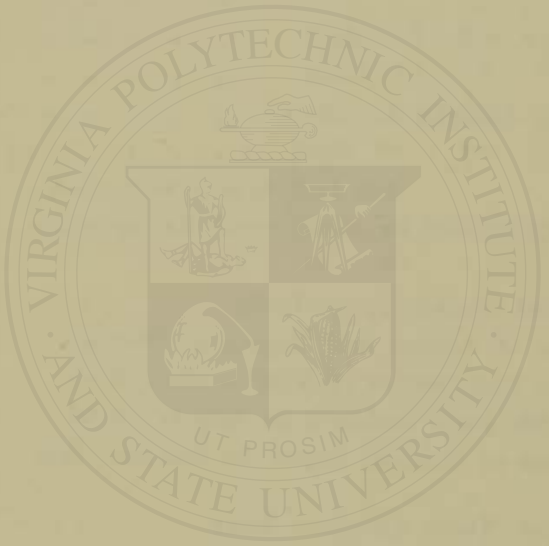




\section{FOOD, HEALTH AND GROWTH}




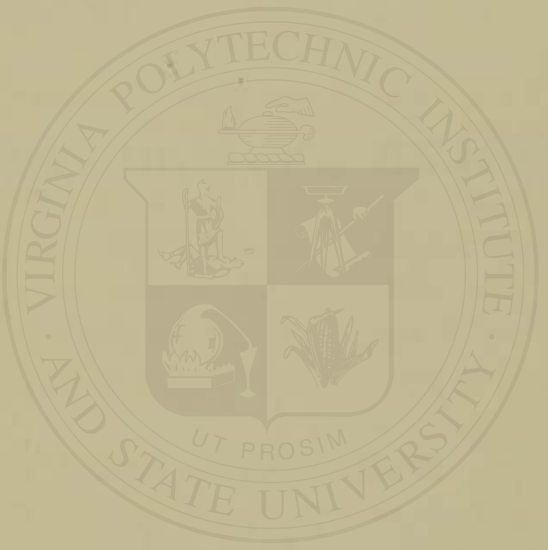




\section{Food, Health and Growth}

\section{CHAPTER I}

\section{Lecture ONe}

\section{Nutrition in Its Relation to Growth, to Progress}

in School and to Resistance to Disease.

THE problem of nutrition is older than the human race. It began when life began upon this planet. The survival of a species of plants and later of animals was conditioned upon their finding proper food and a favourable environment.

Not only the physical development of man but the fate of nations has been in the past in no small degree dependent upon their ability to solve the food question. This is true in peace times; but in war time the problem of feeding an army or navy is quite as important as munitions. It was American wheat quite as much as American men which determined the outcome of the last war. 
Early in 1918 Lord Rhondda, the British Food Controller, is reported to have said to the War Council: "Gentlemen, we are through. The Allies have lost the war. We are reaching the end of our food supply." $\mathrm{He}$ cabled to $\mathrm{Mr}$. Hoover that unless the United States could send an extra allowance of seventy-five million bushels of wheat the Allies could not hold out until the American troops should arrive.

In many revolutions the food question has been the potent factor in stirring people to overthrow their government.

As never before in modern times the sub-

Food and Nutrition Are World Priblems ject of food and nutrition has come to the front today. It is probably the most pressing world problem. It was beginning to be felt even before the war; but greatly decreased production and consequent high cost of food have intensified conditions and made the situation more acute. We have often seen the results of prolonged underfeeding of individuals. We are now witnessing the consequences of the underfeeding of whole nations. The glimpses which we are able to obtain from reports of conditions in Poland and China and, most of all, in Russia help us to realise this to a small degree.

All unfavourable hygienic conditions, lack 
of proper food particularly, bear most heavily upon children. They have less resistance than adults. They are more susceptible to infection, and the consequences of prolonged underfeeding are much more serious. With adults, underfeeding if not extreme in degree, even though prolonged, may greatly reduce efficiency without seriously or permanently impairing health. Not so with children. With them the food allowanee must be not only sufficient for energy and the repair of waste, Children Feel Deprivation but in addition a large allowance must be Most supplied for growth. Furthermore, there are certain food constituents essential for growth, and unless these are furnished in the food growth suffers even though the quantity of food is sufficient.

The health, growth and physical development of children and to a considerable degree their mental development and progress depend upon their nutrition.

It is for these reasons that I have chosen the nutrition of children, especially the food, health and growth of children, as the general topic of these lectures.

The subject is a very broad one; all that will be attempted will be to point out some of the most important bearings of nutrition upon the life of the children, to bring to your 
notice some of the results of the more recent laboratory studies which have shed new light upon this subject and finally to discuss the question of how malnutrition in children, as it exists in this country today, may be solved.

We are continually reminded of the fact that in business there are too many middlemen, and that the public interest suffers in consequence. But is it not true that in science we have too few? There is, I believe, at the

Middlemen Needed in Science present time, a need of one who shall stand between the producer, that is the research worker in the laboratory, and the ultimate consumer, who may be the practising physician, the health worker or the general public. Such a middleman I shall hope in these lectures to be.

Health and normal nutrition are not quite synonymous terms; yet as applied to children during the period of growth they are so closely allied that one may be taken as an index of the other. While there may be normal nutrition without health, there cannot be health without normal nutrition.

Nutrition in infancy has been given a great deal of careful study for the last thirty years. So successful has been the eampaign both in this country and in Europe which has been waged against a high infant mortality, that 
some of the results seem little short of marvelous. In New York City, for instance, the infant death rate has been reduced during this period practically to one-third the figure of a generation ago. The average for the last four years is 86 per 1000; formerly, in 1880 , it was 280 per 1000 . This has been brought about by the coöperation of many agencies; among which we may mention the pasteurisation or sterilisation of milk; closer supervision and new standards for the production and handling of the milk supply; cleaner streets; supervision of infants in milk stations and in their homes by visiting nurses; a better understanding of the problems of infant feeding and hygiene both by the profession and the laity; more rational and more intelligent treatment of infants acutely ill, and many others. Not much of this has been accomplished by legislative means ; most of it is the result of educational measures. These have taken time, organisation, money and effort. Not only the ignorant mother had to be Educational Measures the Most educated, but nurses, health officers and most difficult at times of all, the practising physician.

Success or failure in nutrition in infancy is soon evident even to the most unintelligent. It is not difficult to see whether a baby is 
thriving or not thriving. Death follows so regularly and often so soon upon failing nutrition that even those least enlightened can hardly fail to connect cause and effect.

Strangely enough, after this perilous period of the first two years of life was passed, vigilance as to health and nutrition almost ceased; very little attention has been given until the most recent years to these subjects during the remainder of the growth period. Not until a child entered school did he come under any kind of public supervision. Something was done then through the medical examination of school children, but this has in most instances had for its object the exclusion of cases of contagious disease or the detection of defects of vision or hearing, or the presence of large tonsils and adenoids or carious teeth. Observations upon the nutrition of school children have been until the last two or three years entirely omitted and the whole question ignored.

The child of pre-school age has received even less attention than the school child-in most communities none at all except when acutely ill.

One reason for the neglect of the child's nutrition after infancy has been that the effects of failure are not evident at once, and 
may not be for years. Although these children seldom die as a result of such failure they may be stunted in growth, under weight, anæmic, with feeble resistance to disease and altogether lacking in the physical energy which we call "'animal spirits," which make study, work and play a joy to the healthy human animal.

The first real awakening to actual conditions as to the health and nutrition of the rising generation and their consequences was the result of the selective draft, in which, though exact figures vary in different states and communities, somewhere in the neighbourhood of 30 per cent of our young men were rejected as physically unfit for service. This was really the first general health invenThe Draft, the First Health

Inventory tory which had ever been taken in this country. That similar results would have been found had an equal number of young women been subjected to a critical examination, can only be surmised. In the opinion of many even a worse showing would have been made.

Since that time a number of extensive surveys have been made upon the health and nutrition of school children. These have yielded results which correspond very closely with those obtained by the draft. The proportion of under-weight children and those suf- 
fering from defects which affect nutrition and hamper growth has been found to be amazingly large, in most communities fully 30 per cent.

The conditions mentioned are by no means confined to our large cities; those found in rural communities have been quite as bad, often worse. Nor are they seen only among the poor. Ignorance, indifference and neglect are far more important causes than poverty.

It is admitted by all thoughtful persons that the greatest of all the resources of a nation are its children, but without any question it is the one which has been most neglected. Where does the blame rest that we are allowing from six to eight millions of children in this country to grow to manhood and womanhood with a physical development which renders them quite unequal to meet the demands of modern life?

My own opinion is that the responsibility Responsibil. for the neglect of the nutrition of children ity for Our Neglected children can be laid partly upon the home, partly upon the state and certainly a share of it must be laid at the door of the medical profession.

The failure of the home may be ascribed to several causes, probably the most important of which is the ignorance of parents themselves regarding often the simplest prin- 
ciples of nutrition. We know about any subject only what we have been taught either by our own experience or that of others. Some of this knowledge which relates to food and health is family tradition; some of it represents racial custom. Much of it is the result of prejudice or even superstition and rests upon ideas long proven by modern science to be erroneous.

In most homes a growing child is simply a member of the household. After the first two or three years he gets the same food as the adult members of the family. That there are certain needs of the body for normal growth which must be supplied in the diet of children, and which adults do not require, is something which most mothers have never heard.

That the failure of a boy or girl to grow properly was in any way to be connected with the food given, if only it was abundant in amount, would seem to most parents absurd.

Again, the weak indulgence of their children by many parents permits the formation of tastes and habits in the selection of their food, in the manner of eating, and their mode of life generally, which are quite incompatible with normal nutrition and growth. This 
is a cause which will always be most difficult to remove.

Economic conditions-poverty, intemperance, vice and general shiftlessness-are causes which will always exist as a basis for

Education of Parents an irreducible minimum number of malnourished children. If most parents fail because of lack of knowledge who is responsible for teaching them? They will certainly go on repeating indefinitely the mistakes of their parents, unless some intelligent outside help is given. The public press has done a good deal in recent years, especially since the beginning of the Great War. Mothers have been taught something in elubs; something by visiting nurses in the homes and in clinies or hospitals; something by health literature distributed by private organisations, or public health agencies. In schools, older girls have been taught something about foods and cooking. But what has been done so far has barely scratched the surface. That so little has been accomplished, the medical profession, I believe, is in no small degree to be blamed. For it is they who should be the teachers and the leaders in forming a public opinion which is absolutely necessary if the present conditions are to be materially im. proved. 
But one sometimes hears the remark made - "doctors don't know anything about health; all their time and energies are devoted to a study of disease; their interest is in disease, not in health." The medical schools have taught little or nothing about health, only about disease. That a knowledge of normal nutrition, which is the very basis of health, is an essential part of a physician's education is a very recent conception. That his highest duty to his patients is to teach them the rules of health and how to obey them, is something very few physicians probably would admit. But is it not true as regards the children under his care?

In the past, the physician was consulted only in ease of illness or accident; no one ever thought of seeking his advice at any other time. The physician's function was to relieve people of their aches and pains and help them on their feet. His office was the repair shop. If a mother felt the need of some advice regarding the diet of her children she asked her mother, some friend, or possibly a nurse, but seldom her physician. The chief reason why his advice was not sought in matters of diet and general hygiene was because it was discovered that about these things he knew very little more than 
other people. The cause of this was in large measure due to a failure of the medical school where he was educated to take any account of these subjects, or it looked upon them as quite unimportant.

But a decided change is gradually coming about. In the last few years there is one phase of nutrition which in most communities has come to be recognised as a physician's field, viz., infant feeding and hygiene.

That there was more knowledge on these matters than was the possession of grandmothers and gray-haired nurses, a large proportion of the young mothers of the present generation have come to appreciate, and an improved crop of babies and a great reduction in the amount of sickness and death of infants has been the result.

The possibilities in the prevention of disease, not only in infancy but during the entire period of childhood and indeed throughout life, are just beginning to dawn even upon the medical profession. There still exists, I regret to say, a large number of physicians who look upon these modern movements in preventive medicine as something

Opposition to Pre-

ventive Medicine to be deprecated, which is interfering, and they consider very improperly too, with their legitimate business. There is at present an 
organised body of physicians in New York City-I am glad to say not a very large or influential one-who systematically oppose public health measures upon this ground. Such a feeling is perhaps not unnatural, but cannot outlast the present generation of physicians who, trained in the school of old traditions, find it hard to adapt themselves to a changed order of things.

That one of the most important functions of the physician is that of a health teacher, and also that one of the most important branches of education is health education, are two ideas which are rapidly coming to be accepted by the most intelligent and forwardlooking persons, but have not yet touched the majority of physicians or school superintendents and teachers.

If there is any period of life when the application of science to health should show results, it is during the period of growth. A knowledge of the physiological and biological principles upon which normal nutrition rests must be given to the medical student. The Childhood, the Oppor application of this knowledge in the supervision and direction which it enables the physician to give to those who have the responsibility for the physical welfare of children, should be regarded as not only one of his 
The Duty of the State

The Government Spends Iuberally for Animals chief duties, but as one of his greatest opportunities. It is certainly the opportunity of the young physician.

Has the Federal or State Government any share of the responsibility for the health and nutrition of children? If the home has utterly failed and if the medical profession has not met the situation, it surely becomes the duty of the State to take a hand. How far shall the State go? Shall it be content simply with efforts at enlightenment of the public, or shall it go further and exercise some sort of supervision, through the schools or the health authorities, of the physical development of children? These are questions which the future must decide.

It has long been recognised as one of the legitimate functions of government to establish and maintain experiment stations where methods of raising pigs, calves and poultry in the best and most economical way are studied and determined by experts. The Federal Government spent last year $\$ 9,700$,576 in appropriations for the Department of Animal Industry. This department has 4045 employees. The appropriation is nine times as large as it was twenty years ago. Besides this, many states maintain separate experiment stations which are working at 
these same problems. All this expert knowledge is, through the bulletins issued, at the service of the smallest farmer in the most remote country district.

What is the Government doing for the nutrition of the children? The Children's Bureau which was established in 1912 has a staff of about one hundred and the appropriation for 1921 was $\$ 271,000$. The Public Health Service is principally concerned with epidemic diseases, quarantine conditions and other problems in which the relation of health to commerce is especially close. Its appropriation for the health of children last year was $\$ 40,000$, most of which was expended in making surveys.

In addition to what is spent by the Federal Government for health there must of course be added the amount appropriated by local authorities. The average annual appropriation for all health purposes of cities of different classes in the United States is as follows:

12 cities with population of over $500,000 \ldots \ldots \ldots \ldots . \$ 1.06$ per capita

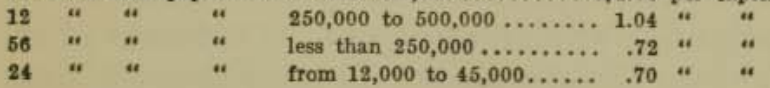

For most of these figures I am indebted to the Committee of the American Public Health Association. 
There are good-sized towns in the East and in the Middle West whose total expenditure for health is less than fifteen cents per capita; less than the average single admission to a moving picture show.

Of course only a small part of this appropriation has to do with the health of children. New York, which is more liberal than most cities, spends about one-sixth of its total health appropriation for children, or seventeen cents per capita.

If we estimate the worth of anything by what we are willing to spend for it, the value set upon health and especially the health of children in this country is not a very high one.

While much has been done and is still being done by private agencies to promote education in matters of health, we conceive it to be the duty of the State to make available for its humblest citizen the very best which modern science has discovered with respect to the nutrition of children.

We insist in this country upon compulsory education of children (some of it pretty poor, it must be admitted). Is compulsory health

Compulsory for these school children a Utopian dream, or
Health? may we not hope that this may one day be realised, even in a democracy? 
With conditions as they are today in the average home, and in the present state of medical knowledge and practice in the greater part of this country, surely the State must in some way come to the rescue of the children. Whether this can best be done through Federal, State or local authorities or by coöperation of all of these, as our roads are built, experience must determine.

The nutrition of the child is dependent upon three factors: The character and quantity of his food; his general hygiene; and his inheritance. The last mentioned we cannot influence, but the other two it is quite within our power to direct and control. The problem of the nutrition of the child then is a soluble problem to a very large degree. The slogan of the New York Department of Health, that "public health is purchasable," is in no field so true as that which relates to the health of children. Upon the nutrition of the children depends very largely the future of the race from a physical standpoint, and one might almost say from an economic standpoint also.

Every live thing that is young must grow; growth is evidence not only of health but of life. The growth of the body is conditioned by its nutrition. That not only the health 
Growth

Dotermined by Food

but the size, weight, vigour, even the fertility of animals can be controlled by the kind of food given, has been demonstrated in many experimental laboratories. These points are most easily determined with small animals like rats or guinea pigs whose life cycle is a short one. That the same biological laws apply to the human race is beyond question.

The opinion was once held that the stature of certain races was due to climate. It is now generally believed that these racial differences are chiefly the result of differences in food. Of course climate affects the available food supply, so that indirectly it is an important factor. That the size of the Japanese is greatly influenced by their diet during the growth period can hardly be doubted.

Dr. Hirai, Professor of Pædiatries in the Imperial University of Kyoto, writes me in the following terms in response to my inquiry concerning the usual food of children in Japan :

"Rice plays the most important part in their diet after infancy.

"No milk, cheese or butter forms a part of the regular diet.

"The fat used is principally vegetable oils. 
"They rarely get meat but take much fish.

"Green vegetables are extensively eaten, especially in summer.

"They are fond of sweets and consume much of them."

This diet would seem clearly to be deficient in growth proteins and probably in the fatsoluble vitamine and in calcium.

The curves for weight and height of Japanese children, for which I am also indebted to Professor Hirai, show some interesting comparisons with those of American children.

During the first year almost no difference is seen. But after infancy when the general diet is taken, the divergence of the curves both for height and weight is very striking. I have had no opportunity to make personal observations upon the growth of the Japanese in this country; but statistics given in the Report of the Japanese Educational Association of America, compared with those of the Educational Department of the City of Tokio, show that Japanese children in the United States, both boys and girls, are taller and heavier than those of corresponding ages living in Japan. This is evident in spite of the fact that although the Japanese diet has undoubtedly been much modified by residence

Japanese Children in the U. $\mathbf{S}$.

Larger than in Tokto 
here, it is still very different from the American diet for children.

I can, however, speak from personal observation upon the Russian Jews. Those adults who come to the United States are for the most part scarcely taller than the Italians. But the children of the successful and prosperous ones, those who have become to a considerable degree Americanised, are almost as large as those of our native-born population; the children are frequently four or five inches taller than their parents. No such results of emigration, however, are seen among the very poor, whose food and mode of life have been little altered from those of their parents.

It is my own observation, corroborated by most of the physicians with whom I have discussed the subject, whose experience entitles their opinion to weight, that among the most intelligent classes, the generation of Ameri-

Better Feeding and Hy. giene in In. fancy Produce Better Children can boys and girls, now fully grown, is larger and heavier than their parents. Newsholme states that the same thing has been observed in England in the boys at Rugby. This result is due, I believe, to better feeding in infancy and early childhood, and no doubt to increased attention given to out-of-door interests during the period of growth. As yet, 
however, these influences have affected only a small fraction of the ehildren of the country. Owing largely to a climate which gives greater opportunity for out-of-door life, the children of California are taller and heavier than those of corresponding ages living in the East and Middle West.

To ignore the mental and moral aspects of eugenics and endeavour to breed a race of physical supermen and women is not exactly the program we would be understood as advocating. We do not in this age give so high a place as do savage and barbarous races to physical size and strength. It may not be thought necessary or even desirable that children should be as large as possible and grow to be large men and women.

Happiness, usefulness and even success in life are by no means conditioned upon the height and weight of the individual. Still, a fine physical development is everywhere regarded as an asset of no mean value. The handicap in life of a frail body and habitually poor health is a very serious one. We certainly owe it to every boy and girl to give them the opportunity to reach the best physical development of which they as individuals are capable.

The effect of nutrition upon efficiency is 
one of its most interesting aspects. In childhood this is determined chiefly by the character of the work done in school. There is not yet a great deal of reliable data available upon the relation of nutrition to school work. Most of those who have studied critically upon a large scale the kind of work done in school, have considered it from the point of view of the teacher rather than that of the physician.

Studies upon retardation in school have hitherto dwelt chiefly upon other causes than health, such as late entrance, irregularity of attendance, etc. Even where health is considered at all it is usually only referred to as illness which keeps a child from school or as defects of hearing or vision which interfere with school work.

In school language a retarded child is one that is below his grade for his age. Retardation may be due to late entrance, but in very much the largest number of cases-fully twothirds it is estimated-those who are retarded are so because they fail of promotion and are obliged to repeat the work of the grade. The problem presented by this group of children in our public schools becomes, when one realises its vast extent, a very important one to teachers and school superintendents. 
Ayers, who has made for the Russell Sage Foundation a very exhaustive study of the problem of retardation in fifty-five cities, found the average number of retarded children to be 16 per cent of the pupils enrolled. It is a question which involves on the basis of Ayers' calculation some six millions of children in the United States. The cost to the cities of the country alone in educating this retarded group, Ayers estimates to be $\$ 27,000,000$ a year.

What particularly concerns us now is how large a part health and general nutrition play Its Ixtent and Cost in school retardation. In Ayers' admirable monograph the subject of nutrition is not even mentioned. He did find, however, that children with physical defects made definitely slower progress than the average.

The curriculum of the elementary schools is theoretically completed in eight years. The average time in which this was done in thirtyone cities studied by Ayers was nine and a third years. In six cities the average time was more than ten years. These were in every instance, I believe, cities with exceptionally bad health records. While not establishing a relationship between health and retardation these facts are certainly suggestive. 
Weight and School Grade

As far back as 1893 Porter's observations in St. Louis showed that the children who gave evidence in their school work of more than average capacity, as measured by progress in their studies, were both taller and heavier than their companions of the same ages whose work was inferior. He gives the weights of 1736 boys, eleven years old. They were in all school grades from the first to the sixth. The average weight increased regularly with the advance in grade. For example:

The average weight of eleven-year-old boys in flrst grade was $63.4 \mathrm{lb}$.

Similar results were observed in the weight of girls.

The average weight of thirteen-year-old girls in third grade wag $75.2 \mathrm{lb}$.

That there is a close correspondence between physical development and mental progress in school has been confirmed by no less than eighteen subsequent investigations in the United States, besides others published elsewhere from Canada, Germany, Russia, etc.

The following are some of the conclusions stated by those making the studies: 
"Physical development and intellectual ability are closely connected."

"Physical and mental conditions are in-

Physical

and Mental

Dovelop.

ment Closely terdependent."

"Groups ahead in grade are taller and heavier than groups of average grade."

"Tall and heavy boys and girls are physiologically older and further advanced in school progress than those who are small and light."

"School progress goes hand in hand with physical development."

"Bright boys, as shown by school progress, are better developed physically and heavier for height than retarded ones."

"There is a positive correlation between physique and intelligence; the largest boys are in the highest grades."

The conclusion reached by those who have studied this question is practically a unanimous one, that mental development parallels physical development.

Two recent investigations, one in Washington and one in Detroit, deserve special notice because they have been made since the subject of nutrition has been brought particularly to notice.

In 1919 Bryant made under the auspices of the Child Health Organisation a survey of 
the school children in Washington, particularly as to their nutrition. One thousand tenyear-old children were studied; this age being the middle of the school period, it was thought would show an average of school

MUTRITION ANO SCHOOL PROCRESS - NASHIKaTON, O.C.

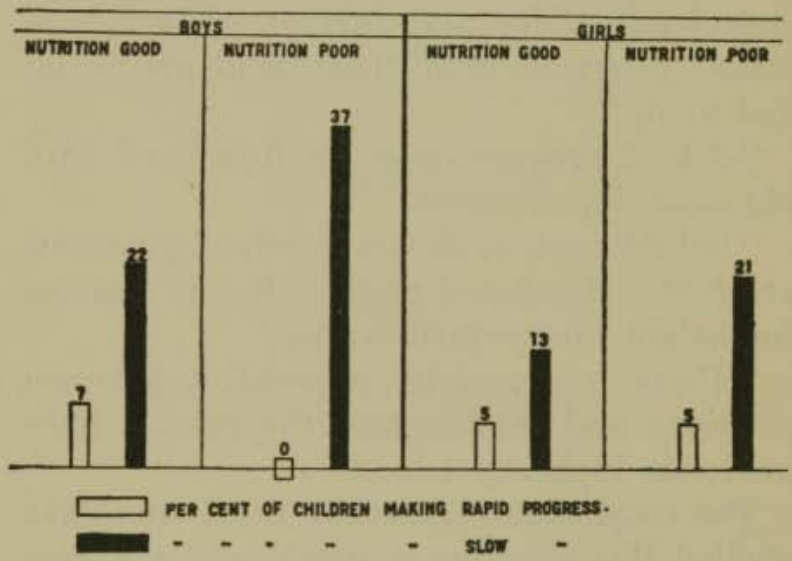

Frg. 1.

conditions. She found ten-year-old children in all the grades from the first to the seventh. The proportion of those with good nutrition was twice as great in the three upper grades as the three lower grades. Among the boys, rapid progress, i.e., skipping one or more grades, was observed in 7 per cent of those well nourished and in none of those poorly 
nourished. Slow progress, i.e., repeating one or more grades, was seen in 22 per cent of those well-nourished and in 37 per cent of those poorly nourished. The difference in the school standing of the girls according to the condition of their nutrition was similar but not quite so marked. Among them rapid progress was observed in 5 per cent of the well nourished as compared with 9 per cent of the poorly nourished. Slow progress was seen in 13 per cent of the well nourished and in 21 per cent of the poorly nourished. (Fig. 1.)

The conclusion reached from this study was that among boys, especially, poor nutrition distinctly handicaps progress in school; excellence in school progress is dependent upon Good Nutrition Essential for good nutrition; a boy must be well nourished to attain more than average grade or go faster than his fellows.

A study was published in 1921 by Packer and Moehlman of a survey made in the City of Detroit, which covers observations upon height, weight, age and school standing of 84,389 children. With but few exceptions, at every age from six to fourteen and a half years, the degree of retardation or acceleration in school work, corresponded very closely with the body weight. This is shown in the 
WEIGKT AND SCHOOL PROGRESS.

41,151 OETROIT BOYS.

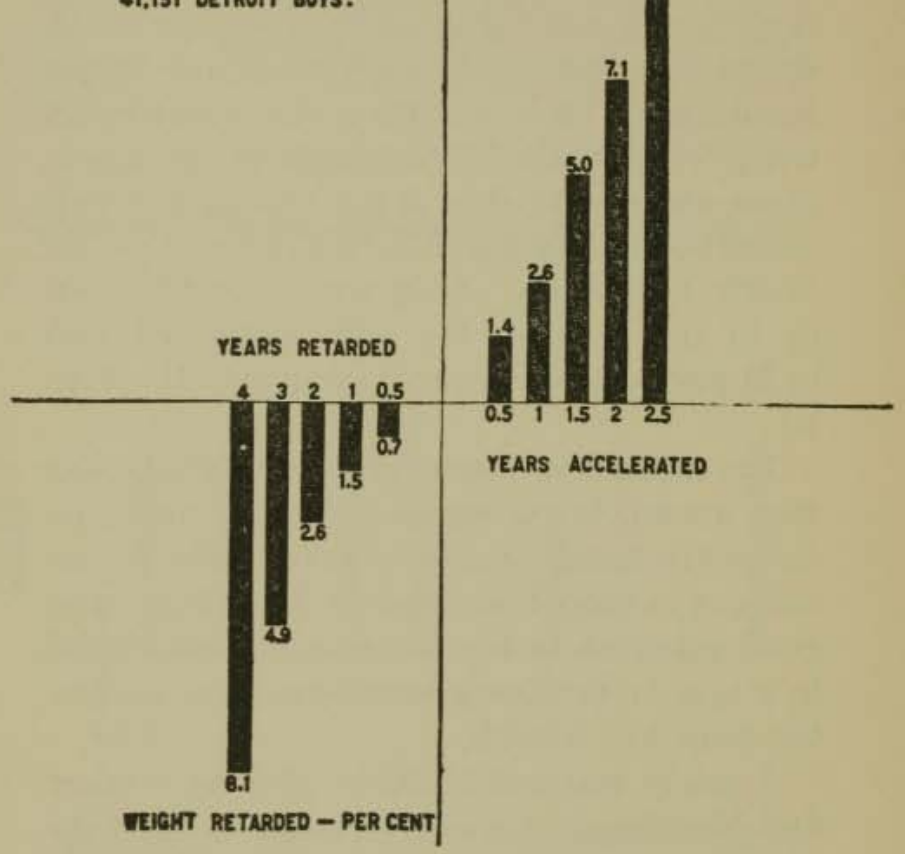

Fig. 2.

chart (Fig. 2) which gives the relationship between weight and school progress of 41,151 boys. The weight of 5987 boys who were in the normal grade for age is taken as 100 per cent. 
The weight of boys retarded 1 year was 1.5 per cent below the average weight for the grade.

The weight of boys retarded 2 years was 2.6 per cent below the average weight for the grade.

The weight of boys retarded 3 years was 4.9 per cent below the average weight for the grade.

The weight of boys retarded 4 years was 8.1 per cent below the average weight for the grade.

The weight of boys accelerated 1 year was 2.6 per cent above the average weight for the grade.

The weight of boys accelerated $11 / 2$ years was 5 per cent above the average weight for the grade.

The weight of boys accelerated 2 years was 7.1 per cent above the average weight for the grade.

The weight of boys accelerated $2 \frac{1}{2}$ years was 10.2 per cent above the average weight for the grade.

The accelerated children were for the most part in the lower grades. After the tenth year the number of the retarded, and of those who were below average weight, steadily increased. At the age of fourteen and a half Retarded Children Bolow Aver-

age Weight: Accelerated Children there were no accelerated children but many retarded and many below average weight. The charts for the girls were very similar, but a little less regular than those of the boys. In some of the upper grades, girls were more frequently found above average weight but below their grade than was the case with boys; but in both sexes these exceptions to the general rule were surprisingly few.

These and many other data fully confirm all the other studies made upon the question, that, as a rule, children physically well developed and well nourished do better school 
work than those of inferior physique and who are undernourished. Poor nutrition, furthermore, is a frequent reason for children beginning school late, and also for frequent absences for minor illnesses to which these children are so liable. Both of these conditions tend to increase the amount of retardation seen in this group of pupils.

The problem of the nutrition of school children and its bearing upon progress in school work is one whose importance teachers and school boards have not as yet appreciated. To expect an underfed, malnourished child to

Good School Work Cannot be Expected of Malnourished Children profit by educational advantages, no matter how superior these may be, is a grievous error. The old saying that it is hard for an empty bag to stand upright, is nowhere more true than here. You cannot fill the head when the stomach is empty; nor can you expect application or concentration of mind from an anæmic, nervous child who is fifteen or twenty pounds below normal weight. In such circumstances a large part of the time and energy of the teacher is wasted effort.

An interesting study of the mental and nervous manifestations in school children as a result of malnutrition was made by Blanton of Wisconsin when he was with the 
Army of Occupation. He made observations upon 6500 children in Trier, Germany. He found that at least 40 per cent were suffering from malnutrition to a degree causing loss of nervous energy; double the usual number failed to pass their grades; the number doing superior work was reduced by one-half, and the number doing inferior work was increased by 50 per cent. The most striking symptoms noted among the malnourished children were (1) lack of energy; they were easily fatigued mentally and physically, would often fall asleep in school; (2) inattention, it was difficult to hold their minds to any subject but a few minutes at a time; (3) poor memory, closely associated with inattention, for instance it took the children thirty minutes to memorise a few lines which ordinarily could be done in half the time, and it seemed almost impossible to remember arithmetic; (4) slow comprehension; as one teacher put it, "it takes the children longer to think"; they found it difficult to follow explanations; (5) unusual restlessness, the children could not sit still, they either wanted to talk or giggle or whisper and it was difficult to maintain discipline, and misbehaviour was common. Other groups were unusually 
dull and quiet and immobile and seemed mentally stupid.

We all recognise this group of symptoms, they are familiar ones to every school teacher, but not always referred to their proper cause. Many of these children would be classed as mentally dull or stupid, proper subjects for an ungraded class, when the real cause is malnutrition.

The conclusion seems to be fully justified that there is a physical basis for dulness or brightness in school work. If better work is to be done in school by the average pupil, his nutrition and physical development must be improved. In the large problem of school retardation I believe it will be found to be one of the most important factors; that it has received so little attention in the past seems most surprising.

The nutritional problem presented by the school child is part of the educational problem, and must be recognised as such by both teachers and school boards. It might prove

a matter of economy if some part of the twenty-seven millions now expended in this country annually in teaching retarded pupils were devoted to health education and hot school lunches to improve their nutrition.

An interesting sidelight upon the relation- 
ship between physical development and mental capacity is afforded by a study of the weight and height of defective children. In Goddard's report upon 6480 defective children from nineteen institutions it was shown that the physical deviation from the normal was regularly proportionate to the degree of mental deficiency. He concludes that there is a definite and a remarkable correlation between physical growth and mental development. When large groups are considered, feeble mental capacity goes with small bodies.

For the physician one of the most interesting phases of nutrition is its bearing upon the question of resistance to infection. Experimental animals when deprived of certain foods, those containing the fat-soluble vitamine, for example, show a great susceptibility to bacterial infections and a very high death rate from them, especially those of the lungs.

With the great majority of diseases the state of nutrition has a very important relation to resistance to infection. This is shown both in laboratory experiments and in clinical experience.

Nutrition and $\mathbf{R e}_{-}$ sistance to Infection

Dr. Trudeau's early experiments with tuberculosis afford an excellent illustration. Young guinea pigs in all respects as nearly 
alike as possible were inoculated with tubercle bacilli in the same manner and with the same doses. One group had good food, sunshine, fresh air, in short all the conditions required for normal nutrition. The other group were given none of these things but were confined where they had to live under unhygienic and unfavourable conditions. The first group recovered from their infection, grew and gained weight, thrived normally and when finally killed the lesions produced by the infection were found to be cured. They had entirely recovered. The second group lost ground steadily after inoculation and all succumbed to tuberculosis in the course of a few weeks or months.

Upon these and similar experiments the whole modern treatment of tuberculosis has been built up. Our clinical observations confirm the results seen in animals. Infection by the germs of tuberculosis is very wide-

Impaired Nutrition Favours Development of Tuberculosis spread, but its active development in an individual is most frequently due to conditions which have lowered bodily resistance by impairing nutrition. The campaign against tuberculosis has become essentially one for improving nutrition by food and personal hygiene.

The most striking illustration of diminished 
resistance to infection, owing to impaired nutrition, is not only the remarkable increase of tuberculosis and all infections in children in those parts of Europe where war conditions bore most heavily, but also the very high mortality from these diseases.

Nowhere perhaps is the influence of nutrition upon resistance to infection seen to a greater degree than in the common infections of infancy. A robust infant admitted to a hospital for a surgical condition may remain for weeks in excellent health. But the infant whose nutrition is much below the normal is so susceptible that, in spite of the utmost precautions, he contracts infections due to common pyogenic bacteria which excite inflammations, especially of the respiratory tract, frequently with most serious consequences.

It is almost impossible in winter to keep such infants in a hospital ward more than a week or two without their developing rhinopharyngitis, otitis, bronchitis or bronchopneumonia. The difference in the way the two types also react to infection is very great. The robust infant, as a rule, soon throws it off; in the poorly nourished child, apparently mild infections frequently follow one after another until the child finally succumbs to 
their combined effects. It is for this reason that hospitals for infants have such limitations in their usefulness. Roomy wards with ample space between beds and, most of all the cubicle system of construction, will do much to lessen the dangers from infection in these susceptible patients; but they can never altogether overcome them.

Again, the outcome of attacks of pneumonia, empyema, typhoid fever, or dysentery and many other infections is dependent in no small degree, first, upon the previous nutrition of the child and, secondly, upon our ability to maintain nutrition during the period of acute illness.

Notwithstanding all the time and labour that have been expended in the search for specific remedies for disease, the list of those in which this has been achieved is a very short one. Malaria, syphilis, diphtheria, cerebrospinal meningitis, and certain types of pneumonia practically complete the list.

For a long time to come, from present indications, it will be the duty of the physician

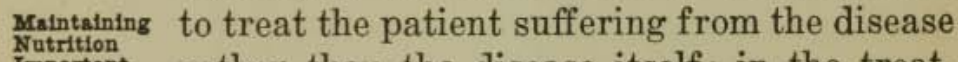
Important rather than the disease itself; in the treatment of the patient we have come to realise that nothing is so important as to maintain his nutrition by careful feeding and hygiene. 
But it is not only the child who is much under weight whose state of nutrition renders him peculiarly liable to infection. There are large, fat, flabby children, especially infants, who seem quite as susceptible to infection and to exhibit as little resistance when infected. This appears to be related to the chemical composition of the body which to a certain degree is dependent upon the diet. Infants whose diet is excessive in carbohydrates and low in protein and fat form one of these groups. The laity often make a distinction between good fat and flabby fat. This idea contains, I think, a hint of the true explanation. It is well known that such a diet as that mentioned tends to a rapid increase in weight without a corresponding increase in strength. A familiar example of this type is the typical, condensed-milk baby. Observations upon animals indicate that a considerable part of this weight is due merely to excessive retention of water in the tissues of the body, and that this is regularly increased by increasing the proportion of earbohydrate in the diet. Infants of the type mentioned are peculiarly liable to diseases of the digestive tract and show but little resistance when attacked.

The rapid and almost incredible loss in 
weight which these infants suffer with an acute diarrhcal attack is of course due simply to the draining away of water from the tissues, and in them the loss is much greater as the water held in the tissues is greater.

In chronic disease during infancy and childhood the result depends very largely upon our ability to maintain normal nutrition. What has been said regarding tuberculosis applies almost equally well to cardiac disMalntenance ease during this period. This has been
of Nutri. tion Largest Part of the Treatment of Children with Chronic Heart shown very clearly in the cardiac clinies in New York. The problem of the child with cardiac disease has come to be regarded as very largely a problem in nutrition, and it differs in no very essential features from the problem of the undernourished child when the cause is a different one. Quite as important is constant supervision of diet and general hygiene, and even more important, the necessity for a proper adjustment of rest and activity. Provided nutrition can be maintained with these patients during the period of growth, the great majority of them reach adult life with so little erippling that they are not seriously handicapped. But how different is the outlook for cardiac cases among the poor or ignorant, where the conditions of proper nutrition have been impossible or have 
been neglected. Dilatation of the heart increases; compensation soon fails. With treatment by rest, proper feeding and care their most aggravated symptoms are temporarily relieved, but too often soon return. The heart each time is left a little worse than before until finally the condition becomes a hopeless one and death follows.

It is not then any special treatment which the average child with a cardiac lesion requires, but only continuous intelligent supervision of his hygiene and nutrition. If these are neglected no amount of medication can prevent a steady advance in the pathological condition of the heart.

Growth and repair, while not identical, are very closely related processes, and are influenced by much the same conditions. Repair after injury can take place at any age, but it is much more active during the growth period. At all ages it is greatly influenced by Repair after Infury or Disease Largely In. fluenced by the state of nutrition of the patient. This is Nutrition even more true of repair after the lesions of disease than after those produced by injury.

In all organic disease recovery is greatly aided by the fact of growth. Provided normal nutrition can be maintained, growth makes possible a degree of repair of organs damaged by disease to a degree that those 
who are familiar with the repair of the adult organs can hardly appreciate. Within certain limitations children may actually outgrow an organic disease.

In all chronic disease in childhood the organism has a twofold task: first, to combat the pathological process and repair the damage which it has wrought; secondly, at the same time, to provide for growth. It is often impossible for the body to do both these things, and growth is always what suffers. The effect upon growth of certain types of chronic nephritis is so marked as to give rise to the term "renal dwarfism."

But when the pathological process is one which affects the organs specially connected with nutrition, like those of the digestive tract, the consequences are the most serious. As a result, in some disorders like that commonly known as chronic intestinal indigestion in its severe form, growth may be arrested for years, so long, in fact, that it is never entirely made up and the child is dwarfed for life. "Intestinal infantilism" the condition is often called.

When we turn now to consider the functional disorders of childhood the question of nutrition assumes a still more important rôle. 
The rapid growth of the brain and the development of the nervous system render the growing child peculiarly susceptible to nervous disturbances, whenever conditions of life are such as to interfere with normal nutrition. Most of the neuroses of childhood depend entirely upon disorders of nutrition. The headaches, insomnia, disturbed sleep, chorea, habit spasm, hysterical manifestations and a multitude of others are relieved only by correcting the faulty diet and habits which are the Most Functional Nerv. ous Diseases of Children due to Disordered Nutrition basis of the disturbed nutrition.

The relation of nutrition to surgical results, surgeons are only just beginning to appreciate. Those obtained in chronic bone or joint diseases, for example, depend far more upon the patient's nutrition than upon the technical skill with which an operation is done or mechanical appliances used.

The impulse of all young things to grow is a very strong one. It can be held in abeyance in various ways for considerable periods, when, if the conditions which have inhibited growth are removed, the loss can be made up. But if the cause continues to operate for too long a time, the normal growth response is no longer present and permanent dwarfing of the body is the result. 
Experiments upon young animals prove Growth Ar-
rested by Underfeed. Underreed-
ing for Long for long periods simply by underfeeding,
Porlods Porlods which may be done in a great variety of ways, withholding one or another of the necessary elements of food.

It has been shown that with dogs, if the period of underfeeding did not continue through the entire period of adolescence, animals were still capable of growing vigourously; but if the inhibition extended through the customary growth period, the capacity for growth was lost. A healthy young dog was kept for ten months upon a diet which did not promote growth, but was still sufficient to maintain weight. Afterwards the animal was given a full diet. A considerable increase in weight occurred but very little growth.

Osborne and Mendel's white rats grew vigourously after growth had been inhibited by underfeeding for as long periods as ten and twelve months. This represents in these animals about one-third of the life cycle, and it is a longer period than is usually required to complete normal growth.

Data are lacking as to what are the ultimate effects upon children of prolonged underfeeding. We constantly see in indi- 
viduals early retardation of growth made up by abnormally rapid growth at a later period, when the cause of the retardation is not continued and especially when the cause is not some organic or pathological condition.

Children in Vienna recently observed by Noël and Paton of England showed an average of 17.5 per cent below standard weight, some were as much as 27 per cent below. The group averaged 8 per cent below standard height. These figures indicate that the children were nearly four years below normal weight and nearly three years below normal height for their respective ages.

What will be the ultimate effect of six or seven years of underfeeding of the children in some of the European countries? That it will affect stature seems certain. Will it also affect fertility or longevity? We do not know. The powers of recuperation in childhood are certainly very great. But there are limits beyond which nature will not go. It is probable that many permanent results mentioned may be seen, particularly in individuals who were originally of poor physical stock. If to prolonged underfeeding we add chronic disease, which has developed in so many as a result of such feeding, and other unfavourable conditions, the inevitable con- 
sequences would seem to be permanent stunting of growth, a high mortality in early adult life, greatly impaired physical energy, lowered mental capacity and premature old age.

Enough illustrations have already been given to show that both to the physician and to the surgeon a personal knowledge of nutrition, or at least an appreciation of its importance in the work of each of them, is absolutely indispensable if they would successfully combat disease during the period of growth. To the nurse, the parent and the teacher also, a knowledge of the fundamental principles of nutrition is essential if they are to be equal to their responsibilities regarding children.

It remains to consider very briefly certain definite pathological processes which are produced by failures in diet to supply some things which are essential to normal nutrition. The list of these so-called "deficiency diseases" is not a long one, but they form an important group.

In scurvy it is well established that its cause is a diet lacking in an essential accessory food substance-the antiscorbutic vitamine. In beri-beri, a disease rare in this country but common in certain parts of Asia, the cause is a lack of another of these substances, com- 
monly referred to as the water-soluble vitamine. A disease is produced in animals in which the most prominent symptom, inflammation of the eyes, goes on unless arrested to complete destruction of the organ and known as xerophthalmia. A closely analogous one, if not identical with it, kerato-malacia, is Diets met with in children. Both these conditions are due to a lack in the diet of another accessory food substance, known as the fat-soluble vitamine.

There are two other common diseases of nutrition-rickets and pellagra-which are closely associated with defective diets, but in which the evidence is not conclusive that they are due to the absence of a specific accessory food substance or vitamine.

In forecasting the future of medicine as it relates to children it seems likely that progress will be made as we are able to solve the problem of the acute infections, and that of nutrition. The problem of the acute infections is likely to be solved by measures of prevention rather than by the discovery of specific forms of treatment. Preventive

Great Pos sibility of Improving by Better Nutrition during

Growth Perlod measures will include not only sanitation, quarantine, isolation and the development of preventive sera, but quite as important perhaps as any of these, increasing the resist- 
ance of children by improving their nutrition. This is the most hopeful field of preventive medicine.

With chronic organic disease we have in childhood almost nothing to do except as a sequel of acute processes, which are usually the result of infection.

In infancy fully half the total deaths are still directly traceable to disorders of nutrition. Though greatly reduced from former figures, infant mortality is still unnecessarily high. Improvement of conditions in infancy will be reflected also in improved results in early childhood.

It is not too much to expect that with a better understanding of the subject of nutrition there may be accomplished for the older child something comparable to what has been done for the infant. We may perhaps not see a greatly reduced death rate but we shall surely see a much higher standard of physical development and general health. 


\section{CHAPTER II}

\section{Lecture Two}

The Amount of Food Required by Children

THE food requirements of children have been discussed from many points of view. By different investigators various phases of this general subject have been studied. One group has been devoting its attention to basal metabolism, " or the needs of the body at rest. Others have taken up the study of the protein requirement and the growth properties of certain proteins; still others, the total food requirement for children in terms of calories." Just now the attention of investigators is focussed upon the accessory food substances-the so-called vitamines.

The estimates which have been made re-

- The term metabolism is used to cover all the chemical changes taking place in the body cells and in foodstuffs after absorption, before their products are eliminated.

** A calorie is an arbitrary heat unit. It is the same whether the heat is produced from coal, gasoline, or food taken into the body. It is the amount of heat required to raise one litre of water (about one quart) from zero to $1^{\circ} \mathrm{C}$. 
garding the total food needs of children have sometimes been purely hypothetical, but more generally based upon the requirements of adults. Observations made during the last few years, especially in this country, have thrown new light on this subject.

In reviewing the older literature, which is chiefly German, one is struck with the small number of the observations upon which their deductions have been based. The conclusions drawn from them do not seem warranted either by the number of their observations or the conditions under which they were made. For instance, one author studied only a single child; another's observations were made almost entirely upon his own children; a third based his conclusions

Small Number of $\mathrm{Ob}$. gervations Which Have Seen Made upon observations of three children two of whom were quite exceptional, being much over weight; while a fourth made his studies upon children who were inmates of an institution, most of them under weight. Yet these observations are quoted over and over again in textbooks and periodical literature and have been made the basis of very broad and widely accepted deductions.

It is evident to all who study this subject that even in normal healthy children there are very considerable individual variations 
in food requirements. In abnormal children, especially when observed under unusual conditions, these variations are of course much greater.

The Different Factors.-In estimating the total caloric requirements all the different factors which go to make up this total must be taken into account. These are essentially four: the requirements for basal metabolism, the needs for growth, the needs for muscular activity and finally the food values lost in the excreta. Unless all these factors are considered, serious errors will be made in our estimates.

The first of these, the basal requirement, is fairly uniform for children of the same weight. The second, the growth requirement, differs at different periods of childhood. The proportion of the food required for growth is naturally greatest at the periods when growth is most rapid, viz., during the first two years and during adolescence. Growth variations are fairly uniform with all healthy children. When we come to consider the third requirement, the needs for muscular activity, we find great variations with individual children; but in general, activity tends to increase steadily with age. The fourth factor, the caloric value of the foodstuff lost in 
the excreta, appears to be subject to very narrow variations with healthy children of the same age, unless there are very marked differences in the diet.

Basal Metabolism.-Regarding basal requirements, that is, the needs of the body at complete rest, a great deal of accurate in-

The Needs of the Body at Complete Iest formation has been accumulated during recent years. This has been obtained by calorimetric observations, made in this country chiefly by Benedict and Talbot, DuBois and Murlin, and abroad by Rubner, Magnus-Levy, Heubner and others. The greatest number of observations have been made upon adults, both in health and disease, and upon infants. The intervening period from the end of the first year to the completion of growth has not been so generally investigated. Benedict and Talbot are the only observers who have studied systematically this entire period; they have recently published the results of about 250 observations made upon children of both sexes, more than half of whom were over one year of age.

The range of individual variation in the values obtained was, as might be expected, considerable. Yet the number of observations made is so large that the data seem sufficient to warrant us in accepting their results, 
as representing the average for the period of growth. They have shown that the basal metabolism per kilo. of body weight is low in the newly-born infant and that it rises rapidly until about nine months when the weight of eight or nine kilos. is reached. After that it slowly diminishes up to adult life. They found some differences between the basal needs of boys and girls. After a weight of 10 kilos.-about one year-is reached, the basal requirement of boys exceeds that of girls until a weight of about 35 kilos. is reached,

In Proportion to Body Weight This 18 Greatest at About Nine Month: at about eleven years, when the basal needs of girls for a time are greater.

The total basal requirement increases with age, but the relationship is best expressed as calories per unit of body weight, or of body surface. In the opinion of Benedict and Talbot there were no important differences between caloric values expressed per unit of body surface and per unit of body weight. In our discussion therefore we shall use the unit of body weight as it is simpler and more convenient.

The observations of others made upon a smaller number of children have yielded results somewhat higher than those of Benedict and Talbot. After comparing all their figures, however, it seems reasonable to accept 
the values for basal requirement given by Benedict and Talbot as representing what they have fermed "the irreducible minimum" which must be supplied to the human organism for maintenance.

Growth Requirements.-In considering the food requirements which must be supplied for

What is

Needed for Growth growth, special growth needs, such as vitamines or proteins which furnish the essential amino-acids, etc., will not now be discussed, but only the energy requirements for growth which are met by the fat, carbohydrate and protein furnished in the ordinary articles of food.

What is required for growth must, it is obvious, be greatest when growth is most rapid and diminish when growth is slower. How the growth rate diminishes during the early years and increases in the later years of childhood may be expressed by the annual increase in weight and height from birth up to the time when the body reaches its mature size. This average annual increase in weight and height is shown for both sexes in the accompanying chart (Fig. 3). If we combine This Great
est when Growth is in weight, and that for the annual increase in height we obtain a curve which may be taken to represent approximately the annual in- 


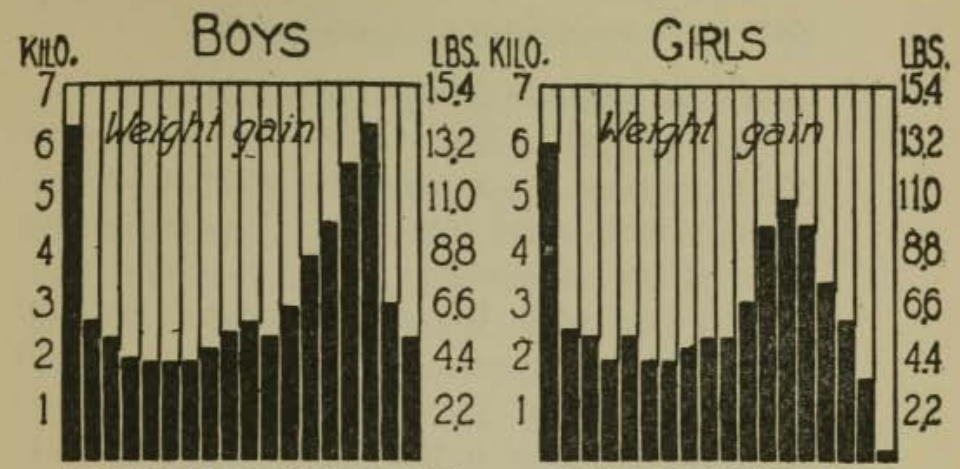

$123456789101112131415161718 \cdot$ Years +1234567891011121341515161718

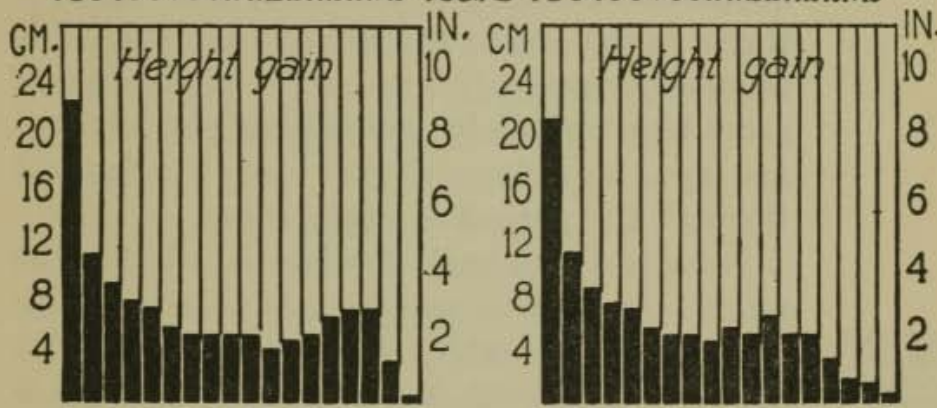

1234567891011213415161718-Years-1234567891011121314516178
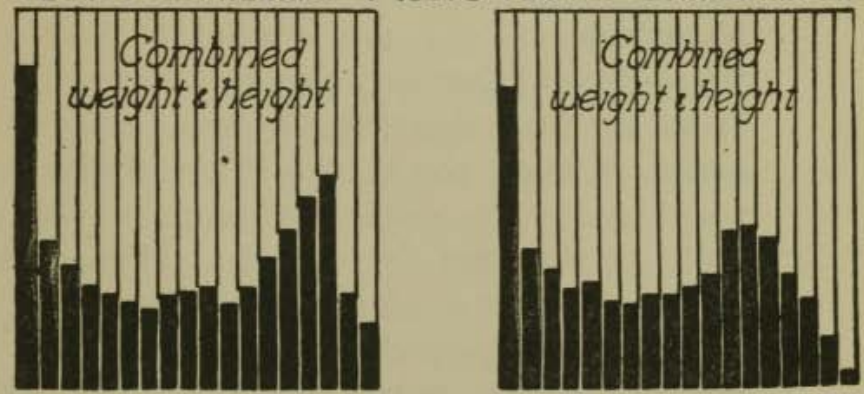

1234567891011213445161718 -Years 12345678910111213415161718

Fig. 3.-The heavy black verticals of the two upper charts show the annual gain in weight in kilos. and pounds, and the gain in height in centimetres and inches, for both sexes. The lowest charts show value. obtained by combining the two. 
crease in the size of the body during the period of growth. This rate falls rapidly after the first year, but rises again after the tenth year in both sexes, reaching its maximum in boys at the sixteenth and in girls at the thirteenth year when the rate is nearly twice as great as at ten years.

In calculating the total caloric requirements of the child in the past, it appears that sufficient consideration has not been given to these variations in the rate of growth. The increase in the body's needs for growth which must be supplied by the food is not uniform as age advances from early childhood through the period of adolescence.

If we use as a basis for our calculation the annual increase in weight, it is possible to es-

Eatimated Oalories

Needed for Growth timate approximately the number of calories needed for growth by a child at any given age and weight. Rubner estimates that about 80 calories a day are needed to increase the weight of the body one kilo. in one year. If we multiply this value by the average increase in kilos. per annum it would give approximately the number of calories needed daily at that age for growth. Thus a boy between the ages of four and eleven years who gains approximately $2 \frac{1}{4}$ kilos. (5 pounds) a year would require on the basis 
of Rubner's calculation an average of nearly 200 calories a day for normal growth.

During the sixteenth year, when the average gain in weight is 6.5 kilos. (about 14 pounds) there would be needed for growth alone about 500 calories a day. After this time the growth requirement rapidly falls and when growth is completed, usually in the eighteenth year, it of course ceases entirely. We have found it impossible to verify in the laboratory the correctness of Rubner's method of estimating the caloric needs for growth, but clinical observations lead us to the opinion that his estimate gives results which are very nearly correct.

Requirements for Activity.-When we come to consider the caloric allowance which should be made for muscular activity we meet the greatest practical difficulty. It is Requitements for hard to estimate even approximately how many calories should be provided. Allowance must be made for all activity, whether productive or unproductive. Even the energy expended in the process of digestion must be taken into account. Benedict states that the energy needed to digest the food taken, uses up about 6 per cent of the total calories of the diet. This he terms the "cost of digestion." Like the food value lost in the excreta it is 
one of the inevitable losses, and one for which allowance must be made in estimating the total caloric requirement of the child.

The requirements of individual children for activity differ very greatly, more widely than they do in any other respect. A nervous,

Very Active Ohllaren Need More Food

lively, energetic child will use up many more calories in activity than one of quiet, placid temperament and indolent muscular habits. How great the difference is between the actual needs of these two types we can with our present knowledge only conjecture.

Lusk has estimated that during the period from four to fifteen years the very active child requires more than double the total calories of a quiet child. Since three of the four factors which make up the total, namely, basal requirement, growth requirement and the food value lost in the excreta, are nearly the same for these two types of children, it would appear that practically all of the increased allowance which he proposes, or considerably more than half the total food taken, is used up by the very active child in muscular activity. For young children this seems excessive. It certainly cannot be taken as an average.

The restriction of activity to conserve health and promote growth when food supply 
is insufficient is both intelligent and scientific. We are told by Leonard Hill that many mothers in Germany when the food shortage was greatest were accustomed to keep their children in bed the greater part of the day, not allowing them to get up until eleven and putting them to bed at four o'clock.

In general, a progressive increase in the calories which are needed for activity must be allowed as age advanees. As soon as a child has learned to walk a great increase in activity takes place, and loss of weight occurs when no increase is made in the amount of food given, sometimes even in spite of it. The loss of the baby fat with the increase of activity which is seen in the third and fourth years is a familiar fact. With the normal healthy child activity increases pretty steadily with each year up to the period of adolescence.

DuBois estimates that a man walking at a moderate pace on the level uses per hour about three times his basal caloric requirement. On this basis, a boy of 30 kilos. weight, or about ten years of age, walking on the level for two hours, would require about 270 calories to supply the energy for this amount of activity. But such exercise would represent a small part of the energy 
expended in a day by an average healthy boy of ten.

The great difference in food requirements of children because of the difference in their activity is not in most cases sufficiently taken into account in providing their diet. If the increased caloric need of the active child is not supplied by the food, growth inevitably suffers.

A child's food intake may be considered his

How a Ohlld May Üse His Income physical income. Out of this certain overhead expenses must always be met first. These are, the needs of basal metabolism, the normal, necessary activity of life, and the loss in excreta. What remains may be spent, i.e., used up in excessive activity or saved, i.e., utilised for growth. Both of these he cannot do. Excessive activity is always at the expense of weight and growth unless the food intake is proportionally increased. Every physician and parent knows how difficult it is to make the nervous, energetic, active child put on weight, even with the usual food intake and with a normal digestion.

Loss in Excreta.-No accurate observations on the food values lost in the excreta have been published regarding children over six years of age. Our own studies lead us to the opinion that this factor varies less with 
age than do the other three factors which make up the total food requirement and that in health the loss of calories is equal to about 10 per cent of the food intake for children of all ages after infancy.

Extensive work done by the Department of Agriculture on the diet of adults has established quite definitely that the loss in the Loss in excreta, when a mixed diet is taken, averages about 9 per cent of the total calories ingested. Atwater and Sherman, who followed the metabolism of three six-day bicycle riders, found an average loss in the excreta of 9 per cent of the total calories taken.

The most exact observations upon children past infancy as to the loss in excreta have been made by Müller who studied thirty-two children from two to six years of age. In order to determine the exact food value lost, he dried the stool and urine of each child as well as a sample of the composite food of each and determined the exact caloric value of these substances by burning samples in a calorimeter. His estimation of the loss in the urine was calculated on the basis of its nitrogen content. His calculation gave an average total daily loss in the excreta of 10.5 calories per kilo, which was almost exactly 10 per cent of the intake. 
In our own observations we have found

About 10 Per Cent of Food Taken Lost
Total

Calories

Required

Estimated by Body Weight that healthy children under six taking a mixed diet have from 10 to 20 grams of dried matter in the daily stools. Using as a basis for calculation Müller's average figure for the caloric value of the dried stool, and also his method of estimating the loss in the urine, we have found the combined loss in urine and fæces by healthy children from one to six years of age to be approximately 10 per cent of the calories usually given at the ages mentioned.

The loss through the excreta in children with disturbed digestion is much greater than this, and is of practical importance. We have found the loss in mild forms of chronic intestinal indigestion to reach 25 per cent of the total calories taken. The estimate of 10 per cent of the calories for loss in the excreta seems therefore a reasonable average allowance for normal children taking a mixed diet.

Total Calories Needed.-Having considered the four factors, let us now take up the question of the total calories, estimated according to body weight, or the calories per kilo. Not much work has been done in the determination of the caloric intake of children past the age of one year. In 1917 Gillett was able to collect from literature only 143 
cases, and these were from eighteen authors, most of them German, in which this calculation had been made. The number of observations made by each author was small, and in several cases neither the condition of the children nor their environment was such as to permit us to draw general conclusions. The observations made have brought out many interesting facts, but they are not sufficient to warrant deductions as to the needs of the average child.

For instance, two over-weight girls of nine and eleven years, studied by one author, took only 65 and 61 calories per kilo. Of three over-weight girls of eleven, thirteen and fifteen years, studied by another, none took more than 45 calories per kilo; while some under-weight boys from two to six years old took an average of 113 calories per kilo.

Camerer studied his own five children, four girls and one boy, for a period of years. In his observations made when the children were below seven years old, the results were about those generally accepted as average for the period. At a later period when the children were much older their intake was very low. At the age of fifteen it was only a little above the needs for basal metabolism as given by Benedict and Talbot. This is in spite of the 
fact that the children were considerably below average weight; one cannot resist the conclusion that they were under weight becavse they were under fed. Yet Camerer's results have been more widely quoted and used as a basis of feeding than those of almost any other author.

The great individual variation in the total food intake of children is brought out by the observations of Tigerstedt, who found for example that the intake of nine children in the twelfth year ranged from 44 to 89 calories per kilo. Since the weights of the children are not given it is somewhat difficult to interpret these wide variations.

One of the most interesting and signifieant

What Boys, at 8 t. Psul's School Took contributions to this subject is that of Gephart, who made observations upon the boys at St. Paul's School at Concord, New Hampshire. The school contained about 360 boys whose ages ranged from twelve to seventeen years.

The method he employed was quite different from that of most of the German observers, and is the one which has been employed in studying the food consumed by soldiers in the army camps. It seems a reliable method of determining the average intake of large groups. 
Gephart first calculated the caloric value of all the food purchased during the period of observation, which was the entire school year. From this he subtracted the values obtained by analysing at various times the garbage and the waste. The remainder he divided by the total number of meals served, and thus obtained an average caloric value per meal for the school.

In addition to the meals which were provided by the school, the boys were accustomed to buy from a confectioner's shop controlled by the school, considerable extra food, chiefly sweets-chocolate, cakes, etc. The total amount purchased there during the period was known, and was apportioned by Gephart among the boys of the whole school. The calories furnished by this additional food were found to amount to about one-eighth of the total food consumed.

Table 2-SUmmary of Gephart's Observations on Boys at ST. PaUL's SchooL

\begin{tabular}{|c|c|c|c|c|c|c|c|}
\hline \multirow{2}{*}{ School } & \multirow{2}{*}{$\begin{array}{c}\text { Average } \\
\text { Age in } \\
\text { Years }\end{array}$} & \multicolumn{2}{|c|}{ Average Weight } & \multicolumn{3}{|c|}{$\begin{array}{l}\text { Average Calories per } \\
\text { Kilo. }\end{array}$} & \multirow{2}{*}{$\begin{array}{l}\text { Average } \\
\text { Total } \\
\text { Daily } \\
\text { Calories }\end{array}$} \\
\hline & & Kilos & Pounds & School & $\begin{array}{l}\text { Food } \\
\text { Shop }\end{array}$ & Total & \\
\hline Lower .... & 13.5 & 43.6 & 96 & 98 & 15 & 113 & 4949 \\
\hline Middle..... & 14.5 & 50.8 & 112 & 88 & 13 & 101 & 5126 \\
\hline Upper... & 16.1 & 60.6 & 133 & 71 & 11 & 82 & 4997 \\
\hline
\end{tabular}


The average daily caloric intake was found to be about 5000 calories per boy; and all but the group of the oldest boys took over 100 calories per kilo.

While the conclusions which might be

An Active Growing Boy Needs Much Food drawn from these observations may perhaps be open to some question, still, the results show what amount of food is actually taken by the average American school boy at the ages studied, under the special conditions represented by these observations. It is true that these conditions were somewhat exceptional. The boys were living in a rigourous climate; they were taking much out-of-door exercise and they were at an age when growth is most rapid.

Furthermore, the well-known disposition of boys of these ages, when not restricted, to eat apparently beyond their actual needs must also be taken into account. Still, when due allowance has been made for all these conditions, the fact remains that the enormous appetites of active, growing boys of the ages of those Gephart studied, represents a physiological need, which in the past has not been given sufficient consideration.

Studies made on such large groups are likely, we believe, to give results much nearer the truth than observations made on a few 
individuals or the children of one family, no matter how carefully such observations have been made. The results of the German studies to which we have referred would lead one to allow too little food for children during the active growing period. From observation of the food habits of the average German one is inclined to believe that this deficiency is quite made up later in life.

The Department of Agriculture has made many observations on the amount of food taken by families, including children, but has not determined what proportion of the food was taken by each child. They have apportioned the diets theoretically according to a commonly used system of coefficients; for example, assuming that if a man takes one portion, a woman takes 0.8 , a boy of twelve takes 0.8 , a boy of eight takes 0.7 , etc. This method of ealculation is open to serious objections.

Proposed Schedules of Calories per Kilo.

Several of the authors to whom we have already referred have proposed complete schedules of caloric requirements per kilo. from infancy to adult life.

Among the German authors, Camerer's schedule has been most often quoted as a standard. His allowance for boys is 89 calo- 
ries per kilo. at the age of one year, this diminishing to 75 calories at four years. After five years the per kilo. allowance rapidly and steadily decreases to adult life. His values after six years are low, while after the twelfth year his allowance is below 50 calories per kilo. As Benedict and Talbot have found the basal requirements at this age to be nearly 40 , only 10 calories per kilo. are left for growth, activity and loss in excreta.

Steffen offers a schedule for children up to six years of age in which he allows over 100 calories per kilo. through this entire period.

Uffelmann has proposed a schedule for the first five years of life. His values are lower, ranging from 88 calories per kilo. at one year to 68 at five years.

Gillett and Sherman from the published observations which they have collected have presented a table of values for total daily calories for children of both sexes throughout the entire period of growth. Their average allowance for boys diminishes gradually from 95 at one year to 68 ealories per kilo. at nine years and is kept at about that figure up to the age of fourteen. After this age the average allowance is rapidly decreased to 55 calories per kilo. at sixteen years. Such 
a decrease in calories per kilo. during the period of most rapid growth seems unwise.

Lusk has proposed total calories per kilo. for three types of children: one for the quiet child, one for the active, and one for the very active child. His values for the very active child are about twice those for the quiet child, quite irrespective of age or weight. AcDifferences According cordingly, his estimates for the calories for the active and for the very active child are extremely high for the early years, amounting respectively to 129 and 193 calories per kilo. for a boy of two years. The fall in calories per kilo. with increasing years is very rapid for all his groups. His values for the quiet child after the age of thirteen are very little above the requirements for basal metabolism and normal growth, leaving practically nothing for activity. This of course can never be reduced to zero.

Fewer authors have given schedules for girls. In those of Gillett and Sherman and also of Camerer the allowance is considerably lower than that for boys; after the twelfth year that given is only a very little more than the needs for basal metabolism and growth. It is certainly quite inadequate.

In the light of our own observations and from a study of those of others, theoretical 


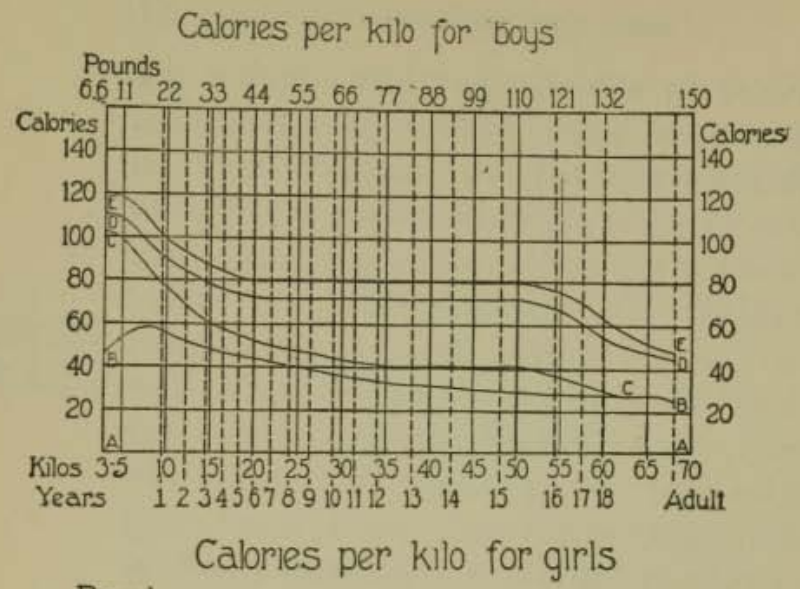

Pounds

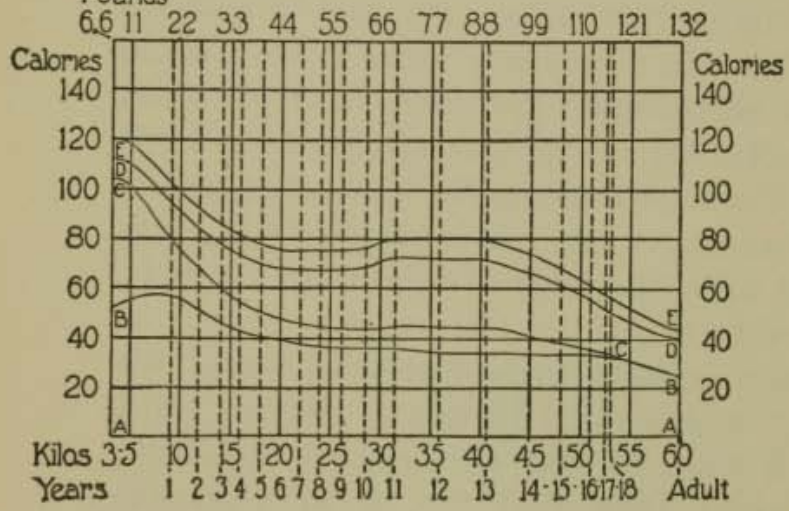

Fig. 4.-The solid vertical lines indieate weights in kilos; the broken lines, approximate weights at each year of age. The space between lines $\mathrm{AA}$ and $\mathrm{BB}$ shows allowance for basal metabolism; between $\mathrm{BB}$ and $\mathrm{CC}$, that for growth; between $\mathrm{CC}$ and DD, that for muscular activity; between DD and EE, food values lost in excreta. The space between the lines $\mathrm{AA}$ and $\mathrm{EE}$ shows the total ealoric allowance per kilo.

Fig. 5.-The vertical and eurved lines have the same significance as in Fig. 4. 
schedu'es indicating average calories per kilo. of body weight have been ealculated for both sexes and are shown in Figures 4 and 5, indicating the total calories per kilo. for difper Killo. ferent weights for approximate ages, also the proportion of the total which is allowed for each of the different factors which have been considered.

It will be observed that the basal requirement per kilo., adopting that of Benedict and Talbot, reaches its maximum at about the ninth month, after which it falls steadily throughout the entire period of growth to adult life.

The calories allowed per kilo. for growth fall steadily from the first to the sixth year, remain practically constant up to eleven years for girls and thirteen years for boys, when a marked increase takes place

This increased need is evident for about three years with both sexes, after which the growth needs rapidly diminish to zero.

The needs for basal metabolism and for growth though subject to considerable individual variation are as averages practically irreducible.

In the absence of definite data upon many points what should be allowed for activity is admittedly hypothetical. For reasons pre- 
Diffeult to Estimato Accurately Needs for Activity

viously discussed this has been increased steadily from the second to the thirteenth year for boys and to the twelfth for girls. Whether the allowance for activity should be further increased during the period of most rapid growth is somewhat doubtful. It is a matter oi common observation that while the body is increasing so rapidly in size as it does at this time there is not infrequently seen in both sexes a growing disinclination to active muscular exertion, which is usually accompanied by a corresponding disinclination to mental activity. For these reasons no increase in the caloric allowance per kilo. for activity has been made during these years of most active growth; possibly even a slight reduction should be considered.

The number of calories we have allowed for loss in the excreta after the first year of life is 10 per cent of the total.

With the values proposed for the different factors just discussed, the total calories per kilo. are for both sexes about 100 at one year, falling to 93 calories per kilo. at two years,

Average Requirements Estimated According to Body Welght and to 80 at six years. This value we have continued for boys up to about the sixteenth year. For girls the calories per kilo. have been slightly increased during the eleventh year, since there is at this time an increased 
growth need and since the basal needs for this and the next few years are nearly uniform. After the sixteenth year in boys and the fourteenth year in girls, the total calories per kilo. have been rapidly reduced to adult standard-about 48 for males and 44 for feAdult Allowance males-since there is a rapid decline in growth needs and possibly some reduction in activity.

The chief differences between this schedule for total calories per kilo. and others which have been proposed is that the per kilo. allowance is nearly uniform from the age of six to the end of the period of rapid growth.

In the practical application of these suggested values it must be borne in mind that each component part of the caloric requirement is subject to considerable individual variation. The curve suggested aims only to give averages. Activity is of course the most obvious variant. An extremely active child will undoubtedly utilise more calories than the average which we have allowed, while the needs of a quiet child may be supplied by somewhat less than the allowance made.

Another cause for variation in the caloric requirement for the individual is the relation 
Under-

weight Children $\mathrm{Re}$ quire More per Killo. Over-weight Children

Less

of weight to height and age. All observations show that the under-weight child will take and will utilise more calories per kilo. than the child of average weight; while, as might be expected, one who is over weight does not take and does not need the average number of calories per kilo. These facts must always be taken into account in the caloric allowance for an individual child. The average, however, is not quite the same as the normal.

An allowance of from 5 to 10 calories per kilo. both above and below the average allowance may be considered a normal range. When activity is excessive, however, an increase of 20 or even 30 calories per kilo. above the average may be well utilised.

Camerer's schedule gives very little allowance for activity except between the ages of four and eight and after the age of thirteen years practically none at all.

The curve based on the average values offered by Gillett and Sherman does not differ greatly from the one here proposed up to the age of seven years. From seven to fourteen years it is nearly parallel with it, but is somewhat lower. After fourteen years their curve falls rapidly. The allowance they have made both for activity and for growth during adolescence seems much too small. 
Total Daily Calories.-Thus far only the calories per kilo. of body weight have been considered. In Figure 6 and Figure 7 are given the curves which show the total daily calories allowed for healthy children of average, normal weights at the different ages, using the values above suggested. They also show for the different years the proportion of the separate factors which make up the total, viz., basal needs, growth needs, allowance for activity and for loss in the excreta.

The daily calories allowed for both boys and girls are about 950 at one year. The increase with succeeding years is a little more rapid for boys than for the girls until the age of twelve is reached. From twelve to fourteen the total calories for the girls exceed those for boys.

After fourteen the allowance for boys is considerably greater than that for girls. The highest values for daily calories are 3330 for girls at the age of fourteen and 4100 for boys at the age of sixteen. After these maximum figures are reached the values drop very rapidly to adult standards for moderate activity -about 2640 for women and 3360 for men. ${ }^{1}$

${ }^{1}$ Sinee this lecture was written some English figures on the metabolism of adolescents have been published by 


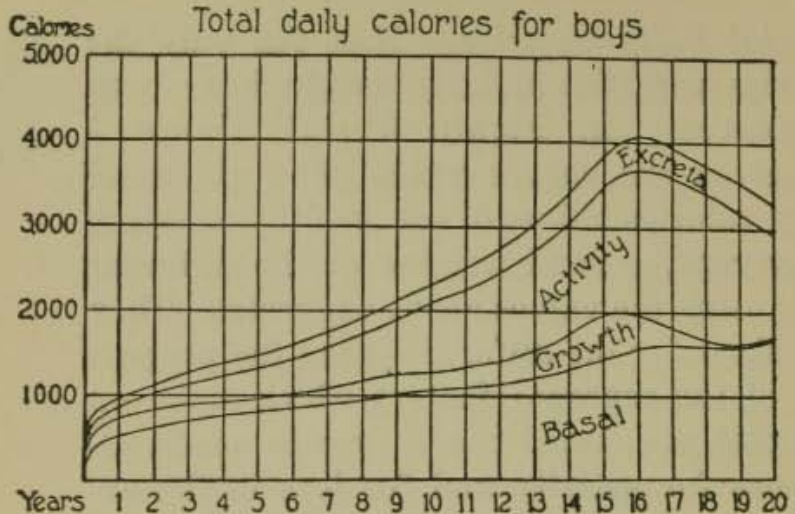

Fig. 6.-The distance between the base and the upper line shows the allowance for total daily calories according to age, from birth to adult life. The spaces between the various lines, from the base line upward, indieate the allowance for the different factors which make up the total, namely, for basal requirement, growth, activity and loss in exereta.

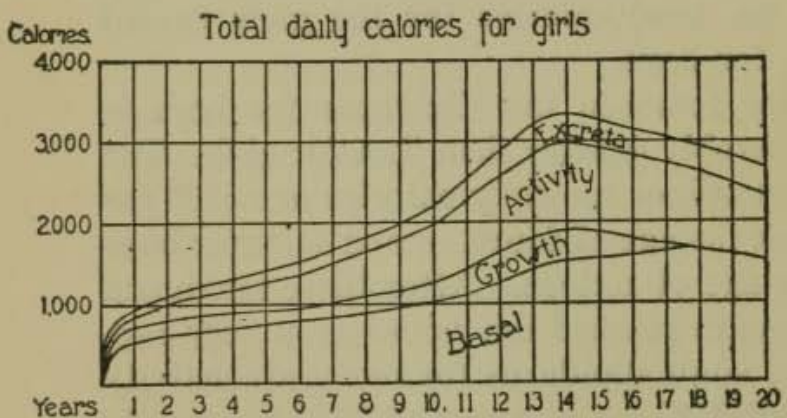

Fig. 7.-The eurved lines and spaces have the same significance $2 \mathrm{~s}$ in Fig. 6. 
These charts show the provision which must be made for the growth needs during the period of adolescence. The maximum growth need, calculated according to Rubner's formula previously referred to, for girls amounts to 380 ealories daily during the thirteenth year and for boys to about 500 ealories daily during the sixteenth year. This Growth represents about 14 per cent of the food intake. This greatly increased need for normal growth at this period has not been sufficiently taken into account by most authors in estimating the total daily calories required.

The large allowance for activity is of course the most debatable factor in the estimate presented. Some may think this allowance excessive but the more recent observations, particularly those of Gephart, seem to justify the position taken. The total daily caloric allowance for boys of the age of those studied by Gephart is still much below the calories which he found to be actually taken by the St. Paul boys observed by him. However, as previously stated, these boys were no doubt living under rather exceptional

Wright. His observations were made upon boys in training ships. The minimum daily intake recommended at thirteen and fourteen years is 3800 calories and fifteen and sixteen years 4100 ealories, which corresponds very strikingly with the allowance here suggested. 
conditions and the calories that were taken by them can hardly be used as a basis for estimating normal averages.

According to the schedule presented, the allowance for activity varies from 6 per cent of the total calories during the first year to a maximum of 44 per cent of the total calories during the period of adolescence. This does not seem excessive for this active period.

An Adolescent Boy or Girl Needs More Food than a Man or Woman
It is a common observation and undoubtedly a true one, that during adolescence the average boy or girl takes more food than the average adult man or woman. Unquestionably this is proper and represents a real physiological need. It is only by assuming such values for calories per kilo. as have been proposed that one can reach a total daily caloric intake which will be in accord with these conditions.

Other authors who have given complete schedules for food requirements have all steadily increased the total daily calories with age through childhood and adolescence up to the standard allowance for adults. No one has proposed a schedule according to which the values for total daily calories during adolescence exceed adult standards and fall to adult standards with the completion of growth. This seems to be absolutely neces- 
sary; for unless this is done, the increasing growth needs must be deducted from the allowance for activity, leaving for the latter a very small remainder; or, on the other hand, if activity is maintained, growth must suffer. The modern child, boy or girl, is usually an active person during adolescence. If in school, he is required by school routine to take of Growth systematic exercise. If he has left school and gone to work, he is required continually to expend a good deal of physical energy. In view of these facts it is quite evident that the food taken by probably the majority of boys and girls of the class which leaves school at fourteen or fifteen years and enters industry during this period of rapid growth, is totally inadequate.

After completing our theoretical schedule for total food requirements we have endeavoured to test its accuracy by a study of the number of calories that healthy children living under good conditions actually took in their usual diet. In other words, having determined what children should take to meet the separate needs as we had calculated them, we next proceeded to find out if what might be considered normal healthy children did take anything like such an amount of food. This proved no easy task. As already stated, 
the observations upon such children reported in literature have been few in number.

We have at present collected over one hundred individual diet records of children from one to sixteen years of age-a sufficient number to warrant some conclusions. They were

What Healtiny American Childran Usually Take

Comploto Diot Kopt of Eaeh Child for Four Consocuttre Days selected children; chosen because they were healthy, well cared for and normal as to digestion. Almost all were children in private families, living in excellent surroundings. The parents were nearly all well-educated, interested in the purpose of our experiment, and willing to coöperate. Our aim was to learn what such children, fed, it was believed, intelligently, actually took in their accustomed diet, with the belief that the diet they were receiving was fairly typical of what is usually taken by well American children. They were not all from New York City. A number lived in the suburbs and some were from New England in the vicinity of Boston, so that the diet does not represent the ideas of any one physician or group.

A report of the net weight, height, activity, appetite, general condition, etc. was obtained, together with a record of the exact amount of each separate item of food taken by the child for four consecutive days. From these data the caloric value of the average daily 
diet was calculated. Not only was the value for the total calories obtained, but also the distribution of the calories as fat, carbohydrate and protein, which, together with other facts brought out, will be discussed in the next lecture. We used for the most part established caloric values of the common articles of food compiled by Locke. The values of a number of articles were calculated from the results of analyses made in our own laboratory.

This method of estimating the calories taken by children is of course not absolutely accurate, but it undoubtedly gives a very close approximation. While there are slight variations from the usual caloric values of the food taken, owing to differences in the methods of preparation, it is probable that these errors tend to balance each other and that they do not materially affeet the net result. We feel certain that in no case did the child receive less food than was reported. It is not unlikely that in some cases a child actually took more than was reported, especially some of the older children whose diet is not so carefully supervised and who are more likely to eat between meals without the knowledge of the parent. If there is, therefore, an appreciable error in the estimation it is 
that the calculated amount is low rather than high.

The largest number of the records were of children under eleven years of age. There are from five to twelve observations for each year up to the age of eleven. Beyond this age the number of observations for each year is too small to warrant definite conclusions, yet the results are interesting.

In Figure 8 are shown the total calories taken daily by each of these children arranged according to age. The curves shown are those based upon the schedules proposed for average daily calories at different ages, which have already been discussed. The curve for boys is indicated by the solid line; that for girls, by the broken line. The individual observations for boys are shown by the large dots; those for girls, by small circles.

Explanation of Some Wide $\mathbf{V}$ ariations

This chart shows, as was to be expected, a considerable variation in individual observations. However, for the most part they fall near the curves; and up to the age of eleven the average falls very near the curves. Beyond that age there are as yet too few observations to be conclusive. However, those made on older boys are very close to the proposed curve. 


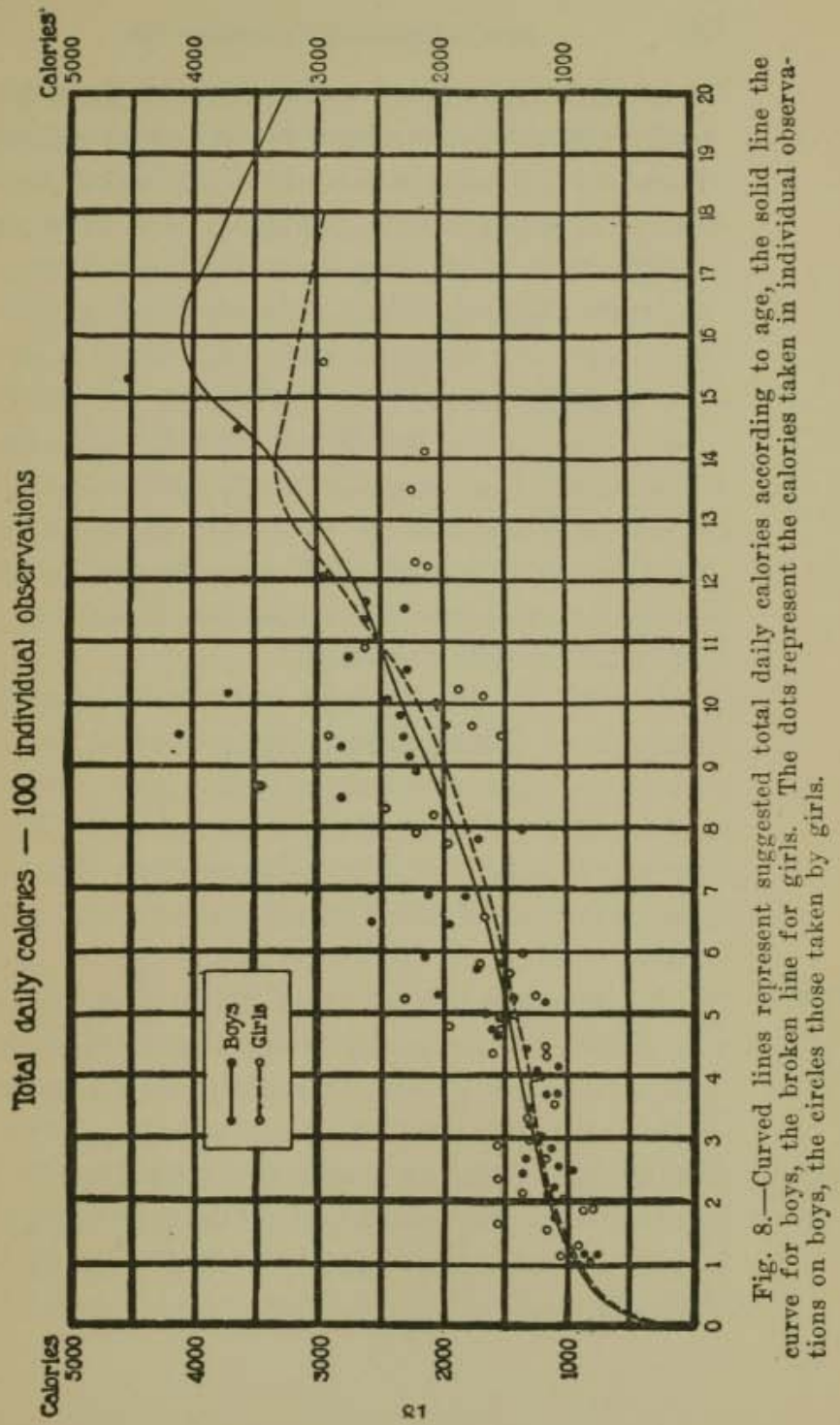


Some of the observations which vary most widely from the average curve deserve special mention. There were eight children whose total calories taken amounted to over onethird more than the theoretical average requirement; but every one of these children was reported to be exceedingly active. There were only two children whose total calories were more than one-third less than the theoretical average requirement, but these girls were both very large for their ages, in fact, had nearly attained adult stature and accordingly did not need the number of calories for growth usual for that age.

On the whole, it would seem that the curves suggested are approximately correct for the average caloric requirements up to the age of eleven years. We feel confident that a larger number of observations for the later years will verify the estimates for those years also.

summary To sum up our discussion to this point, it is clear that in calculating the total caloric requirements of children there must be considered separately the component parts of which the total is made up, namely, the requirements for basal metabolism, for growth, for museular activity and food values lost in the excreta. 
The great differences in the calculations of different writers who have estimated theoretical values for total calories per kilo. for children, are in part due to the fact that they have not sufficiently considered the component parts which make up the total.

The basal requirements per kilo. are highest at about nine months and steadily fall from this time up to adult life.

The food value normally lost in the excreta is a nearly uniform proportion of the intake, about 10 per cent, for all ages after infancy.

The requirements for growth are greatest during the period when growth is most active, namely, during the first years of life and during adolescence. From the fourth to the tenth or eleventh year they are nearly uniform.

The average for three factors-basal, growth requirements and food values lost in excreta-are nearly uniform for healthy children of the same weight living under similar conditions. The requirement for activity is the only factor which varies widely with different individuals.

The average caloric requirement of children is about 100 calories per kilo at an age of one year. For boys it falls to about 80 Avorage Requirecalories at six years and remains practically constant at this value up to the age of fifteen

ments 
years as the increasing requirements for activity are offset by the reduction in basal requirements. After a weight of 50 kilos. (about fifteen years) is reached the calories per kilo.

\begin{tabular}{|c|c|c|c|}
\hline \multirow{5}{*}{ 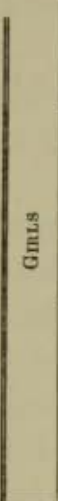 } & \multicolumn{2}{|c|}{ 홀 } & 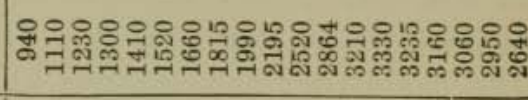 \\
\hline & \multirow{2}{*}{ 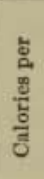 } & है। & | \\
\hline & & $\stackrel{\circ}{\overline{4}}$ & 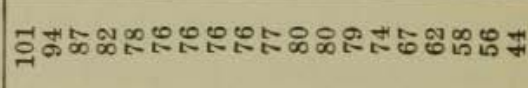 \\
\hline & \multirow{2}{*}{$\begin{array}{l}\text { हैँ } \\
\text { हैँ } \\
\text { है } \\
\text { है } \\
\text { हैँ } \\
z\end{array}$} & 产 & สีํำผ \\
\hline & & 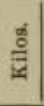 & 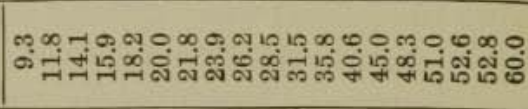 \\
\hline \multirow{5}{*}{ 产 } & \multicolumn{2}{|c|}{ 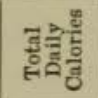 } & 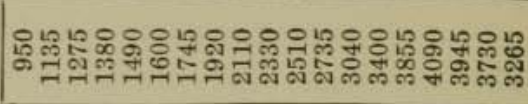 \\
\hline & \multirow{2}{*}{$\begin{array}{l}\text { ఏ. } \\
\text { ฏूँ } \\
\text { हूँ }\end{array}$} & छั & 국유 \\
\hline & & 혐 & 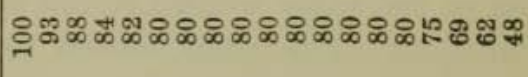 \\
\hline & \multirow{2}{*}{ 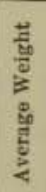 } & 善 & 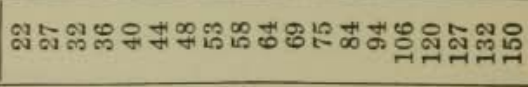 \\
\hline & & 官 & 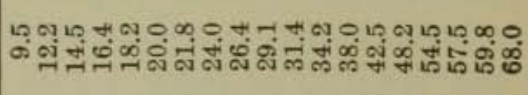 \\
\hline \multicolumn{3}{|c|}{ 选崫 } & 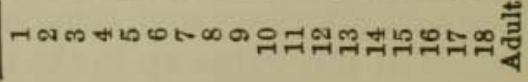 \\
\hline
\end{tabular}


can rapidly be reduced to adult standards, about 48 calories per kilo. The requirement for girls falls to 76 calories per kilo. at about six years and continues near this value until growth is complete, then falls rapidly to adult standards, about 44 calories per kilo.

In this calculation there have been allowed considerably more calories per kilo. during adolescence than have been recommended by others. This seems to be necessary because of the increased growth needs at this time and the large requirement for muscular activity.

According to our allowance the total daily caloric requirement of children of both sexes during adolescence exceeds by nearly 1000 calories the requirements of the adult man or woman of moderate activity.

Children who are under weight require more and those who are over weight fewer calories per kilo. than those who are of average weight for their age.

The schedule here proposed is a tentative one and is based on present knowledge which is in many respects incomplete. There are a number of points which must be studied more fully before definite standards can be established.

The practical value of such a standard is 
that it represents a normal average. Such an average is of course not to be rigidly applied to every individual child. Still an average standard is useful; with this one may compare the diet of individual children who may not be thriving and also it may be used as a guide in providing for large groups of children in asylums, homes or large boarding schools, although perhaps it is less important than other factors in the diet to be considered later, 


\section{CHAPTER III}

\section{Lecture Three}

I. Protein Requirement

Is the previous lecture the total calorio requirement throughout the entire period of growth was discussed. In the present one we shall consider somewhat in detail the different conditions which influence or which determine the amount of each of the important constituents of the child's diet,- - the protein, fat and carbohydrate.

All three of these nutritive substances are sources of energy ${ }^{\bullet}$ and may be utilised as such in the body. There are, however, other important considerations which affect the amount of each one of them in the diet. Especially is this true of the protein. Before considering the other food elements it is desirable to establish first the protein requirement.

- Energy as applied to food may be expreseed in terms of heat or mechanical work; it may be used up immediately or stored in the body for future use. 
The proteins are indispensable to life; no other foods can supply the nitrogen which is necessary for the constant renewal of the cells of the body. They are very complex substances, being composed of some sixteen or eighteen different amino-acids. These aminoacids are sometimes called the building stones of the body. The proteins differ very much in their value as foods, according to the amount

Protelns Are Very Complex Substances and Have Different

Values of the particular amino-acids of which they are made up. So that it is impossible to consider how much protein is needed during the growth period unless we also take into account the kind of protein which is given.

In the process of digestion the proteins of the food are split up in the intestines into their various amino-acids. These are absorbed and subsequently recombined to form the proteins of the body. Now the proportions of amino-acids in the body proteins are not the same as in the food proteins. It follows therefore that not all the amino-acids of the food are utilised in building up the body structure or in making the repairs which the wear and tear of every day makes necessary. Those amino-acids which are not utilised in this way as building materials are used largely for energy, being broken down into urea and excreted in the urine. 
The food proteins differ greatly in the amino-acids they contain; they may, therefore, furnish a considerable excess of one or more of those needed as building materials, while at the same time they may be deficient

Kind of Proteln as Important for Growth as the Amount in others which are quite as necessary. Certain of the amino-acids such as leucin, glutamic acid, arginin, prolin and others, which form a large proportion of the body proteins, are present in abundance in practically all the proteins of the food; consequently an ample supply of these is always assured.

But there are other amino-acids especially needed for growth, such as lysin, eystin and tryptophan, which are found in much smaller amounts, and in widely varying proportions in the different food proteins. Many of the food proteins are in fact entirely wanting in one or other of these particular amino-acids. Hence, special care must be taken to provide in the diet of growing children either those proteins having the larger proportions of these important amino-acids, or if the proteins which have the smaller proportions of these substances are given, they must be furnished in the diet in greatly increased amount. It is obvious, therefore, that the total protein requirement for children during the period 
of growth is to a great extent dependent on the kind of the protein given.

It is well known that the animal proteins resemble the proteins of the human body more nearly than do those of vegetable origin; for this reason they are definitely preferable during the period of growth. For the child, therefore, the animal proteins, such as are furnished in milk, eggs and meat, are distinctly of a higher grade than the vegetable proteins. With our present knowledge it seems neeessary, if vegetable proteins are depended upon in the diet of children, to supply them in larger amounts than when animal proteins are given and even then we may not secure normal growth.

Treods of Children Diflerent from Those of Adulta

In estimating the child's protein need there are two distinct functions of protein which must be considered. The first is the requirement for tissue repair and general maintenance; the second is that needed for growth. In adult life the first need is the only one which has to be supplied. In childhood the second is quite as important.

Even the protein requirement of the adult has been the subject of much controversy. It has been found possible to maintain nitrogen equilibrium, or a balance between intake and excretion, in an adult man or woman on a 
protein intake as low as 40 grams daily. There are some writers who believe that this Protein Requifements minimum allowance is a sufficient supply. The average adult dietary, however, furnishes very much more than this; as compiled from many sources it allows from 100 to 120 grams of protein daily. This amount, which may be considered as an expression of human experience, has been regarded by many as the optimum protein need. This amount of protein allows an average of about 1.4 grams of protein per kilo. of body weight.

Sherman, who has recently investigated the average protein intake of over 100 adults, found the average minimum to be 44.4 grams per day. This represents about 0.6 gram per kilo. for a person of average weight. His conclusion is that for an adult 1.0 gram of protein per kilo. is quite enough for maintenance.

The question has been much debated whether this maintenance need can be entirely supplied by vegetable proteins. The work of a number of investigators indicates Proteina that this is possible. Sherman, however, believes that better results are obtained by supplying part even of the maintenance requirement by animal protein. Among the vegetable proteins there are certain ones, notably 
zein, a protein of corn, which are insufficient even for maintenance.

From what we know of the adult protein need it may reasonably be inferred that the growing child with his more active metabolism requires for maintenance from 1.0 to 1.5 grams per kilo. of body weight daily. It seems probable that this ean be supplied either from vegetable or from animal sources.

In addition to the maintenance need, however, the child must be supplied with a gener-

Animal Proteins Best for Growth ous allowance of protein for growth. Because the vegetable proteins as a group are so poor in certain of the important amino-acids, it seems necessary to supply the protein needed for growth by animal protein. It is quite possible then that an adult might be kept in perfect health upon a vegetarian diet; but it is extremely doubtful whether such a diet for a child would insure normal growth. How much protein should be furnished to cover the growth requirement it is difficult to estimate.

No experimental work has been reported on the protein need of children and the effect on their growth of either a very low or a very generous protein intake. Osborne and Men- 
del have been able to obtain very definite quantitative results on protein needs in their work with rats. These are not only interest-

Effect of Different Proteing on Growth of Rata

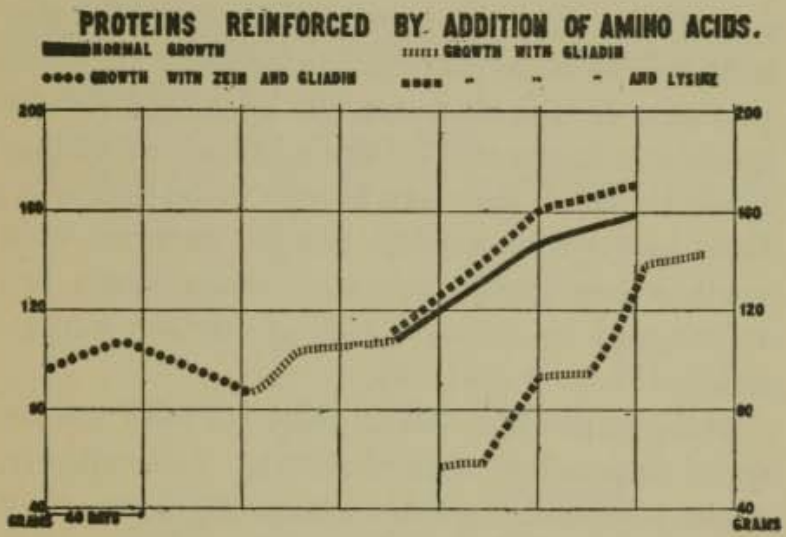

Fi6. 9.-This ehart shows that the amino-acid lysin is indispensable for growth. It is taken from Osborne and Mendel and shows the effeet upon the growth of rats of adding lysin to and withdrawing it from the diet.

In the first part of the upper curve the protein given is eomposed of equal parts of zein, a protein of corn, and gliadin, a protein of wheat. Zein is one of the poorest proteins and animals eannot be maintained upon it when it is the only protein in the food; it contains no lysin; gliadin has only a very small amount of lysin. In the seeond part of the upper eurve, when all the protein is furnished by gliadin, a slight growth is observed; but when lysin is added an immediate growth begins which persists (dotted line) at a rate exceeding the normal inerease (solid line).

In the first part of the lower curve the protein is gliadin. When lysin is added there is a quiek growth response which ceases when the lysin is omitted, is resumed by its addition and again stops when the lysin is withdrawn. 
ing in themselves but have an important bearing upon the protein needs of children. They have determined exactly how much of certain proteins are required to support normal growth in rats; also, what is especially significant, to what extent the amount of these proteins in the diet can be reduced if their quality is improved by the addition of aminoacids in which they are known to be deficient; thus how rapid growth ean be secured with certain low grade proteins when these are reinforced by the addition of certain aminoacids (Figs. 9 and 10).

Such experimentation is by its very nature quite impossible with children. Accordingly, about the only guide which we have to a knowledge of the total protein need for children is to be found in a study of the actual amounts of protein which are taken by normal, healthy children in their eustomary diet. It is fully realised that the results of such a method of investigation as this are not conclusive, but they are strongly suggestive.

To begin with, let us consider the nursing Woman's infant. The total protein intake of a normal in Protein infant at the breast is very low. Up to the age of eight or nine months the amount seldom exceeds 12 grams daily; this is equivalent to only about 1.5 grams per kilo. This amount, 
it is to be remembered, must supply not only the maintenance requirement but the need for growth, and that too during the most active

\section{PROTEIMS REIMFORCED BY ADDITION OF AMINO-ACIDS}

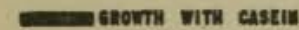

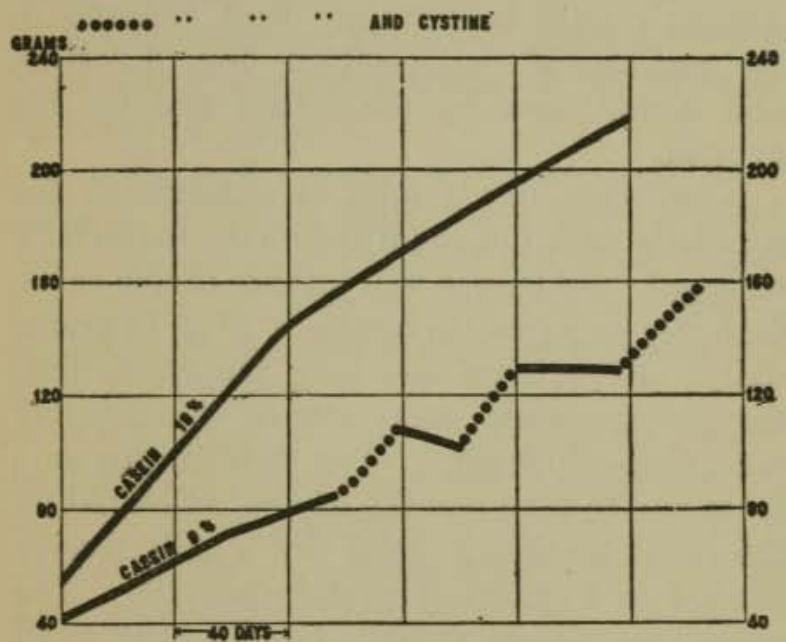

Fig. 10.-In this chart from Osborne and Mendel the upper eurve shows the growth of rats whose food contained 18 per cent easein. The first part of the lower curve shows the slower growth upon 9 per cent casein and the effect upon growth of adding and then withdrawing eystin. Casein protein is notably defieient in eystin and a larger amount of easein must be given to insure normal growth.

period of growth in the life of the child, as the healthy child usually doubles his weight in the first five months. That this amount is 
sufficient needs no argument. We find our best examples of good nutrition and growth in breast-fed infants.

The reason why this small protein intake does supply the infant's entire requirements is to be found in the fact that the protein of woman's milk is certainly best adapted in its amino-acid composition for digestion and assimilation by the infant and for his growth.

More is Required when Cow's Millk is the Food

Now when cow's milk is substituted for woman's milk the conditions have materially changed. No longer will infants thrive satisfactorily on a protein intake of 10 or 12 grams daily. Experience has long taught us that the protein intake must now be considerably increased-doubled or even trebled. Infants from one to nine months of age, when fed on the usual modifications of eow's milk, receive from 3 to 4 grams of protein per kilo. The great increase in protein requirement when cow's milk is substituted for woman's milk is probably due to the difference between the two milks in the amino-acids which their proteins contain. The protein of woman's milk is protein of a very high grade. It is composed of two-thirds lactalbumin; and lactalbumin of all the proteins contains the highest proportion of leucin, lysin and trypto- 
phan, amino-acids which are particularly important for growth. Woman's milk contains about twice as much lactalbumin as does cow's milk. Casein, which forms about fivesixths of the protein of cow's milk, is of comparatively low grade as a growth protein, being notably deficient in cystin. In order to secure an adequate supply of this amino-acid a greatly increased amount of casein must therefore be taken.

This is well shown by Osborne and Mendel's experiments upon rats; they obtained good growth when the food contained 18 per cent of casein; poor growth with 9 per cent, but good growth with 9 per cent if cystin was added (Fig. 10).

The failure of condensed milk as a food for infants has been ascribed to many causes; by some, to its low fat and its relatively high sugar content; by others, to the effect of heat Failures in Feeding Low Protoins and age upon its vitamine content. With the facts just mentioned before us it now seems clear, that equally important-perhaps more important than either of these considerations -is its low protein. In the dilutions in which this is usually fed, the percentage of protein ranges from 1 to 1.4 , which is only about the amount which an infant taking woman's milk receives. 
Again, in the early days of milk modification by the percentage method, it was thought that formulas from cow's milk in which the proportions of fat, sugar and protein were as nearly as possible the same as those found in woman's milk, would be the best substitute for it. But those who followed this plan in practice, were doomed to disappointment. The failures from the use of such formulas were variously explained; by most, they were ascribed to the too high fat, and no doubt this was sometimes the case; but it now seems quite evident that an important error was the low protein in many of these formulas. With elinical experience it has become increasingly clear during the last few years, that the majority of infants will not thrive normally upon cow's milk unless they are given two or three times as much protein as is contained in woman's milk; also that the higher total protein of cow's milk is not the principal cause of its difficult digestion by the average infant.

The proportion of vegetable proteins in the diet of infants is a very small one. Infanta Re. Whether nursed or artificially fed the infant Animal Protoling receives practically his entire protein supply in the form of animal protein, at least during the first six months of life. It is only 
when cereal additions are given, either as flour incorporated in the milk formula or as cereal given separately, that a portion, although at first a very small one, of the protein given is of vegetable origin.

When we come to consider the diet of children past the period of infancy, we find that almost no attention has thus far been paid to Amount of Protein Recommended for Older its quantitative composition. There is, therefore, very little material to be found in the literature concerning the actual daily amount of protein taken by older children. The few scattered data which have been published are for the most part incidental to researches on other subjects. Most of the authors, whose reports on the total calories taken by children were discussed in the previous lecture, have also reported the protein content of the diets taken.

Gillett has compiled from eighteen authors, 145 cases in which the amount of protein taken daily is given. These include most of the values for protein intake published in the literature up to 1917. Her summary shows that the average protein intake of all the groups was at least 2 grams per kilo. and the average of the younger children 3 grams per kilo.

Müller studied the diet of 32 children from 
two to six years of age, inmates of an institution, who took an average of 3.5 grams of proteins per kilo. daily. It should be borne in mind, however, that these children were much under weight. He thinks that the protein need of children is proportionally very much greater than that of adults, and that Children's no attempt should be made to reduce the pro-

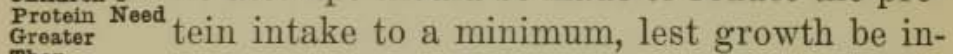
Than terfered with and general nutrition impaired.

Gephart in his observations on the adolescent boys in St. Paul's School found the protein intake to be very high at these ages. The average total daily protein was about 160 grams; while the average protein per kilo. ranged from 2.6 to 3.8 grams.

Camerer recommends over 4 grams of protein per kilo. for the first year, from 3 to 4 up to the eighth year, over 2 grams until the fourteenth year, diminishing to 1.7 grams at the end of the growth period.

In the previous lecture were presented the values for total calories actually taken by over one hundred healthy children from one to seventeen years of age. In each of these cases it will be recalled we obtained complete diet records for a period of four days. These children were from intelligent, well-to-do 
families and may be assumed to be taking diets which are fairly representative of what children under such circumstances usually receive.

A study of the amount of protein taken by them should, therefore, give some idea of the usual amount in the diet of healthy American Amount Taken by Healthy American children. These results correspond quite closely with those just quoted, except that

Children

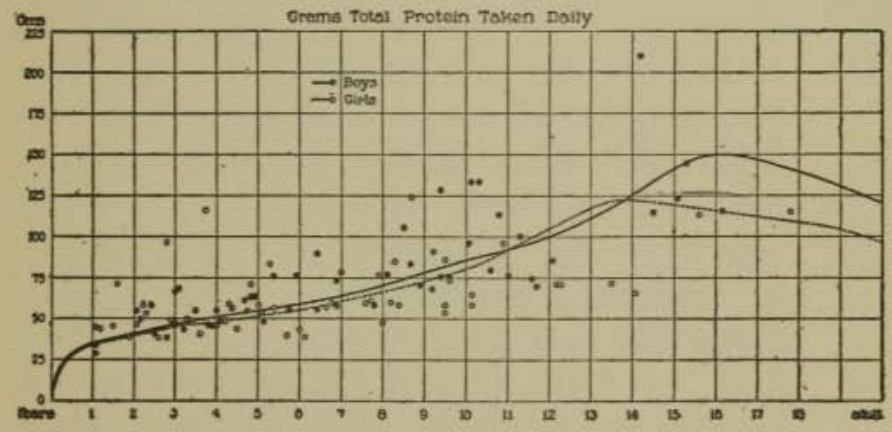

Fig. 11.

during the adolescent period of rapid growth the intake was the greater, and diminished after growth was slower and completed.

A verage total protein in 2 nd and 3 rd yrs, was 49 grams; 4.0 per kilo

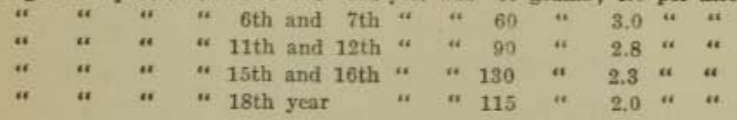

Our observations indicate that in the usual 
diet approximately 15 per cent of the total calories taken by children over one year old should be supplied by protein.

In Figure 11 is given the total daily intake of protein of the individual children. The solid and dotted lines represent for boys and girls respectively the grams of protein which are equivalent to 15 per cent of the calories recommended. While the great majority of

Bxceptional Protein Intake these cases fall reasonably near the average lines there are some interesting exceptions which are worth noting. There are four young girls whose protein intake was very high. All were extremely active children, in excellent health, whose total food intake was very high. There were two large girls of thirteen and one-half years and fourteen years who took a very low amount of protein. But both had attained practically their full growth and for them really the only protein need was that for maintenance.

There were three boys about ten years old with very high intake. The explanation in each case was excessive activity. A fourteen-year-old boy taking 210 grams of protein daily is an example of what is so often observed, that is, the very large amount of food frequently taken by an active, rapidly growing boy at this age. It will be recalled that 
the average intake of the St. Paul's School boys was about 160 grams daily.

The grams of protein per kilo. of body weight taken by these children agree pretty With ${ }_{\text {Whit }}$ well with the findings which have been published by others. Four-fifths of the children observed took between 2.2 and 4.4 grams protein per kilo. The average was 4.4 per kilo. for the youngest group. The fourteen who took more than 4.4 grams per kilo. were mostly young and very active children, only three being as much as five years of age. In general, the intake per kilo. tended to diminish as age advanced. That for the oldest group, from fourteen to seventeen years, was between 2 and $21 / 2$ grams per kilo.

The values for some of the older children, particularly for girls between twelve and fifteen, are low; but it is probable that with more data the average of these years would be higher than is shown in the table owing to rapid growth at this age.

These observations on normal children have also been analysed with respect to the proportion of animal and vegetable protein in the diets taken.

Most of the children took over 60 per cent of their total protein in the form of animal protein, from milk, eggs, meat, etc. The 


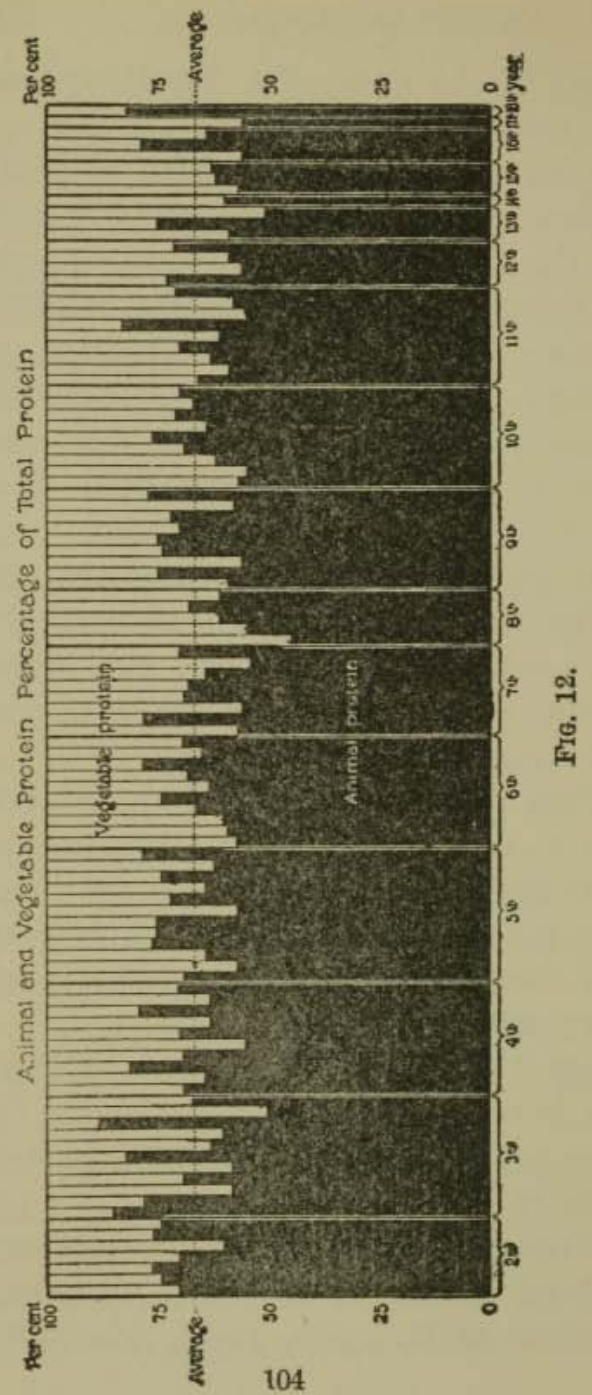


average was 66 per cent of the total protein from animal sources, and 34 per cent vegetable protein. Figure 12 shows graphically the percentage division of the total protein in the diet of each child. The values are arranged in order of age; there was no constant variation noted.

That there was found so little variation in the proportion of animal and vegetable protein in the diet of the different children was a matter of much surprise.

These observations indicate that healthy children in their usual diet take about 4.0 grams of protein per kilo. at the age of one year, the amount diminishing to about 2.5 grams per kilo. or 0.25 per cent of body weight at six years of age and remaining at about this value or slightly below it until the end of growth, and that of this total practically two-thirds is animal protein. This quantity of protein may perhaps be regarded at present as the optimum and may therefore be recommended as a suitable intake for the growing child.

When we come to consider how much of this total should be animal protein we have very little knowledge to guide us. It is quite possible that children might do well if less than two-thirds of this was animal protein. How- 
ever, from what is known of the growth properties of the vegetable proteins as a class it is evident that a much larger amount of vegetable protein would be required if the aminoacids necessary for normal growth were supplied.

Vegetable protein cannot replace animal protein gram for gram. Accordingly, if one

Vegetable Proteins of Lower

Grade and More Must be Given

gummary is to give a larger proportion of vegetable protein than the usual one-third of the total requirement, it seems clear that the total protein intake must be considerably increased. In our common vegetable foods protein is always associated with carbohydrate and when the amount of vegetable protein given is increased very much above the average, it should be realised that the amount of carbohydrate is necessarily increased also, and this may be undesirable and may be a cause of disturbance to digestion.

In conclusion it is evident that no estimate of the amount of protein required for the proper nutrition of children can be made without taking into account the kind of protein given, since the amino-acid content of different proteins varies so considerably; also that in estimating the protein needs of the child not only must the need for maintenance be supplied, as with the adult, but also 
a liberal amount of protein must be allowed for growth.

The fact that the small amount of protein taken by nursing infants is adequate is due to the superior amino-acid composition of the proteins of woman's milk.

When cow's milk is substituted for woman's milk the amount of protein allowed should be increased-doubled or trebled.

Vegetable proteins as a class are of a distinctly lower grade than animal proteins, and while they may be adequate for maintenance, with our present knowledge, it is hazardous to depend upon them for growth.

\section{Fat Requirement}

The amount of fat which is required in the diet during growth has not yet been, and cannot be established until the exact rôle of fat has been determined. Until quite recently it has been generally believed that fat did not play any specific part in nutrition, but, like carbohydrate, served as a source of energy and as a sparer of protein. Because of this belief very little attention has been given to the amount of fat which is desirable in the diet, except in the case of infants. Recent investigations, however, have shown that fat is of greater importance than was for- 
merly believed, and that it has specific functions in nutrition quite apart from those which it shares with the carbohydrates. It has been shown that during growth fat is especially important. There are now recognised to be several reasons for regarding fat as a necessary constituent of the diet of children.

Fat is the carrier of the fat-soluble vitamine which has been proven to be essential for health and normal growth. A fuller discussion of this will be taken up later with the general subject of accessory food substances. How much of this vitamine should be provided for the child is not yet known.

From the evidence which has been obtained it would seem that the amount of fat needed for this purpose is comparatively small; but in order to insure normal growth it is probably wiser to supply in the diet a generous amount of such fats as are known to contain this substance.

Among the usual foodstuffs the richest sources are milk fat, egg yolk and certain animal organs-liver, kidney, etc. It is especially abundant in cod liver oil. This vitamine is also found in the green leaves used

The Fat-

Soluble

Vitamine or as vegetables, but since the young child can take only a comparatively small quantity of 
these in the diet it is not wise to depend upon them as a source of this vitamine to any great extent.

Since the function of the vitamines has been appreciated there has been a growing tendency on the part of those particularly interested in them to regard the fat of the diet of special importance only as a carrier of vitamine $\mathrm{A}$.

These investigators seem inclined to attribute all the bad effeets of a diet low in fat to a vitamine deficiency. The fact that such a diet predisposes to rickets and possibly to œdema, that it increases the susceptibility to infection and retards growth, is explained by them in this way. Their contention is that if sufficient vitamine $\mathrm{A}$ is supplied in a diet which is fat-free but otherwise adequate, the conditions just mentioned will not develop.

Most of the conclusions regarding the functions of vitamines have been drawn from exAnimal Experiments upon small laboratory animals, chiefly rats. Mendel and Osborne have recently published the results of experiments continued for from four to eight months in which they obtained what they considered normal growth in rats on a diet in which the fat was extremely low, amounting to but $1 / 20$ of one per cent of the total food; but the diet 
included the necessary amount of the vitamine $\mathrm{A}$, derived in this case from dried alfalfa leaves. They conclude that "if true fats are essential for nutrition during growth the minimum necessary must be exceedingly small."

To apply too dogmatically to human beings the results of experiments upon small animals which are of a species so different, seems open to some question. The natural diet of the rat is very unlike that of human beings and consequently its digestive processes may not be entirely comparable. Hence, it is conceivable that fat may have functions in human nutrition which may not be required of it in the nutrition of the rat, quite apart from that as a purveyor of vitamine A.

Von Gröer of Vienna has observed the effects of a diet practically fat-free upon two infants from birth. The food given was separated cow's milk containing only 0.01 per cent of fat, with enough cane sugar added to give a total carbohydrate content of about 8.5 per cent. This diet was not only practically devoid of fat, but also extremely low in vitamine $\mathrm{A}$ and very high in earbohydrate. Both infants gained in weight with fair regularity for six months. But after six months the gain ceased. Both developed rickets and were 
very susceptible to infection. The conclusions reached by von Gröer is that for at least the first six months of life infants can be successfully nourished on a diet which is practically fat-free provided the calories needed are supplied by sugar. His reported results hardly bear out this contention.

Another function of fat which is questioned by some is its influence on mineral metabolism. This has been much debated and the subject cannot yet be regarded as entirely settled. Many laboratory observations have been made to ascertain the influence of the fat intake upon the mineral metabolism of infants and very young children.

Unfortunately the results thus far have been conflicting and final conclusions have not yet been reached. Although some investigators are convinced that there is no relation between the fat intake and the mineral metabolism in general, we feel certain that in the case of calcium metabolism at least a very definite relation exists. The work on calcium metabolism done in the Babies' Hospital laboratory indicates that the best calcium absorption takes place when the fat in the diet bears a certain relation to the calcium and when the intake of both is liberal, The results indicate that the daily fat intake 
of children from two to four years of age should not be less than 3.0 grams per kilo. to insure proper absorption of calcium. This requirement seems to diminish up to six years of age to about 2.0 grams per kilo., but is probably maintained at about this figure throughout the remainder of childhood. Since adequate absorption of calcium is necessary for bone growth, this need seems a very important one. The observations also show that for the purpose of calcium absorption a vegetable fat will serve quite as well as an animal fat.

Some authors have recently taken the ground that the fat of the diet has an important influence on the metabolism of protein.

It is contended that the amount of fat in the diet should at least be equal to the amount of the protein. Thus fat should not be regarded as supplementary to the dietary requirement but an integral part of it. It is certainly a very significant fact that in woman's milk the fat exists in a considerably greater amount than the protein while in cow's milk they are nearly equal.

Fat and Resistance to Infection

It is generally accepted that the lack of fat in the diet increases susceptibility to infections, especially to tuberculosis. Although children may apparently do very well for a 
time on a low fat or a fat-free diet, the complete elimination of fat from the diet or even its reduction to insignificant proportions, as recently proposed by Pirquet, seems a hazardous experiment.

Furthermore, it seems clear that a reasonable amount of fat in the diet is useful in maintaining normal chemical and bacteriological conditions in the intestine. This is indicated by observations on the character and composition of the stools. When fats are excluded or greatly reduced in the diet there is inevitably a great increase in the carbohydrates. Among many stools studied we have not found any which would be generally regarded as typically normal in character and consistency under these conditions. With children whose digestion is normal the change does not take place at once; but after a period usually of a week or ten days the stools generally become softer, more of a "mushy" consistency with greatly increased acidity and after a short time mucus usually appears. There is also a change in the intestinal flora. The addition of fat to the food very quickly brings about a decided improvement in the appearance of the stool.

Only a small part, usually about 5 per cent, of the ingested fat is not absorbed; but we 
believe that this amount has, as Hutchison has recently suggested, a special function to perform, and is not to be regarded as a pure excretion.

Excreted.

Iargely as

8oaps

The fat excreted is largely in the form of soaps which give solid consistency to the stool. When the normal amount of soap is present there is no excessive acidity. The action of soaps to a certain degree seems to be to protect the mucous membrane of the intestine from injury by the products of excessive fermentation of the carbohydrates. The acidity of the stool is to a great extent dependent upon the relative proportions of fat and carbohydrate in the diet.

Aside from these reasons for regarding the fat per se as an important constituent of the diet of the child, it must not be forgotten that as a source of energy fat provides more than twice as many calories per gram as does either protein or carbohydrate.

It seems, therefore, quite clear that a certain amount of fat is desirable and probably essential for the best nutrition of the growing child. The quantity needed, however, is difficult to determine. At the present time it can only be conjectured. Many authorities think that the diet naturally chosen is an indication of a physiological need. That fat is an impor- 
tant component of the diet of the infant is shown by the composition of woman's milk. The normal amount of fat in woman's milk averages between 3 and 4 per cent; and this furnishes approximately half the total Amo'unt Taken by Nursing calories in the diet of the nursing infant. This cannot be without significance. It seems hardly conceivable that so much fat would be supplied by nature if the only specific purpose of the fat were to furnish vitamine $A$. The nursing infant usually receives during the early weeks as much as 20 grams of fat daily. This total increases by the seventh month up to an average of 40 grams daily. This represents about 4 grams per kilo. of body weight. Nothing is more characteristic in the nutrition of the nursing infant than the facility with which this large amount of fat is taken and utilised. Nothing certainly contributes so much to firm tissues and the appearance of perfect health as this.

Fat is also generously provided by nature for the young of all mammals. All the animal milks contain a large amount of fat, many of them in greater proportion even than is found in woman's milk. It is also noteworthy that in nearly all milks the amounts of fat and protein run almost parallel.

The infant fed on modifications of cow's 
Infants Can Take Less Fat in

Cow's Malk

milk seldom receives as much as does the nursing infant. This is mainly because the digestion of the fat of cow's milk is somewhat difficult for most infants and it must therefore be given in smaller amounts and increased cautiously. The fat intake must be varied with the individual reaction of the infant to the fat of cow's milk. A few infants can take more than this with advantage; many must be given less.

Although there are in the literature many statements regarding the amount of fat recommended for children after infancy there are but few records of the amounts of fat taken by individual children, and few observations as to the effects of either a very high or a very low fat intake. The amount of fat taken by over one hundred normal children studied by us may perhaps be regarded as typical of that usually taken by healthy children. Over three-fourths of these children took between 2 and 4 grams per

Amount of Fat Taken by older Children kilo. daily. The average for both sexes during the early years was a little over 3 grams per kilo. of body weight. As age advanced there was a gradual reduction in the grams of fat per kilo. Most of the instances of very high fat intake were in children of extreme activity whose total food intake was high. 
Two boys in their fifteenth and sixteenth years, respectively, took over 150 grams of fat daily. There is a practically steady increase with age in the average total fat intake, the maximum being reached, as would be expected, during the fifteenth and sixteenth years.

Müller gives the average fat intake of thirty-two children from two to six years of age as 3.45 grams per kilo. This is in accord with our findings for corresponding ages.

Most of the observations reported by other German authors show lower values. Those of Camerer, who has been widely accepted as an authority, are especially low, most of his values being less than 1.5 grams per kilo. Among the German authors who have proposed a scheme of feeding in which exact quantities of the food constituents are given, Steffen is about the only one who recommends a generous fat intake. Pirquet has taken the position that fat is not a fundamentally essential article of diet and that it can be replaced by carbohydrate without harm to the organism.

In Gephart's report upon the diet of the boys of St. Paul's School he states that they took about 200 grams of fat daily.

The younger group, averaging thirteen. 
Amount

Taken by Adolescent Boya

and one-half years of age, took an average of 4.5 grams of fat per kilo., and the older group, averaging sixteen and one-half years, took 3.4 grams of fat per kilo. All these values are much higher than has been thought normal.

The average adult diet based on many observations contains only about half the amount of fat taken by these boys. The fact that the fat intake of healthy boys was so high is undoubtedly significant. This large amount of fat apparently had no deleterious effect. On the contrary the boys thrived upon it and it seemed to represent a physiological need. It confirms our belief that the fat requirements are especially large during the periods of most active growth (infancy and adolescence) and that at the latter period they exceed adult requirements.

There is a disposition among certain clinicians to ascribe most of the digestive disturbances in children taking a mixed diet to the fat in the food, particularly the fat of cow's milk. It is undoubtedly true that under certain conditions a very high intake of fat, particularly if accompanied by a reduction in the carbohydrate intake, may bring about quite serious disturbances of digestion. German writers describe it under the name Milchnährschaden. The characteristic symptoms 
in such eases are familiar: the coated tongue, bad breath, general malaise, constipation, with large gray stools containing a high proportion of fat, and occasionally severe and prolonged attacks of vomiting.

These symptoms are regularly relieved by greatly reducing fats and increasing carbohydrates in the diet.

There are many other cases, however, when fat is blamed, when the real cause is simply too much food; as when children of limited activity are given a quart or more of milk, often rich milk too, daily, in addition to a liberal diet of solid food. It is important before attributing the trouble to the fat to consider the diet as a whole, both as to the total amount of food taken and the relative amounts of fat and carbohydrate which the diet contains. There is evidence that when the diet is properly balanced, that is, contains the fat, protein and carbohydrate in the right relation to each other, a child can digest very much larger amounts of fat than when the diet is unbalanced.

While it may not yet be proven that a large amount of fat is essential in the diet during growth, there are so many reasons for a liberal allowance of fat, and so little evidence that this is harmful, that it does not seem 
wise, with our present knowledge, to endeavour to reduce the fat in the diet to a minimum, or even to give much less than the amount which healthy children usually take at the present time; while to exclude it entirely from the diet seems quite unjustifiable.

From the foregoing considerations it seems reasonable to allow growing children in the

Amount

Recom:

mended diet at least as much fat as protein. On this basis, the proper amount seems to be nearly 4.0 grams per kilo. daily at one year, diminishing to about 3.0 grams or 0.3 per cent of the body weight at six years and thereafter. It seems probable that the child's nutrition is best assured by not permitting the fat allowance to fall much below this value during the remainder of the growth period.

\section{Carbohydrate Requirement}

The carbohydrates probably have no specific function to perform in the diet of the growing child but are nevertheless very essential components. They serve mainly as a source of energy, supplying the necessary calories not furnished by fat and protein. In many respects fats and carbohydrates in the

Tunetions of Oarbohy. drate in Diet diet are interchangeable, so that in conditions of marked fat intolerance carbohydrates may entirely replace fats for a considerable 
period. However, carbohydrates accomplish other purposes. They undoubtedly play an important part in the metabolism of fat; without the addition of carbohydrate to the diet it is generally believed that complete metabolism of fat is impossible. In its eapacity to spare protein carbohydrate is even superior to fat. These functions of carbohydrate are well known and need not be discussed.

When digestion is normal, carbohydrate is almost if not quite completely utilised in the body. What is not immediately used for energy is stored as glycogen to be later used for energy, or it is converted into fat and added as fat to the tissues of the body. The excess is usually broken down by fermentation in the intestines. While of all the food constituents it is most easily and most completely digested under normal conditions, when digestion is disturbed it is the one which breaks down readily to form irritating products in the intestine.

The carbohydrates are altogether the most economical food we possess from both a commercial and a physiological point of view. They can be produced more cheaply; because not perishable they can be transported and stored with less expense and less likelihood 
of deterioration. They are consequently much less expensive than fat and protein foods. ${ }^{1}$ They are economical physiologically because of their almost complete utilisation under normal conditions. It is not surprising therefore that carbohydrate has come to form the greatest part of the diet at all periods of life except early infancy.

${ }^{2}$ Calortes Purchasable for Ten Cents at a Bmall New York RetaIL Store oN A Given DATE

\begin{tabular}{|c|c|c|}
\hline ARTICLES & Retail Prict & $\begin{array}{c}\text { NUMBER OF } \\
\text { CALOBIES }\end{array}$ \\
\hline $\begin{array}{l}\text { Carbohydrate foods } \\
\text { Sugar, granulated } \\
\text { Karo Corn Syrup } \\
\text { Oatmeal } \\
\text { Rice } \\
\text { Bread } \\
\text { Cream of Wheat } \\
\text { Potato } \\
\text { Jam }\end{array}$ & $\begin{array}{l}6 \text { cents per pound } \\
20 \text { cents per } 2.5 \mathrm{lb} \text {. can } \\
12 \text { cents per } 20 \mathrm{oz} \text {. pkg. } \\
12 \text { cents per pound } \\
9 \text { cents per } 15 \mathrm{oz} \text {. loaf } \\
30 \text { cents per } 28 \mathrm{oz} \text {. pkg. } \\
5 \text { cents per pound } \\
20 \text { cents per } \mathrm{lb} \text {. jar }\end{array}$ & $\begin{array}{r}3100 \\
1970 \\
1930 \\
1360 \\
1270 \\
980 \\
770 \\
530\end{array}$ \\
\hline $\begin{array}{l}\text { Fat foods } \\
\text { Butter } \\
\text { Olive oil } \\
\text { Cream-Sheffield X } \\
\text { (includes some pro- } \\
\text { tein and sugar) }\end{array}$ & $\begin{array}{l}49 \text { cents per pound } \\
65 \text { cents per pint } \\
32 \text { cents per half pint }\end{array}$ & $\begin{array}{l}740 \\
600\end{array}$ \\
\hline $\begin{array}{l}\text { Protein foods (include } \\
\text { some fat) } \\
\text { Cheese, Ameriean } \\
\text { Lean beef, round } \\
\text { Eggs, fresh brown } \\
\text { Mixed food } \\
\text { Milk-Sheffield, } \\
\text { Grade A }\end{array}$ & $\begin{array}{l}35 \text { cents per pound } \\
44 \text { cents per pound } \\
60 \text { cents per dozen }\end{array}$ & $\begin{array}{l}590 \\
200 \\
180\end{array}$ \\
\hline
\end{tabular}


But even at this time the lactose of Form and woman's milk supplies nearly one-half of its Amount caloric value. The nursing infant takes daily about 30 grams of lactose during the early weeks and usually as much as 80 grams during the latter part of the nursing period. Young infants taking modifications of cow's milk often receive considerably more carbohydrate than do nursing infants. This is chiefly because it is impossible to give them the amount of fat which the nursing infant usually receives.

The nursing infant receives carbohydrate entirely in one form-lactose. The infant fed on cow's milk may take entirely lactose or partly lactose and partly saccharose, maltose, dextrin or starch or various combinations of these. It is not usual for any large proportion of the earbohydrate to be given as starch until after infaney, when the child takes a mixed diet. In a mixed diet after one year at least one-half of the carbohydrate is usually in the form of starch, the rest being various sugars-milk sugar, cane sugar and fruit sugar and occasionally some dextrin or maltose.

The amount of carbohydrate taken by children over one year of age varies considerably according to the theories of the parent 
or physician and even more to the habit or taste of the child.

On account of the conditions mentioned there is at present a growing tendency to alDisposition Too Much Carbohy. drate low earbohydrate foods to form a larger and larger proportion of the diet. There are some children the largest item of whose diet is bread; with others it is potato or cereal. There is also a steady increase in the consumption of sugar and sweets by all classes. One hundred years ago the per capita consumption of sugar in the United States was eight pounds; last year it was 84 pounds. This is either taken as sugar in or upon food or in the form of syrup, jelly, jam, eandy, etc. An official of one of the large five and ten cent store corporations has made the statement that their annual sales of candy exceeded 60,000 tons!

The carbohydrate intake which was calculated of over one hundred healthy children

Amount Taken by Healthy Children in Usual Diet studied by us ${ }^{1}$ illustrates the wide variation in the usual diet of normal healthy children. Since the ages of the children varied from one to eighteen years the variation in intake is best shown per kilo. of body weight. The

1 The details of these observations showing intake of the individual cases have been published elsewhere-see American Journal Diseases of Children, July, 1922. 
usual range was from 8 to 12 grams per kilo.; the average of all the eases being about 10 grams. There were more instances of very high than of very low intake. In a number of cases the children took over 15 grams per kilo.

The actual amounts of carbohydrate taken by the different children were also interesting. There were few instances of very low intake; there were, however, several exceedingly high ones. One girl, between eight and nine years of age, took 464 grams of carbohydrate daily. One boy of nine took 560 grams; one of ten took 488 grams; and one of fourteen took 683 grams daily. The total daily intake increased with fair regularity with the years. The boys averaged more than the girls except during the earliest years.

The observations reported in the literature, in which the carbohydrate intake of children after infancy was ascertained, showed variations quite as wide as those in our own cases. In general, the amount of carbohydrate per kilo. of body weight reported taken by young children is higher than that taken by older children.

Gephart found that the amount of carbohydrate taken by the boys at St. Paul's 
School was much in excess of the average adult consumption and averaged over 600 grams daily. Part of the large intake of these boys is to be explained by sweets they consumed. The carbohydrate intake represented an average of 13.7 grams per kilo. for the youngest group about thirteen years old, and 10 grams for the older group averaging sixteen years.

What O1der Boys and Adults Take

How much this represents can best be judged by comparison with the usual adult dietary which allows 400 to 550 grams daily and which is from 5 to 8 grams per kilo. of body weight. Murlin found that the men in the U. S. Army training camps took an average of 545 grams of carbohydrate daily, or about 8 grams per kilo. of body weight.

From the data obtained concerning the diet taken by the group of normal children studied it was possible to calculate very approximately the amounts of sugar and starch which made up the total carbohydrate.

The values obtained are only approximate, since the relative amounts of sugar and starch used in cooking various articles of food such as cake, puddings, etc., could in most cases be only estimated from a knowledge of common recipes. It is believed however that these estimates are fairly accurate. 


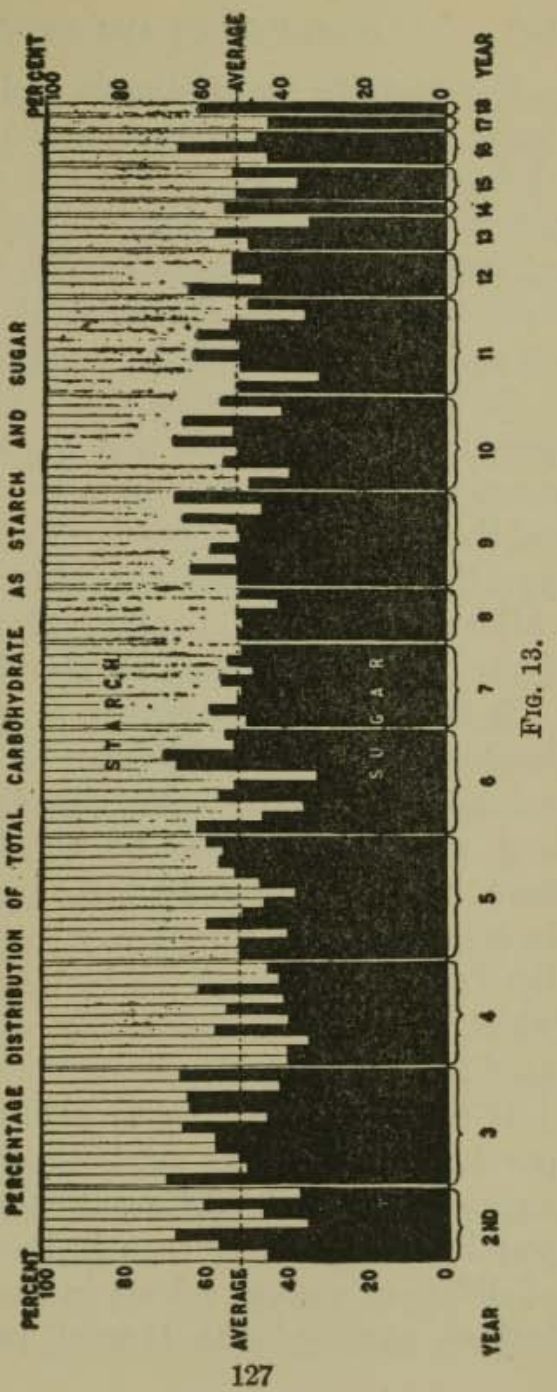


It was quite surprising to find that the av-

About Hale the Carbohydrate Taken is sugar erage of all the cases, regardless of age, showed that 51 per cent of the carbohydrate taken was sugar of some form. The range of sugar taken was naturally wide, but in over two-thirds of the cases it was between 40 and 60 per cent of the total carbohydrate.

In the accompanying chart (Fig. 13) the proportions of starch and sugar are given, arranged according to age, the heavy vertical lines dividing the years. This shows comparatively little variation with the different children in the proportion of the carbohydrate which was taken as starch and sugar.

It is apparently usual in a mixed diet of healthy American children to give unconsciously practically equal amounts of starch and sugar. It should be noted that sugar here includes not only the saccharose used in cooking or on cereal, candy, etc., but also the fruit sugars and the lactose of the milk which was taken separately or which was used in cooking.

It was also possible to estimate the proportions of different sugars constituting the sugar intake of the different children. There was little regularity seen in the proportions of different sugars taken; in the early years lactose supplied the largest proportion of 
the sugar. The proportion of saccharose increased with advancing years. There was a steady increase with the years up to the eleventh year; during adolescence it was about ten times as much as the average taken by children under five years of age.

It is surprising to note how much of the sugar intake was supplied by fruits. This was largely fructose, but some of it was saccharose and it included also in some instances, as in the banana, a small amount of starch. Other sugars played a very insignificant part in the sugar intake.

Because of the ease with which carbohydrate is utilised in the body and because of its lower cost, there is a constant tendency to allow carbohydrate food to form an excesObjections to Too Mar. bohydrate sive proportion of the diet. There are several disadvantages in this procedure. If the proper number of calories is taken, a very high proportion of earbohydrate means a low proportion of either fat or protein or both. Hence there always exists the danger of lowering the amount of fat or protein below that which is necessary for normal nutrition. In such instances there may result an excessive retention of water in the tissues of the body. A diet excessive in carbohydrate often leads also to an abnormal deposition of fat in 
the body. Such a condition is more frequently seen in infancy where the food is condensed milk or some one of the proprietary infant foods which are largely composed of carbohydrates. The tissues of such infants are high in fat and water but low in muscle development. If acute disturbance of digestion or infection takes place this unnatural weight is rapidly lost. The children have but feeble resistance and they often succumb quickly.

A similar condition was produced experimentally in pigs by Washburn and Jones. They found that young pigs fed upon sweetened condensed milk put on an excessive

Comparison of Growth in Seven Weeks of Six Pigs on Condensed Milk with Six Pigs on Whole Mmk

\begin{tabular}{|c|c|c|c|c|c|}
\hline Feeding & 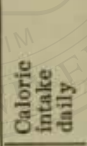 & 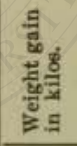 & 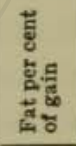 & 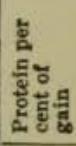 & 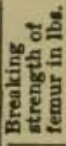 \\
\hline The & 1370 & 11.35 & 9.2 & 15.61 & 362 \\
\hline Sweetened condensed milk & 1270 & 8.10 & 23.65 & 10.92 & 243 \\
\hline
\end{tabular}

Whole milk contained fat 3.3 ; sugar 5.2 ; protein 3.6 per cent.

Sweetened condensed milk contained fat 1.6; sugar 9.8; protein 1.6 per cent.

amount of fat. The protein increase in their bodies was, however, much below normal and 
the bone development was defective, the bones being only two-thirds as strong as when whole milk was fed. The table gives a summary of some of their findings.

There is a growing belief that the large and constantly increasing proportion of carbohydrate in the diet of civilised races has a very important relation to the prevalence of dental caries. The observation has been made by several investigators that Arctic peoples whose diet is almost entirely fat and protein with but very little carbohydrate, Excessive Carbohydrates and Dental rarely suffer from dental caries. Whether this tendency is due to the excess of carbohydrate or to the consequent reduction of other constituents of the diet-fat, protein, mineral salts or vitamines-has not yet been established.

Of more importance probably is the effect on digestion of a diet in which the proportion of carbohydrate is excessive. If a large amount of carbohydrate, especially if in the form of sugar, is taken into the digestive tract at one time, it is often impossible for Produces Disturb. ances of absorption to proceed at a rate rapid enough to take care of this amount, and the consequence is excessive fermentation due to bacterial action; this leads to the formation of gases and irritating organic acids. The re-

Digestion 
sult may be loose, irritating, acid stools. Sometimes there may be serious diarrhœa. If the excess in carbohydrate is in the form of starchy food there may be constipation with abdominal distention, flatulence and colic. Usually these disorders of digestion are acute and not very severe, yielding quickly to proper dietetic treatment. When, however, they are frequently repeated or are prolonged because the dietetic error is not corrected, they may lead to serious chronic disturbances with marked loss in weight.

It has been shown that a fairly definite amount of protein must be included in the diet of a growing child; it seems altogether probable that it is best to include at least an equal amount of fat. When these have been provided, the remainder of the total calories

Proper Allowance for Average Child needed at any age will determine the amount of carbohydrate. On this basis it appears reasonable to allow as an average diet about 12 grams of carbohydrate per kilo. at one year decreasing to between 9 and 10 grams per kilo. at six years and maintaining about this value throughout the remainder of the growth period.

If the total caloric need is increased much 
above the average because of unusual muscular activity, carbohydrate may supply the entire amount of extra energy, since an increase in muscular activity does not increase the protein need above the normal.

Carbohydrate is a desirable and probably summary an essential component of the diet, although it does not have any specific function in nutrition. It forms the largest part of the diet at all periods of life and furnishes the calories needed in the diet which are not supplied by the requisite amounts of fat and protein.

The carbohydrate intake of over one hundred healthy children from one to eighteen years of age, studied by us, averaged 10 grams per kilo. Of this 51 per cent were sugars, including lactose, saccharose, and fructose, and 49 per cent was starch.

Carbohydrate is more economical than fat or protein, both physiologically and commercially. Because of this latter advantage there is a growing tendency to increase the proportion of carbohydrate in the diet beyond the amount which is desirable.

When a very large proportion of the food is in the form of carbohydrate the intake of fat or of protein or of both is likely to be less 
than the normal nutritive need of the body.

A diet excessive in carbohydrate leads to an abnormal deposition of fat without a corresponding increase in muscle development. Children taking such a diet have feeble resistance to infection.

There is much evidence that a relation exists between the high proportion of carbohydrate in the modern diet and the prevalence of dental caries.

Digestive disturbances, chiefly intestinal, may be produced when the earbohydrate in the diet is excessive. There may result increased fermentation with loose acid stools or constipation with flatulence and abdominal distention. When long continued, these disturbances are very difficult to control.

It seems rational to allow in the diet of the child of average activity about 12 grams of carbohydrate per kilo. of body weight at one year, decreasing the amount to about 10 grams per kilo., or 1 per cent of the body weight, at six years and maintaining it at this value through the remainder of the growth period.

If because of unusual activity the total caloric requirement is increased this increase can be supplied by carbohydrates alone. 


\section{Mineral Salts}

A discussion of the mineral salts need not be entered into at length; yet a few words seem necessary. While not sources of energy they are just as necessary constituents of the diet as are fat, protein and carbohydrate. They are in fact indispensable to growth and normal nutrition.

None of the normal physiological functions of the body, such as secretion, excretion or osmosis, can go on without them. These facts have all been well known for many years.

Their special importance in childhood relates to the fact that at this period they have an added function in promoting growth. Spectally Important During Growth This relates obviously to the growth of the skeleton. But there is evidence that they have other functions in growth not so well understood. The effect upon the development of bones of a diet deficient in mineral salts is well known. It is very marked but occurs slowly. However, the degree to which growth and gain in weight are influenced by the mineral salts in the diet is not so generally appreciated. How great this is and how quickly the effects are manifested are indicated by the growth curves of rats in the ex- 
periments of Osborne and Mendel (Fig. 14). The first curve shows slow growth with a diet low in calcium, a sharp rise when calcium in adequate amount is supplied, a cessation of

\section{GROWTH WITH DIETS DEFICIENT IM MINERAL SALTS}

-ovenditT LOW In CALCIUM

InDIET AMPLE III CALCIUM ammanam DIET LOV II PHOSPMORUS

anasenolet aMpLE in PHOSPHORus

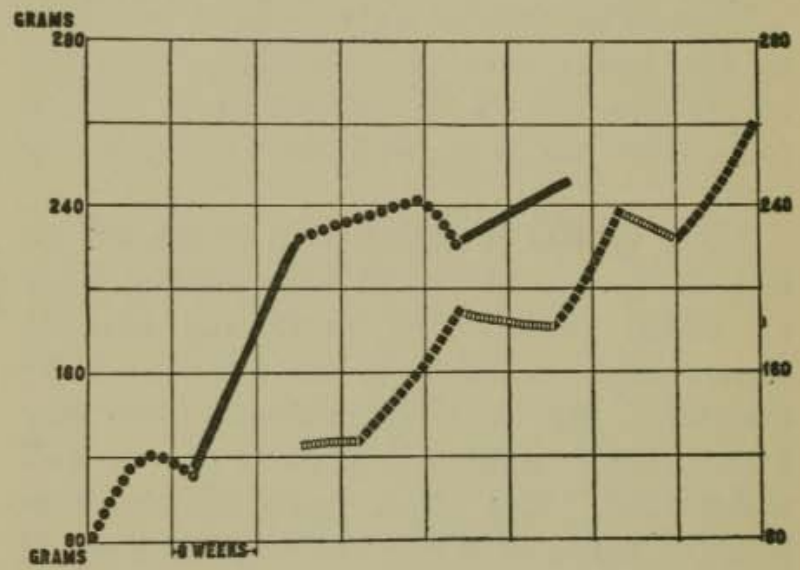

FIG. 14.

growth when this is reduced, and a sharp rise when it is again added. The second curve shows the same thing with reference to phosphorus. The diet was essentially the same throughout except in its salt content. 
Phosphorus and in fact most of the inorganic salts are so abundantly supplied in all our foods that there is little likelihood of a deficiency in any of them when the usual diet is taken. There are, however, two which may be deficient and whose importance is so great that the lack is evident in the nutrition, viz., iron and calcium.

The very low iron content of cow's milk constitutes one of its important deficiencies as a food for infants and very young children. If the diet consists largely or almost exclusively of milk for a prolonged period there is frequently seen a degree of anæmia which may be very disturbing. This most often occurs when a child because of the indulgence Cow's Milk Low in Iron of parents or nurses has not been weaned from a bottle at two or sometimes at three years, and in consequence persistently refuses all other food than milk from the bottle. This is perhaps the most important reason for beginning the use of other foods than milk at an earlier period than was formerly the practice. If a child at eleven or twelve months is taking fruit juice, beef juice, egg and some puréed vegetable, the supply of iron needed is provided.

Our chief sources of calcium are milk, eggs and vegetables, especially the green vege- 
Mill most Important Source of Calcium tables. The quantity of green vegetable which can be given to a young child is small and the number of eggs which can be allowed in the diet is limited. Besides, the amount of calcium in vegetables is not large. A good helping of spinach, which is the richest of our vegetables in this mineral, contains only as much calcium as does one ounce of milk, and one egg has but a little more than this amount.

The importance of milk as a source of calcium becomes at once apparent and it matters little whether it is milk which is drunk or milk used in the preparation of other food; or whether milk is raw, pasteurised, skimmed, dried or condensed, its value from this point of view is not essentially altered by these procedures. If a pint of milk daily is included in the diet, an adequate supply of calcium is probably assured.

It has not been established that any amount of calcium or any other mineral salt that is likely to be taken in the diet produces in health any ill effects whatever. The soluble ones are eliminated chiefly by the kidneys, the insoluble ones by the intestines. It is well known that very large amounts of sodium chlorid may in infants produce serious disturbances of nutrition. 
It is of course in relation to the production of rickets that the particular interest in the mineral salts of the diet just now centers. Calcium and Phosphorus Espocially That an adequate intake of calcium and phosphorus is essential to normal bone development is obvious. But rickets occurs constantly in spite of this. Besides an adequate supply in the food there are other conditions necessary to a proper utilisation of these substances. What these all are we do not as yet fully understand. That there is more than one dietary factor seems established.

While therefore mineral salts are so essential in the diet, we need not fear that the requirements of the body in this respect during growth will not be met, unless for long periods the diet is a very restricted one, and especially if it contains no milk, eggs or green vegetables.

\section{v. Percentage Distribution of Calories.}

Thus far there have been discussed the total caloric need and the amounts of the different food constituents-protein, fat and carbohydrate-which make up the diet of the average healthy child. The next point to be considered is the relation of these food constituents to each other, and the relation of 


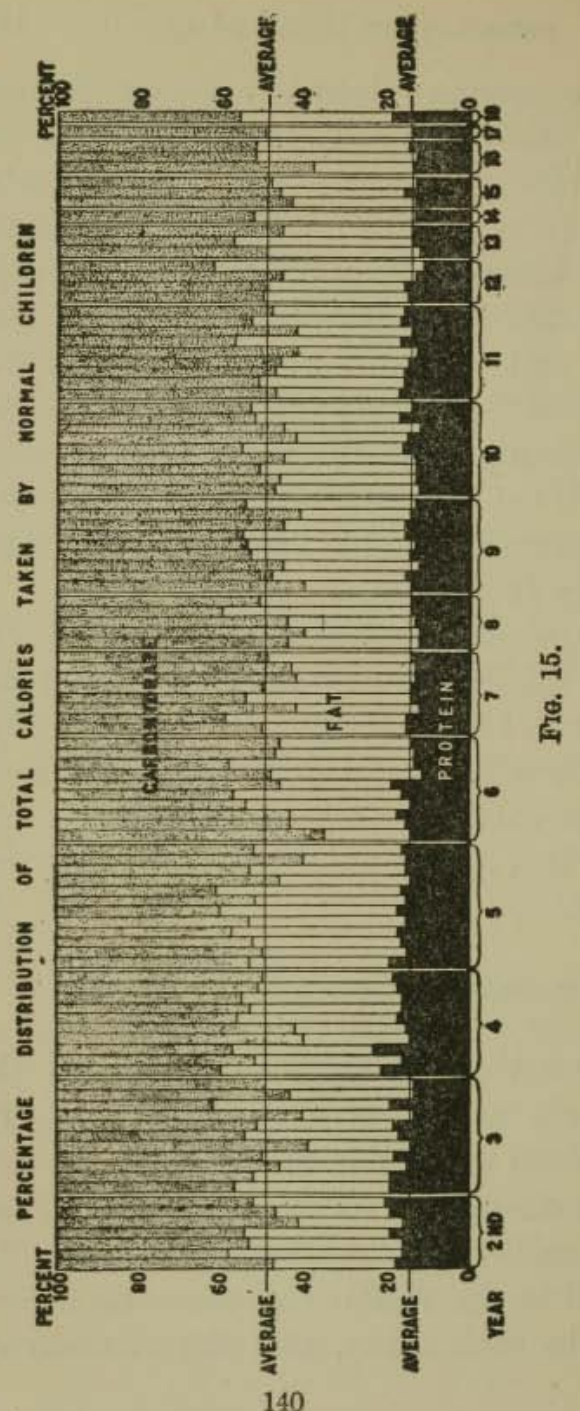


each one to the diet as a whole; in other words, what percentage of the total calories shall be given as fat, as protein and as car-

Relation of the Food Constituents to Esch Other bohydrate.

In order to determine the usual relation of these constituents in the diet of the child we have calculated the percentage distribution of the calories in the diets taken by the one hundred and six healthy children from one to eighteen years of age studied by us. The result in the individual observations is shown in Figure 15. The proportion of the total calories taken as protein is shown at the bottom, that as fat in the middle and that as carbohydrate at the top.

The proportion of the total intake which was protein showed the least variation. The average of all the cases, regardless of age, was 15 per cent; the range was from 11 to 23 per cent, but over one-half the values were between 14 and 16 per cent.

The per cent of the total calories taken as fat varied much more widely. The range was from 21 to 51 per cent, but three-fourths of the values were between 30 and 40 per cent; the average of all the values was 34 per cent.

The proportion of the total calories taken as carbohydrate also showed wide variation, with a range of from 38 to 65 per cent; but

Narrow Varlations in Protein: Wider in Fat and Carbohydrate 
three-quarters of the values were between 44 and 55 per cent; the average was 51 per cent.

There was no regular variation with age, although the per cent of the total calories taken as protein was slightly higher in the early years.

Although there are fairly wide individual variations, it is evident that in the mixed diet commonly taken by healthy children the calories are distributed with surprising regularity. The average of the values obtained in these cases may be assumed to represent the usual distribution. This seems a fair assumption, when the large number of cases is considered, and when it is recalled that those observed were not a single group under any one supervision, but were children in private families in rather scattered localities. Not all of the children lived in New York City. Several lived in Boston, two in Pittsburg, one in the South and many in New Jersey and Long Island.

Regardless of age, the average distribution Orual Dis. Food of Hoalthy Childron Fat 35, per cent, carbohydrate 51 per cent and protein 15 per cent; conveniently expressed in round numbers as 35-50-15. Therefore, a healthy child takes on the average practically one-half his calories as carbohydrate, a little 
more than one-third as fat and only about one-sixth as protein. Since a gram of fat has two and one-fourth times the caloric value

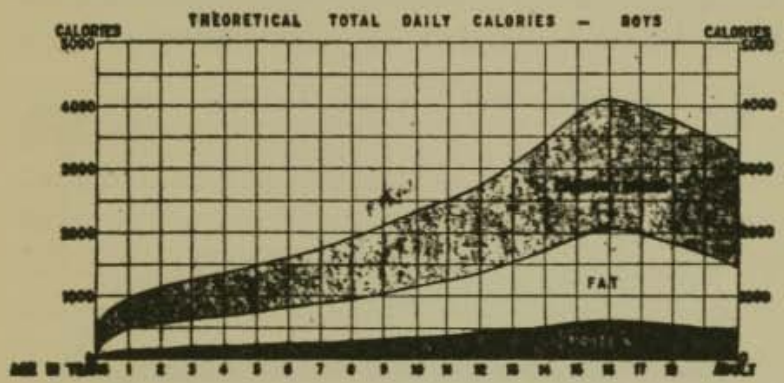

Fie. 16.

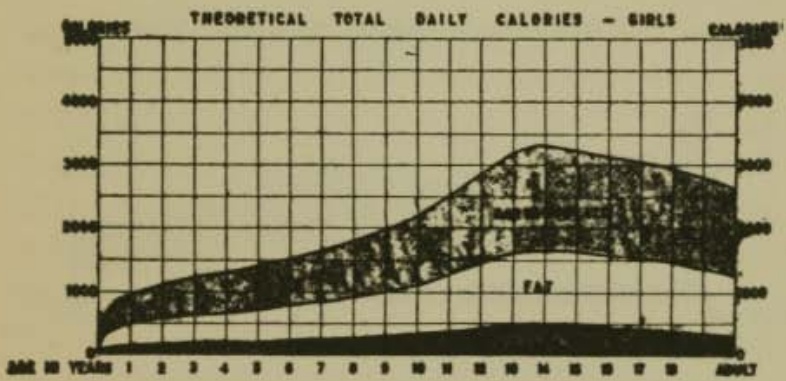

Fie. 17.

of a gram of protein, it is evident that in these proportions the amounts of fat and protein are practically equal, while the amount of carbohydrate is a little more than three times as great as either the fat or protein. 
Using the average distribution of calories just given the exact requirements in fat, carbohydrate and protein have been calculated for the entire period of growth, according to the estimated total caloric requirements given

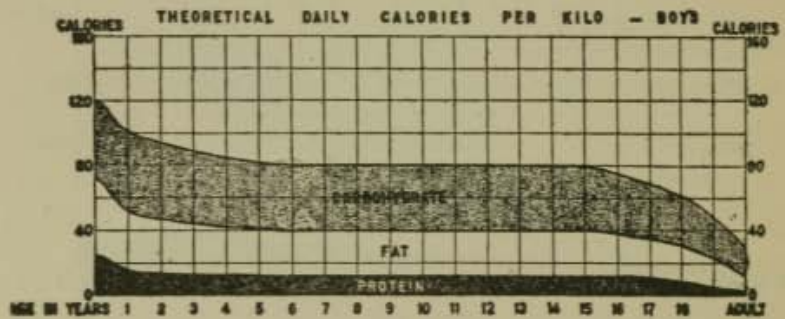

Fig. 18.

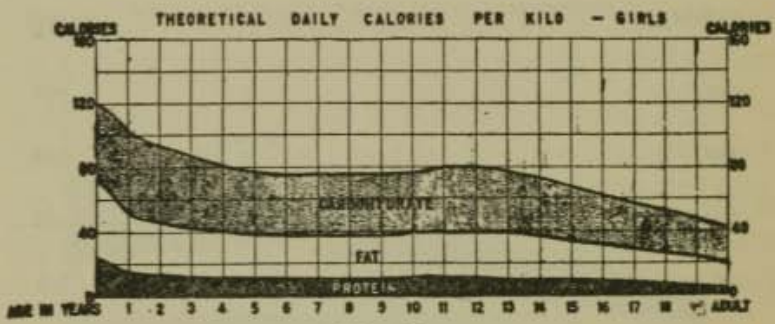

Fis. 19.

in the preceding lecture. Those for boys and girls are given in Figures 16 and 17 . The per kilo. requirements of both sexes are shown in Figures 18 and 19.

As the variation from the average in the total calories which are needed by individual 
children is considerable there will undoubtedly be variation in the distribution of the calories. If the total caloric requirement is increased because of more than average activity, this increase may be met, as has been previously stated, by raising the carbohydrate intake alone.

This would increase the proportion of carbohydrate although the amounts of fat and protein remain unchanged. When the total Variations Required caloric need is lessened because a child is over-weight for height or over-size for age, all three constituents of the diet should be reduced proportionally, the normal distribution of calories being retained, because the diminished caloric needs for growth permit a reduction in the fat and protein as well as in the total requirement. On the other hand, when a child is under-size for age or underweight for height, the total caloric need is greater than the average and the usual distribution of calories should be retained, all the constituents of the diet being increased.

The ration usually considered standard for adults consists of 100 grams of fat, 400 grams of carbohydrate and 100 grams of protein tribution daily. This gives a distribution of the total calories as follows: fat 31 per cent, carbohydrate 55 per cent and protein 14 per cent. 
Murlin calculated the distribution of food taken by the soldiers in our army camps to be, fat 30 per cent, carbohydrate 56 per cent, protein 14 per cent. Neither of these differs very widely from the average for children; viz., 35-50-15.

The evidence already presented shows that

Children

Need More Fat and Protein than do Adnits
German Schedules Low in $P$ at and Figh in Carbohydrate children have greater needs for both fat and protein than have adults; hence, a somewhat higher proportion of fat and of protein should be supplied in their diet than is allowed in the adult ration.

The reports published by other authors of actual diets taken by children show, as would be expected, considerable variation in the percentage distribution of the calories. In most cases, however, the protein taken ranges from 15 to 20 per cent of the total.

The greatest variation is seen in the per cent of fat and of carbohydrate. In most of the German schedules the proportion of fat is considerably lower than that here recommended.

In Camerer's schedule the proportions of the different constituents of the diet are varied with increasing age. He recommends 37 per cent of the calories as fat at one year, but reduces the allowance gradually to 23 per cent at five years of age, maintaining this 
value throughout the remainder of growth. This reduction in fat is met by increasing the calories of carbohydrate. In his schedule the proportion of carbohydrate rises from 45 per cent of the calories at one year to 60 per cent at five years and remains at this figure throughout the remainder of the growth period. His protein allowance at one year supplies 18.5 per cent of the total calories; the proportion is diminished to 17 per cent at five years and remains at this figure during the remainder of growth. His distribution throughout the greater part of the growth period, therefore, may be expressed as $23-60-17$.

In concluding this discussion, emphasis should be placed on the importance of the balanced ration. The protein need of the growing child is very important and there seems to be fairly general unanimity as to the amount needed. All evidence seems to indicate that when 15 per cent of the total caloric need is supplied by protein, the nutritive Importance of a Bal. needs in protein are met. The amount of fat anced Ration required is still a debated question, but it seems reasonable and desirable to give as much fat as protein to the growing child. If the amounts of fat and protein taken are equal, the protein will furnish 15 per cent of 
the required calories and the fat about 35 per cent. The remaining caloric need, that is, 50 per cent of the total calories, is then to be supplied by carbohydrate.

When this distribution is deviated from to any marked degree and for long periods, that is, when what seems to be a proper balance of the diet is disturbed, various undesirable results may follow. If much less fat is allowed, the carbohydrate intake is usually excessive and digestion may be disturbed in consequence. If the fat is too high, the normal fat tolerance may be exceeded and digestion be seriously upset. High fat with high protein forms a combination tending to cause constipation. Low fat with high carbohydrate may give rise to diarrhœa.

On the whole, one may conclude both from theoretical considerations and practical observation that a diet in which the fat supplies 35 per cent of the total calories, the protein 15 per cent and the carbohydrate 50 per cent is one which meets the nutritive needs of the child and is well borne by the digestive organs; that is, it is a well-balanced ration. 


\section{CHAPTER IV}

\section{Lecture Four}

\section{Vitamines}

Is the study of foods and nutrition the emphasis has changed frequently with the years. Formerly foods were valued according to their chemical composition-the amount of fat, protein, carbohydrate and mineral salts which they contained; in infant nutrition interest centered in the proportions in which these different food constituents should be given in the diet. A few years later, when the energy value of foods was better understood, foods were valued and used according to the calories they furnished.

At present interest in nutrition is focussed upon the "accessory food factors" or vitamines. As this is one of the newer fields, it is not surprising that it is absorbing the attention of most of those interested in nutrition, especially from the laboratory point of view. It is because the field of investigation is so A Now Field for Study recent and the results which have been ob- 
served in the studies upon animals, either by adding or withdrawing vitamines from the diet, are so dramatic that possibly we are in danger just now of losing our perspective and of giving too little thought to other factors in nutrition which are quite as important, possibly even of more importance than the vitamines. Our new knowledge does not invalidate the old; it has, however, given a new point of view and this is of great importance.

In our consideration of this subject we

Possible Dangers in Applying Resnits from Antmal Exporiments must not then fall into the error of thinking that the vitamine content of food is really the one and only thing that matters. This, however, is the impression which one might receive from a survey of much recent literature on the subject of nutrition.

Nearly all the laboratory observations upon vitamines have been made by men who were not physicians; it remains for the physician to test, in their application to human beings, the conclusions which have been drawn from a study of animals.

My principal purpose in this lecture will be to discuss the bearing of the facts which the laboratory workers have demonstrated upon the problems of human nutrition, especially the nutrition of children. 
It seems strange that constituents of our diet so important as the vitamines should have so long escaped notice. Although physiologists have had suspicions of the existence of some such substances for a long time, yet practically all our definite knowledge regarding them is a matter of scarcely more than the last eight or ten years.

One of the earliest observations that there were other substances besides fat, protein, carbohydrates and mineral salts, which were indispensable to life, was that of Lunin, a German physiologist. Forty years ago while investigating the importance of inorganic salts in the food he discovered that while mice would live for months in health upon a diet of milk, they invariably died within a month on a ration containing what were supposed to be the essential ingredients of milk, viz., casein, fat, milk-sugar and salts. His conclusion was that there must exist in milk some other substances which were indispensable for life.

Other investigators made many attempts from time to time to keep animals alive upon diets of pure protein, fat, carbohydrates, salts and water, but they were invariably unsuccessful when these substances were carefully purified. The failure was variously ex- 
plained as due to monotony of diet, lack of appetite, absence of flavor in the food, etc.

It is to Hopkins, Professor of Physiology at Cambridge, that the credit belongs for first

Hoplins' Early Observations grasping the significance of these other dietary factors and clearly stating the question. I cannot do better than to quote the conclusions from his experiments which were published in 1906. He says:-

No animal can live upon a mixture of pure protein, fat and earbohydrate, even with the addition of mineral salts. The animal body is adjusted to live upon plant tissues or other animals and these contain countless substances other than proteins, carbohydrates and fat. Physiological evolution has made some of these well nigh as essential as are the basal constituents of diet. ... The field is almost unexplored; only it is certain that there are many minor factors in all diets of which the body takes account.

Funk in 1911 while investigating the subject of beri-beri obtained from rice polishings a substance which prevented beri-beri and also the polyneuritis of birds. As this substance contained nitrogen he concluded that it belonged to a class of compounds known as the amines; as it was essential to life he called it a vit-amine.

In 1912 Hopkins published the results of 


\section{ADOITION OF MILK TO PURIFIED FOODSTUFFS}

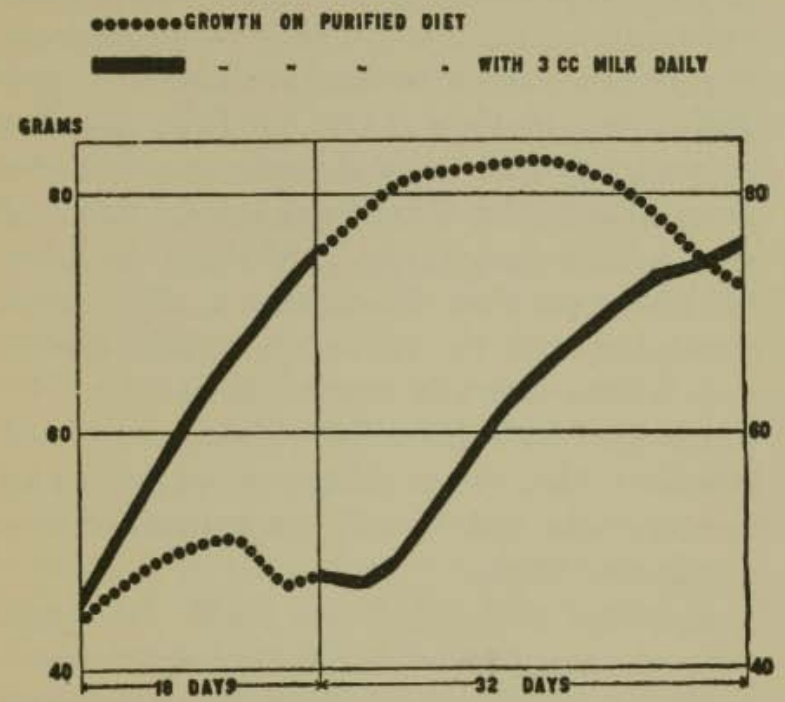

Fig. 20, from Hopkins: By purified foods is meant a diet which eonsists of pure fat, protein and earbohydrate. The upper eurve shows normal growth when a small amount of milk was added to such a diet; growth eontinued at a diminishing rate for about two weeks after the milk was omitted; then ceased and soon a loss in weight oceurred. In the growth represented by the lower curve the experiment is reversed; the animal continued to gain for about ten days after the deficient diet was given, and then lost weight; but upon adding the milk a marked growth response was seen after a few days and thereafter a normal growth eontinued. 
Milk Con-

tained

Somothing

Besides the

Common

Food Con.

stituents

a series of investigations extending over several years. He found that young rats fed upon pure caseinogen, lard, starch, cane sugar and salts, lived and grew to some extent if these constituents were used in a crude state; but if they were carefully purified, growth was arrested and death soon followed, even though the total food intake was sufficient. However, he observed that if he added to these purified foodstuffs a very small amount of milk, the animals continued healthy and normal growth ensued (Fig. 20). His conclusion was that the substance or substances added in the milk were of such a nature that the body could not manufacture or synthesise them.

Hopkins' investigations mark the beginning of an appreciation of the importance in nutrition of what he termed the "accessory food factors." His experiments were repeated by many laboratory workers in different parts of the world.

Osborne and Mendel of New Haven confirmed the statements that growth and pro-

Something Essential, Associated with Butter Fat longed maintenance was not possible in rats fed on a carefully prepared artificial food mixture in which fat was supplied by lard, but that the decline in health was promptly arrested when butter was substituted for 
lard. They later found that the active substance was only in the fat fraction of butter. As the butter used was free from nitrogen, phosphorus or anything soluble in water, they concluded that the substance could not be the same as the anti-beri-beri factor studied by Funk. Osborne and Mendel further showed that the substance which they found in butter was also present in certain other fats-beef fat and cod liver oil-but was absent in fats of vegetable origin.

Funk and Macallum had found that rats would not grow upon their artificial food mixtures, and also that many of them died with symptoms of paralysis which they considered analogous to the polyneuritis of birds (avian beri-beri). With this theory they added yeast to their artificial food mixture and an immediate growth response was the result. Their conclusion was that the growth-promoting factor was not contained in fats, but in yeast.

The experiments of McCollum and Davis confirmed the observation that rats which did not grow upon the artificial ration grew when a substance derived from butter and eggs and soluble in ether was supplied. They also found that this growth was not obtained when the fat in the diet was lard or vegetable oils. 
Both These Necessary to Health and Growth

It was not until 1915 that the existence of two separate and distinct accessory food factors was finally settled definitely. One of

\section{GROWTH ON DIETS DEFICIENT IN VITAMINES}

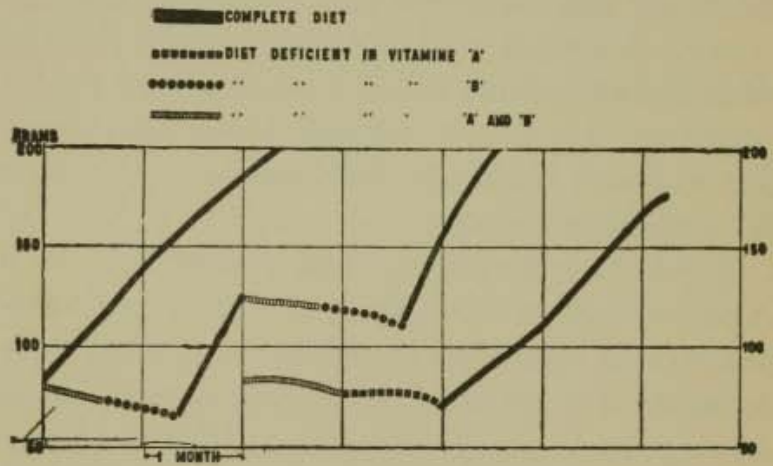

Fig. 21, from Osborne and Mendel, shows that both vitamine $\mathbf{A}$ and vitamine $\mathrm{B}$ are necessary for growth. In the curve to the left, normal growth of rats on a complete diet is represented. In the first part of the seeond eurve the diet is deficient in both $\mathrm{A}$ and $\mathrm{B}$ and $\mathrm{a}$ steady loss in weight occurs; this is not checked by adding vitamine $\mathrm{A}$; but when both $\mathrm{A}$ and $\mathrm{B}$ are supplied normal growth at onee begins. This growth is immediately arrested when both are with. drawn from the diet. In the third eurve no growth oceurs when both A and B are lacking and none occurs when B alone is added, but growth promptly follows when both $\mathbf{A}$ and $B$ are supplied.

these substances was soluble in fat and was removed from the food with the fat; the other had different properties and was soluble in water. Both however were present in milk 
and both were necessary for health and growth (Fig. 21). McCollum suggested the names "fat-soluble A" and "water-soluble B" instead of vitamine proposed by Funk. However, the term vitamine has gained such currency both in popular and medical literature that it is likely to be permanent, in spite of the fact that it is generally believed to be chemically inexact. Laboratory workers still speak of them as the fat-soluble $A$ and water-soluble B, or use the more convenient terms, vitamine $\mathrm{A}$ and vitamine $\mathrm{B}$.

That in scurvy also we had to do with a condition brought about by the absence from the diet of an accessory food substance, has been made clear by observations upon animals, and also that this factor was different from both vitamine vitamine $\mathrm{A}$ and vitamine $\mathrm{B}$.

Scurvy has been known for centuries, especially among sailors, and was ascribed to cold exposure, sea air and salt meats, separately or in combination. Twenty years ago the idea that scurvy was of infectious origin gained wide but not general acceptance. As early as 1734 Bachstrom correctly attributed it to the absence from the diet of fresh vegetables and fruits, observing that these articles would not only prevent but would cure scurvy. 
In 1895 Theobald Smith, then at Harvard, published an observation made upon guinea pigs; that when green food was withheld from these animals and a diet of oats, hay and water was given, a disease developed characterised by hæmorrhages into the different tissues, chiefly about certain joints, which if unchecked was fatal in about four weeks after the green food was omitted. The disease was easily and regularly brought about exAnimals perimentally. The significance of this observation was apparently not recognised and the condition was not identified with human scurvy.

In 1900 Axel Holst of Christiania made the independent observation that if guinea pigs were kept upon a diet of grain and water they developed a condition comparable in all essential features to scurvy in man. He regarded the disease as scurvy and conducted a long series of experiments with various diets both producing and curing the disease. The disease could be prevented and cured by' the addition to the diet of cabbage, dandelion, cranberries and various other substances.

This susceptibility of certain small animals to scurvy has led to a great advance in our knowledge of this disease. It has been possible to ascertain not only the different arti- 
cles of food which would prevent it, but the relative amounts required for protection.

For the last five or six years it has been generally accepted that scurvy was a deficiency disease due to the absence from the food of a definite factor or vitamine. This is conveniently designated vitamine $\mathrm{C}$.

It is now recognised that there are at least three accessory food factors, each of which has a perfectly definite and distinct function in human nutrition, and that all of them are necessary for health and growth. During the last few years our knowledge regarding these factors has rapidly increased as to their distribution in the various foodstuffs, also how they may be injured or destroyed by the various methods of preparing or preserving food, the symptoms which are produced in experimental animals when they are withheld from the diet, and the different clinical conditions in human beings with which each of these substances is more or less definitely associated.

The fat-soluble or vitamine A was first detected in butter-fat and egg yolk and these foods are rich sources. It is, however, very widely distributed among foodstuffs. It is present in abundance in most animal fats ex- vitsmino $\mathbf{A}$ cept lard, also in heart, liver and kidney tissues, many fish oils, especially cod liver oil, 
in which it is particularly abundant. Vegetable oils, such as linseed, olive, cottonseed, corn oil, etc., contain practically none (Fig. $22)$. It is present in green or leafy vegetables, such as cabbage, lettuce, spinach, also

\section{DEFICIENCY OF VITAMIME 'A' IV VEgetable OILS}

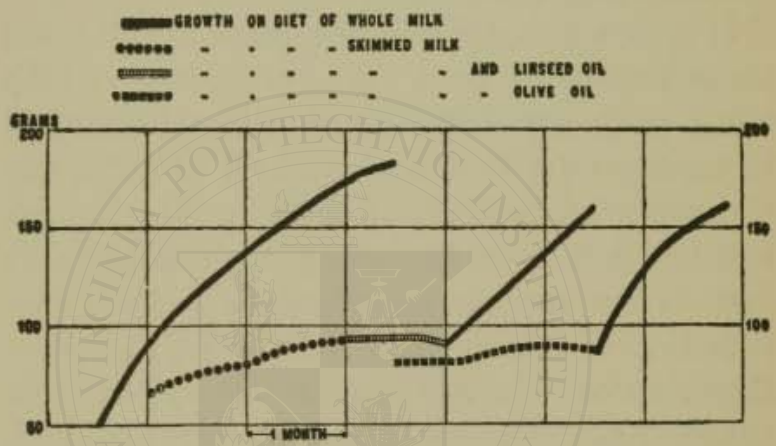

Fig. 22, from Osborne and Mendel, shows that while rats make a normal growth upon whole milk, they make very little growth upon skimmed milk alone, or upon skimmed milk when additional fat is supplied by either linseed oil or olive oil. The longer the feeding experiment was continued the more evident was the diet defieiency.

in alfalfa and clover and other grasses, in sweet potato and carrots but not in any appreciable amount in white potato and beets or mangels. Nearly all observers agree that vitamine $\mathrm{A}$ is stable to the ordinary heat used in cooking.

When this vitamine is withdrawn from the 
diet symptoms do not soon appear. From this fact the conclusion is drawn that it can be stored up in the body, probably with the fat. Fully grown rats can be deprived of it sometimes for months without showing Symptoms low Its definite symptoms of failing nutrition; but this is not the case with young animals. Usually in a few weeks evidences of this deficiency begin to show themselves. Vitamine A seems therefore to be much more important for growth than for maintenance. By some it has been designated the growth factor. It is, however, true that the other vitamines are also necessary for growth, though their effects are shown in different ways; for man and probably for most animals all three are indispensable. Since the animal body cannot manufacture them, this vitamine as well as the other two must be supplied in the food.

Exactly what is the function of vitamine A in nutrition we do not yet know. Young experimental animals, usually rats, whose food is deficient in this factor, in a few weeks cease to grow and soon begin to show other signs of imperfect nutrition, the most striking evidence of which is an inflammation of the eyes which begins with swelling of the lids and conjunctival infection. If the diet is unchanged the process goes on to ulcera- 
tion of the cornea and complete destruction of the eye. This condition is known as xerophthalmia. If before serious structural changes in the eye have been produced, a very small amount of butter, cod liver oil, egg yolk, or any substance rich in vitamine $\mathrm{A}$ is added to the diet, improvement begins immediately and in a surprisingly short time without other treatment the eye is well. This occurs so regularly that it must be regarded as a specific action.

Sooner or later all animals in whose diet no vitamine $A$ is supplied decline markedly in general health and the death rate is high. They show feeble resistance to bacterial infections, especially of the lungs.

A diet deficient in this factor produces in young dogs after several months bony changes which are apparently identical with those of rickets. Mellanby from his study of these changes would include rickets as a deficiency disease, the specific cause of which is the absence of vitamine $\mathrm{A}$. This view is not generally accepted.

The precise rôle of vitamine $\mathrm{A}$ in the human diet is little understood. Opportunities to observe the effects of its complete or almost complete removal from the diet have been very limited. In nearly all cases in which 
this vitamine has been deficient in the diet other deficiencies have also existed, which make definite conclusions from clinical observations difficult. Such observations are, however, interesting and strongly suggestive. There has been observed in infants and young children suffering from serious disorders of nutrition, particularly when living in institutions, a disease of the eye, called kerato-malacia, which closely resembles the xerophthalmia occurring in rats and which is probably identical with it.

In 1904, before vitamine A was known, Mori described a disease of this kind seen in Japan. The diet of the children observed, who were from two to five years old, was chiefly earbohydrates with a small amount of vegetable. Mori attributed the condition to a lack of fat in the diet. He found in cod liver oil a speeific remedy. It is interesting to note his observation that the condition could also be prevented by chicken livers, cod liver oil and other fish oils.

More recently Bloch of Copenhagen has reported in two series of cases a similar disease observed in infants who were hospital or asylum inmates. In the first series the general nutrition of all the infants was very poor. The diet was deficient in fat, as the 
infants were receiving only separated milk. Without other changes in the food than the addition of cod liver oil the eyes began to improve almost immediately and in eight days were well. Improvement also occurred when whole milk was substituted for the skimmed milk, but was much more rapid when cod liver oil was added. In some cases, where the disease was far advanced before treatment was begun, loss of sight occurred. The second series of cases were observed later in a home containing thirty-two healthy children. One group of sixteen got no milk; the only fat in the diet was a margarine made from vegetable oils. Eight of these children developed kerato-malacia. The sixteen in another ward received whole milk as a part of their regular diet. Among them no cases of the eye disease occurred. The difference in the diet of the two groups was simply the whim of the nurse in charge. The cases were all cured by cod liver oil. Bloch regarded the condition as a specific one due to a deficiency of vitamine A.

Ross has recently reported four cases of kerato-malacia observed in Baltimore. All were in marantic infants and the food in all instances had been condensed milk. Three died from the general condition shortly after 
admission. The fourth recovered with the administration of cod liver oil and a change of food, first to whole cow's milk and later to woman's milk.

Czerny and Keller described more than fifteen years ago a disease in young children, to which they gave the name Mehlnährschaden; a condition produced in their opinion by a diet excessive in carbohydrates and lacking in fat. Kerato-malacia was one of the characteristic symptoms.

During the war there was observed both in adults and children, in districts where food was scarce and fats almost unobtainable, a dropsical condition usually called "war or famine œdema" which was attributed to absence of fats from the diet. It is thought probable that this was due to lack of vitamine A.

There is frequently seen in hospitals in marantic infants and in those suffering from severe digestive disorders, on account of which the diet has been greatly restricted, a form of general dropsy most often described under the term, nutritional œdema, which possibly is to be connected with the absence of this vitamine. It is seen when on account of fat intolerance the food consists almost entirely of carbohydrates and protein. 
It is to the excess of carbohydrate in the diet that the condition has been frequently attributed. I have seen it develop when there was no such excess but only a starvation diet. In one instance an infant of three or four months had had for many weeks only barley water for food. In my hospital practice the most successful dietetic treatment of nutritional œdema has been, next to woman's milk, protein milk, which though low in carbohydrates is relatively high in fat. It is interesting also to note that several of Bloch's cases of kerato-malacia also had general œdema.

In none of these clinical conditions except possibly kerato-malacia can one state with certainty that the diet deficiency in vitamine A was the essential cause. Other factors of possible importance were present in practically all of them, the most common one being a very low food intake. Some adults with war œdema had been getting but 800 calories a day, the usual allowance for a baby of ten or eleven months.

Adrantages of Isbora. tory 1n.

restigations

The clinical observations referred to indicate how difficult it is to draw conclusions in conditions of this kind from a study of human beings, and what a large number of cases must be critically studied before a point 
can be definitely established. In feeding animals in the laboratory the conditions can be controlled, the effects of a single diet deficiency studied at one time, so that exact and definite results can often be established from a comparatively small number of experimental observations. It is for this reason that more definite additions have been made to our knowledge of the value of different foods during the last ten years by laboratory methods of investigation than in the previous fifty.

During the last few years the fat in the food has by many pædiatrists been regarded in infant feeding as the constituent of milk most likely to do harm, and a reduction of the fat considered almost the first duty in any disturbance of nutrition. But it should be known that this practice has its dangers. It is my own belief and experience that this practice has gone much too far and that in escaping some dangers that we knew we have flown to others which we knew not of.

Returning to the subject of rickets, it may be said that the question of its exact causation is not yet settled. It has long been believed from clinical evidence that a most important, perhaps the most important, etioRickets not Proven Due to This Canse logical factor was a deficiency of fat in the 
diet. Mellanby has produced rickets in dogs by diets deficient in certain animal fats and believes that the antirachitic food factor and vitamine $\mathrm{A}$ are identical substances.

Paton and Watson conclude from their experimental observations that a liberal allowance of milk fat neither prevents nor cures rickets in laboratory dogs, even when given in such large amounts as 14 grams per kilo. of body weight; but if the animals are kept in the open country they escape rickets on an allowance of less than one gram per kilo.

Young puppies kept in the country on a fat-poor diet escaped rickets; while animals of the same litter kept in the laboratory and given a fat-rich diet developed rickets. Even laboratory animals did not develop rickets on a low-fat diet provided they were given particular care and provided also the diet was in other respects adequate.

In the experience of many observers milk neither prevents nor cures rickets in children. That there is a special antirachitic food factor and that this is the same as vitamine A has not been established. With our present

Cansation of Riekets Not Simplo knowledge it seems highly improbable.

While it is evident that in the causation of rickets diet is an important factor it seems 
altogether probable that more than one dietary factor exists. Environment, especially one which affects the amount of sunlight, is also a factor of much importance, since in a bad environment small diet deficiencies may produce the disease while in a good environment they may not do so.

The water-soluble or vitamine B is now considered identical with the antineuritis vitamine. It cures the polyneuritis of birds which can be produced by a diet of polished Vitsmine B in Eggs, Grains, Vegetsbles and Yeast rice. It is very widely distributed, being found in almost all the foodstuffs examined, although in widely varying amounts. It is abundant in yeast, eggs, most meats, especially in the glandular organs, in all seeds and grains, in the latter chiefly in the germ and in bran, in nearly all vegetables, especially in potato, spinach, cabbage, carrots, turnips, in nearly all fruit juices, particularly orange, lemon and grapefruit, in nuts and finally in milk. The potato is an important source of this vitamine in common diets. No difference has been found between whole or peeled potatoes, or between new and old potatoes.

In the accompanying chart (Fig. 23) are shown results of some experiments upon the growth of rats by Osborne and Mendel in which vitamine B was supplied by different 


\section{GROWTH WITH GTAMIIS 'B FROM DIFTEREMT PLAITS}

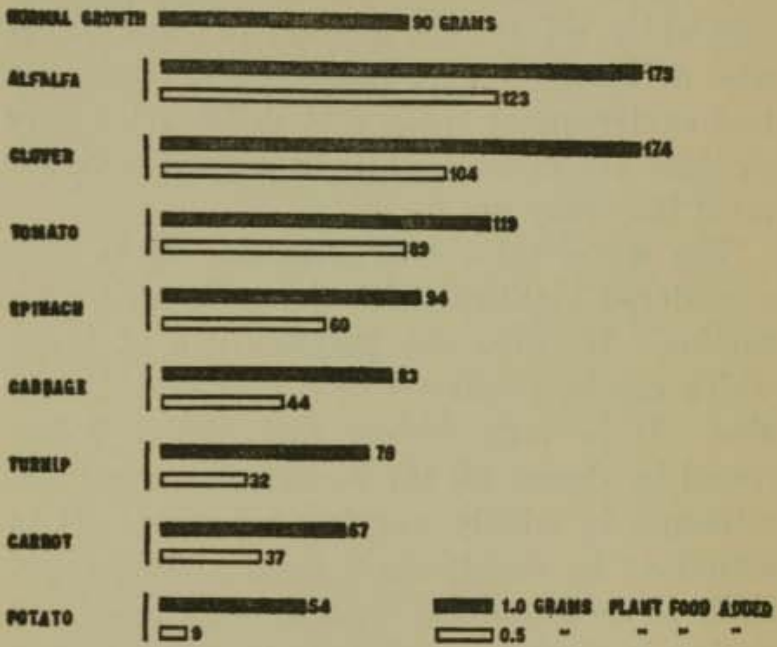

Fig. 23, from experiments of Osborne and Mendel, shows the relative value of different plant foods with respect to the amount of vitamine B which they contain. The normal gain of a rat during eight weeks on a complete diet is 90 grams. When vitamine $B$ is supplied by alfalfa or elover the gain is nearly twice the average, if one gram is added; and even exceeds the average when only one-half gram is added. It is evident from the chart that spinach is nearly twice, and tomato is more than twice, as valuable as potato in the same quantities. The vegetable food given in every case was in a dry powdered form.

foods, and shows their relative value as sources of this vitamine. The columns give the average gain of the animals in eight weeks; the solid black column when one gram 
of the vegetable food was given daily; the white column, with one-half gram. At the top is given the average growth of normal healthy rats on their usual food. Alfalfa Foods Differ in the Amount and clover stand at the head and tomato next. They There is little difference between cabbage, turnip and spinach. Practically normal growth was obtained with each of these with one gram, but not with one-half gram. With potato fair growth with one gram, almost none with one-half gram.

Vitamine B is present in yeast in greatest concentration, more in brewer's than in baker's yeast. The ordinary heat of cooking does not affect it to any important degree, nor does drying, whether applied to eggs or vegetables. It is removed from wheat in the process of milling, being practically absent from white wheat flour and from polished rice. It is present in whole wheat flour, in wheat bran and in whole rice grains.

When this factor, vitamine $\mathrm{B}$, is removed from the diet of young rats and mice the effect is seen almost immediately. Within a few days appetite fails, growth ceases and Symptoms low Its Re. soon a decline in the general nutrition is evimoval from the Diet dent, which continues with increasing severity until the animal succumbs, young rats invariably in less than eight days. In many 
rats and dogs there is seen a degree of muscular incoördination and weakness amounting almost to paralysis. If to such animals or to birds similarly affected, a food rich in the water-soluble vitamine, such as yeast, is given, no matter in what manner, an improvement that is marvelous occurs in a few hours. Frequently, after a single feeding, appetite returns and animals before almost helpless are able to run about and birds to fly as if

Immediate Improvement When Added nothing had been the matter. The rapidity with which the symptoms are produced and cured is in striking contrast to those associated with the withdrawal or administration of vitamine A. It would appear that the animal has no reserve to draw upon, so that vitamine B must be given continuously or nutrition is disturbed.

What the function of this accessory factor in normal nutrition is, we do not know. That it is as essential to man as to animals, clinical experience abundantly proves. Long before the existence of such substances as those we are considering was suspected, the disease beri-beri was connected with certain diet deficiencies. Beri-beri is a very common condition in certain parts of Asia, but rarely seen in this country. As early as 1897 the association of beri-beri with a diet deficiency 
was observed by Eijkman in a prison in Java where the food was largely polished rice. He noted also that poultry fed upon rice refuse from the table developed paralysis much like Bert-bert the Best that seen in his prisoners with beri-beri. The condition was cured by the administration of rice polishings, or an alcoholic exiract of them. Vordermann made, Eijkman states, an exhaustive study of all the prisons in Java and found that everywhere the occurrence of beri-beri was in direct proportion to the extent to which highly milled rice was used as a food. In the prison diet the other articles of food were for the most part poor in this vitamine. The connection between beri-beri and the use of polished rice as a staple article of food has been noted by many observers in different parts of the world.

The use of a limited diet in which bread from white wheat flour forms a very large part, has also been followed by similar symptoms, although not usually so severe in degree. In Labrador and Newfoundland beriberi was unknown when bread was made from whole wheat flour. Since the introduction of white flour it has become a frequent disease and is prevented chiefly by the consumption of potatoes. When the supply of potatoes fails, outbreaks of beri-beri are common. The 
same thing has been witnessed in Ireland during a potato famine.

Holst states that in Norway great sympathy was aroused for the hard lot and poor food of the sailors, and in 1894 in response to public agitation shipmasters were compelled to supply sailors with bread made from white wheat flour or wheat and rye flour. After this went into effect beri-beri, unknown when their bread was made from whole rye flour, became a frequent disease.

The British Army reports contain some interesting facts bearing upon this subject.

No Berl-berl on a Diet of Black Bread
During the siege of Kut-el-Amara in the recent war, beri-beri occurred among the British soldiers who received white bread but not among the Indian troops whose bread was made from a coarse whole wheat flour. At a later stage of the siege, when the supply of white flour was exhausted and the British soldiers were compelled to eat the coarse bread of the Indian troops, the development of beriberi ceased.

When the diet of the mother is lacking in this food factor, her milk is also deficient. It is reported that among the Filipinos beriberi is common among the nursing children of rice-eating mothers of those islands. This is believed to be a large factor in the extremely 
high infant mortality which is seen there. The wide distribution of vitamine $B$ in our common foods makes it improbable that under normal peace conditions either adults or children suffer from a deficiency of this in their ordinary diet, particularly since cooking and drying do not destroy nor greatly injure it.

The antiscorbutic or vitamine $\mathrm{C}$ differs in some very important particulars from the two which have just been considered. It is the only one of the vitamines that is especially sensitive to heat. Certain animals, e.g., rats and dogs, have generally been regarded as not susceptible to scurvy, i.e., not requiring this vitamine for health and growth. The recent experiments of Harden, Zilva, and of Drummond at the Lister Institute throw doubt upon this belief in the case of rats at least. They state that while upon a scorbutic diet these animals gain weight, grow and even reproduce and show no definite symptoms for months, yet they do not thrive as well as animals which get the antiscorbutic vitamine.

More extended investigations and more carefully conducted experiments have shown in the case of each one of the vitamines that they were present, frequently to be sure in very small amounts, in many foodstuffs from 
which they were supposed to be entirely absent. This and the very small needs of some animals may be the explanation of the apparent insusceptibility to scurvy.

Further investigations are certainly necessary before we can regard it as definitely established that certain animals do not require vitamine $\mathrm{C}$.

This vitamine is found chiefly in fruits and

Ohiefly

Found in

Fruits and

Vegetables

May be

Injured

or Even

Destroyed

by Heat vegetables. It is very abundant in the orange, lemon and grapefruit but curiously not in the lime, and there is none whatever in the preserved lime juice. Cabbage and tomato are especially rich sources, also the swede (yellow turnip). There is a moderate amount of this vitamine in potato, in the green vegetables, in fresh meat and a small amount in milk. Cereal grains have none; but Fröhlich has discovered that if grains are moistened and allowed to germinate for a few days the antiscorbutic substance is developed.

A particular interest in this connection attaches to the preparation and preservation of the food, since this vitamine is nearly always injured and may be destroyed by heat, either that used for cooking or for the preservation of foods. The amount of injury done is in some cases very well known; in others, it 
is still a matter of debate. Canned vegetables (string beans and cabbage have been especially studied) lose, according to the experiments of Chick and Campbell, from 70 to 90 per cent of their antiscorbutic potency. A still further loss occurs from storage, so that their value when used is practically nil. Cabbage, boiled for one-half hour either with or without the addition of acid or alkali, is still an efficient antiscorbutic but has lost about four-fifths of its value. Dried cabbage and dried tomato retain much of their vitamine; dried fruits, a small amount.

Canned tomatoes are an efficient antiscorbutic, but must be given in somewhat larger amounts than fresh tomatoes. It has been found that foods which are kept in sealed containers retain their vitamines longer than those in open packages; this is attributed in part to prevention of oxidation.

In dried orange and lemon juice the vitamine is very slightly if at all impaired and when kept in sealed packages they retain their antiscorbutic activity indefinitely. I have eured scurvy in infants with dried orange juice that had been kept in a sealed package for over one year. It appeared to be quite as efficient as the equivalent amount of the fresh juice. 
That dried vegetables are practically valueless as antiscorbutics was shown as long ago as the Crimean War, and the observations have been confirmed in all the subsequent wars in which they have been tried.

Fresh meats are antiscorbutic if the amount taken is liberal. Aretic explorers have subsisted for months with no other source of this vitamine in their diet and have been free from scurvy. But this is not true of canned meats; they are practically without antiscorbutic value. The British soldiers while besieged in Kut ate freely of fresh horse flesh and escaped scurvy; the Indian troops, however, who are vegetarians, suffered severely from it, as they could get no fresh vegetables.

From the point of view of the nutrition of children, the chief interest attaching to the effect of heat upon vitamine $\mathrm{C}$ relates to the heating of milk. In the first place it

Amount of Vitamine C in Milk is 8 mall should be understood that the amount of this vitamine in fresh milk is very small. How small may be appreciated by the fact that Chick and Hume found that to protect a guinea pig, whose food contains no other source of this vitamine, 100 c.c. daily of fresh milk are required, although complete protection is secured by 1.5 c.c. of orange juice. 
It is well established that all heating of milk (I do not, of course, mean warming for feeding) whether by boiling, pasteurising, sterilising, drying or condensing, injures this vitamine, though it does not seem to affect either the vitamine A or vitamine $\mathrm{B}$. The amount of injury done to the antiscorbutic vitamine depends upon the height of the temperature and the length of the period during which the temperature is maintained, and possibly upon whether the heating is done in open or sealed vessels. The duration of the heating seems clearly quite as important as the temperature employed. Short heating at a high temperature apparently does much less injury than prolonged heating at a lower temperature; so far as its effect on the vitamine is concerned, boiling for five or ten minutes seems less harmful than pasteurising for thirty minutes.

While there is still considerable difference of opinion among investigators as to the relative amount of damage done by various types of heating, it may be regarded as proven that they all injure milk in this respect to some degree and that the only safe rule in practice is to supply some efficient antiscorbutic in the diet of all infants reared upon milk Infured by
Heating

Ant1scorbutics Needed for all Infants Fed on Heated Milk treated in any one of these ways. 
The time when it is necessary to begin fruit juice or other antiscorbutic will be influenced by the incubation of scurvy, i.e., the time when symptoms appear after the scorbutic diet is used.

In the guinea pig, which is one of the most susceptible animals, symptoms of scurvy regularly begin after about three weeks. The monkey, a rather less susceptible animal, shows symptoms of scurvy after about three months. Holst and Fröhlich mention the case of a fanatical vegetarian who undertook to live upon bread and water and who developed symptoms of scurvy after seven and a half Incubation months. They give the story of a Russian refugee who was confined with 1400 others in a Russian prison where the diet consisted of bread, tea and a cabbage soup. This soup was so filthy in appearance that he and about twenty other refined people simply could not eat it. In about six months he and his group developed scurvy. The rest of the inmates who took the soup did not.

Definite symptoms of infantile scurvy are most frequently seen from the seventh to the tenth month of age, rarely earlier than the sixth month, and even the indefinite symptoms of scorbutic malnutrition seldom more than a few weeks before this time. 
In my own clinical experience when the sole food has been pasteurised or sterilised milk, symptoms of scurvy do not usually appear until this diet has been continued for from In Infants Usually Five to Eight Months five to eight months. Of the last nine cases of infantile scurvy treated in my hospital service, the period was between five and seven months in seven cases and in none more than nine months. Evidently the body has a sufficient store of this vitamine to meet its needs for a considerable period; when this is exhausted symptoms appear. If the food contains even a small amount of vitamine C, the development of scurvy will be delayed.

To infants whose principal or sole food is any one of the forms of heated, dried or condensed milk, it would appear then to be quite sufficient if an antiscorbutic were begun at the age of four or five months, although there is no objection to giving it at an earlier age.

As to the amount of the vitamine required we have no very definite knowledge; although the relative value of different foods as antiscorbutics has been pretty well determined by Chick and Hume (Fig. 24). According to their experiments the susceptible guinea pig needs daily for complete protection about 100 c.c. of fresh cow's milk or 1.5 
Amount of Orange Juice

Needed for Protection c.c. of orange juice; that is, orange juice is about sixty times as potent an antiscorbutic as is fresh cow's milk. The monkey, whose weight is about ten times as great, requires only about twice as much of either for protec-

\section{WEEDED TO PREVEUT SCURVY IN GUIMEA PIGS}

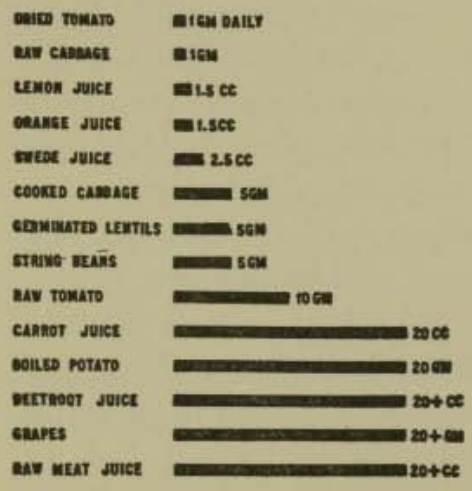

an cov's ant

In Fig. 24, based upon experiments of Chick and Hume of the Lister Institute, are shown the relative richness of common artieles of food in vitamine C. Tomato, cabbage, orange and lemon juice stand at the top; of these only one gram or 1.5 e.e. respectively, are needed for proteetion, while of fresh cow's milk which stands at the bottom more than 100 c.c. is needed.

tion as does the guinea pig. If the human infant were as susceptible as the guinea pig there would be needed weight for weight about two quarts of fresh milk daily, or one ounce of orange juice, at the age when scurvy 
is most often seen. Practically we find that those who get even somewhat less than one quart of fresh cow's milk very seldom develop scurvy. It would seem then that 15 c.c. or half an ounce of orange juice daily was, under average conditions, ample for protection in the latter half of the first year.

Of the common antiscorbutic foods, orange juice is undoubtedly the best, but is somewhat expensive and not always obtainable. The dried orange juice, not yet on the general market, seems almost if not quite as effective and does not lose its activity by keeping. Dried orange and lemon juice seem likely to prove some of our most convenient antiscorbutics.

I have had no personal experience with the juice of the swede but the experiments of Chick and Hume at the Lister Institute indicate that this is quite as effective as orange juice in the same quantities. It is grated and scorbutics the juice squeezed out in a cloth by hand.

The juice of fresh raw or canned tomatoes is cheap and effective as an antiscorbutic. It is perhaps a little more likely to disturb the digestion than is orange juice, but can be given to most infants without any difficulty. I have found it effective both in preventing and in curing scurvy, but it must be given in 
somewhat larger doses than orange juice and the seeds carefully strained out.

Are there conditions present in disease, particularly of the digestive tract, which may interfere with either the absorption or the activity of vitamines, so that the consequences of a deficiency may exist even though these substances may be given in the food in adequate amounts? We do not yet know. But so far as the vitamine $\mathrm{C}$ is concerned this seems not improbable, particularly in diarrhœal conditions. All who have seen much of infantile scurvy know the difficulties in

Conditions Which May Interfere With the Action of Vitamine o treatment when diarrhœe is present or is easily excited. Of course diarrhœa may be present as one of the symptoms of the scurvy. A concentration of the vitamine by removing from orange or lemon juice all the vegetable acids has been used by Chick and Still in such cases as these with most satisfactory results, without causing any disturbance of the bowels. With this concentrated preparation much larger amounts could be administered and very prompt cure effected.

I have myself seen scurvy develop in a hospital patient while under observation and while taking as much as 30 c.c. of orange juice daily. In this case no acute diarrhœa was present but there did exist a serious 
chronic disturbance of digestion with a tendency to looseness of the bowels.

Future investigations may reveal the fact that vitamine deficiency is a cause, which we do not now suspect, of some of the symptoms seen in certain chronic diseases. This is less likely to be the case in acute disease as it is so long before effects of deficiencies in vitamine $\mathrm{A}$ or vitamine $\mathrm{C}$ are evident.

While we have learned a great deal regarding what vitamines do, we know very little else about them. None of them has as yet been isolated. The effect of heat upon vitamine A Oxidation May Destroy Vitamines in has not been definitely settled. Hopkins' recent experiments with butter fat indicate that heat in sealed vessels does not injure the vitamine even though prolonged and the temperature high, while moderate heat with aëration destroys it; also that if butter is exposed to the air in thin layers for long periods it loses its vitamine. The inference is that it is destroyed by oxidation. Most experiments indicate that this vitamine is stable to ordinary heat used in cooking unless the heat is very prolonged.

Vitamine A is soluble in alcohol and ether. Osborne and Mendel have extracted with ether from the green leaves of plants, using spinach, clover, alfalfa, an oily substance with 
which they secured growth quite equal to that obtained with butter fat.

Bolubility of Vitamines
Vitamines Must be Continuously Taken with the Food

Vitamine B, now generally regarded as identical with the antineuritic vitamine, is soluble in water but not in alcohol or ether. It is unaffected by ordinary temperatures used in baking or boiling, but may be injured by prolonged heating at high temperatures. Osborne and Wakeman succeeded in concentrating the vitamine from brewer's yeast but not in isolating it.

Vitamine C is soluble in water and alcohol and passes through porcelain filters. From the fact that acid fruit juices retain their value much longer than vegetable juices, Holst concludes that the antiscorbutic vitamine is more stable in acid than in neutral media. Harden and Zilva have shown that it is rapidly destroyed at room temperature by dilute alkalies. Oxidation seems also to injure it.

I have already alluded to the fact that the animal body cannot manufacture or synthesise vitamines. They are constant body needs and must be taken in continually with the food. The belief at present is that they are synthesised in plants; the herbivorous animals get them from plants, the carnivora from the herbivora. 
Hart, Steenbock and Ellis have made the important observation, since confirmed by others, that the vitamine content of cow's milk is affected by the food of the animal. This was first shown to be true of the antiscorbutic vitamine. The winter milk of stallfed animals was decidedly poorer in this respect than the summer milk of pastured animals.

From investigations made by others this same law seems to apply to all the vitamines. If the food of the cow does not contain an If not in Miik May adequate supply, the milk may be deficient Lack Them in any or in all of them.

The same rule applies to the nursing mother. This may furnish a clue to some of the puzzling cases of scurvy developing in nursing infants. It may also explain why infants do not thrive upon some milks, although the supply is abundant and the proportion of the different constituents, as shown by chemical analysis, is within the normal range.

The important practical application of these facts is, first, to recognise the necessity of supplying to nursing mothers a diet which Essential in Diet of Nursing is ample in all the vitamines. Vitamine $\mathrm{C}$ and Mother vitamine $\mathrm{A}$ are the ones most likely to be lacking in the diet of the poor. These are abun- 
dantly supplied by milk, eggs, green vegetables and fruits, all of which unfortunately are expensive foods, but they should be included in the diet.

It would seem in the diet of children, particularly infants, a wise precaution during the winter to supplement cow's milk by other foods known to be rich in vitamine $A$, such as butter, the yolk of egg or the juice of steamed green vegetables, but best of all by cod liver oil; small doses will probably suffice, i.e., a half teaspoonful of the pure oil daily for an infant of nine or ten months of age. Deficiency of vitamine $\mathrm{C}$ in winter milk, which may exist even though milk has not been heated, should be corrected by giving orange or tomato juice.

Our knowledge of vitamines is as yet only partial and very incomplete. We are really only at the beginning of a line of research in nutrition which has possibilities we can hardly foresee. Constant additions are being made to our knowledge; and many things generally accepted one or two years ago are now shown to be erroneous.

Scientific research along any line is difficult; the pitfalls for the untrained and inexperienced are numerous, and it is not surprising that many premature and unwar- 
ranted conclusions have been drawn from laboratory observations in the investigation of vitamines.

One of the early errors was due to the fact that the purified foodstuffs composing the socalled "basal diet" supposed to be free from vitamines were not pure. Vitamines exist in Some Early Mistakes food in very small quantities, and some articles which were long believed to contain none have been shown to have enough, if large amounts of the food in question are taken, to vitiate the result of an experiment. Or, take the question of the amount of milk required to maintain growth. Equally good observers have gotten quite contrary results in their experiments. We now know that the vitamine content of milk is not constant but varies with the food of the animal.

Lard has been regarded as the one notable exception to the rule that animal fats are rich in vitamine $\mathrm{A}$. The process used in refining commercial lard, however, is in all essential features identical with the process which Hopkins has recently shown to be destructive to vitamine $\mathrm{A}$ in butter. Its absence therefore from lard seems to be explained by the process used in its preparation.

Again, when orange juice was added to the diet, the effects which followed were at- 
tributed to the antiscorbutic vitamine. But Osborne and Mendel have shown that this and some other fruit juices are also rich in vitamine $B$ and even contain some vitamine A.

We are constantly learning how widely dis-

Widely

Distributed
Vitamins not yet Isolated tributed the vitamines are in all natural foodstuffs, but may be injured by methods of preparation. Milk contains much vitamine $\mathrm{A}$, a moderate amount of vitamine B and some vitamine C. Tomato, cabbage and many other green leafy vegetables contain all the vitamines. The potato has considerable of vitamine $\mathrm{B}$ and vitamine $\mathrm{C}$ and even some vitamine A. Even cod liver oil, the rich source of vitamine A, contains many other substances which may profoundly affect nutrition.

It seems quite evident that until these substances which we call vitamines have been isolated, the interpretation of experiments along this line is open to error. Clearly, until this has been accomplished many of our conclusions from animal experiments must be regarded as tentative only.

Again, there is a risk in drawing too sweeping inferences from the results of experiments upon small animals. Almost all the observations thus far have been made 
upon rats and guinea pigs. We have already seen in the case of scurvy that the susceptibility of different species of animals to a deficiency in vitamine $\mathrm{C}$ differs enormously. This may also be found to be true of the other vitamines also.

The great service thus far rendered in the study of vitamines has been twofold: first, it has given a new basis for the evaluation of foods, and secondly, it has shown what damage may be done to natural foods by the measures employed in refining or preserving them.

Out of the searching examination to which all our foods have been subjected, two, hitherto much neglected and often placed at the foot of the class, have emerged with high honours, viz., the cabbage and the tomato. These and other articles which from the point of view of their energy value are almost worthless have been shown to possess a nutritive value which is very great. They furnish something more than flavor to food, to make it more appetising, something very essential in a human diet. The importance of Values some foods in diet is not suggested by chemical analysis. The tomato, cabbage, spinach, lettuce, chard and all the green or leafy vegetables are composed chiefly of cellulose, water 
and inorganic salts. Fruits have sugar, vegetable acids, water and salts; but none of these things suggest their essential value in diet.

Infured by Methods of Handling and Preserving Foods
What We Lose by This
Many of our foods we no longer eat in their natural state. The conditions of modern life have made necessary the transportation of foods for long distances and the preservation and storage of food in immense quantities for long periods. A certain amount of injury is done to our vegetables, fruits, milk, meats and grains by the processes to which they are subjected in preparation, preservation and storage. The study of vitamines has helped us to understand, to some degree at least, the nature of the harm that has been done. Some of this occurs from the heat applied during our ordinary processes of cooking; some is a consequence of heat applied for purposes of sterilisation, whether for the destruction of the germs of disease or for the preservation of food by canning.

Another example is what we have sacrificed in their nutritive value by the refinement of our foods, as in polishing rice and using only the white flour of our wheat to make our bread, feeding to pigs and cows the balance of the grain. The coarse black bread of the Middle Ages and of the European peas- 
ant of today is despised by our modern civilised city dweller.

But there is another side to the question; What wo let us not at the same time forget the immense benefits of the preservation and storage of food. Take for example the question of white wheat flour. As long as wheat was grown and milled in this country, as it still is in most European countries, within a comparatively short distance, seldom more than one or two hundred miles of where it was consumed, and was used within a few weeks of milling, the problem was a simple one.

At present much of our milling is done one or two thousand miles from our large centres of population. Not only must the time requíred for transportation be taken into account, but the necessity for storage of very large quantities as a normal food reserve. New York City, for instance, consumes over 20,000 barrels of flour every day. Very much of this, it is estimated, has been milled five or six months before it is consumed. White wheat flour keeps indefinitely, certainly for six months, without any important deterioration. But whole wheat flour can be kept only about thirty days; after that it is likely to become "wormy" from the development of ova which are deposited in the husk. One whole 
cargo of 1000 barrels sent to Glasgow during the war had to be thrown away for this reason.

Flour experts tell us that the general adoption of whole wheat flour for bread in this country is an economic impossibility. But the modern method of milling and our system of transportation and storage make a bread famine here almost impossible. In China, however, without facilities either for transportation or storage, there may be famine in one province when wheat is abundant and selling, Thos. W. Lamont tells us, for a few cents a bushel in another province.

Although heating milk may injure or destroy its antiscorbutic vitamine, this fact does

Advantages of Heated Milk, Dried and Canned Foods not invalidate its great advantages, such as protection from diseases which may be communicated through milk, and the preservation of milk by drying, condensing or sterilising which permits its wider use as a food all over the world.

The same may be said of the canning and drying of vegetables, fruits and eggs. These preserved foods are of great benefit in the nutrition both of children and adults. We could not stop the use of them if we would, and we would not if we could.

Our present knowledge of vitamines has 
pointed out that these same procedures have their disadvantages, even their dangers; but when the nature of these is once thoroughly understood and their importance appreciated, the remedy will come also; possibly in some improvement in the processes now in use, or it can always be done by supplying in the diet by other articles of food the particular vitamine which has been injured or destroyed.

The food of infants or older children is in normal times almost never lacking in vitamine B. It is the antiscorbutic vitamine only that is likely to be injured by any process to which their food is subjected in preparation or preservation. But I have never seen and have never known of a case of scurvy in a child over two years old who was living under normal peace conditions. So far as vitamine A, so indispensable for the growth of children, is concerned, it is necessary only that care be taken that the diet include an ample supply, since it is not likely to be injured in the preparation or preservation of food.

We know well the dangers of vitamine deficiency when the diet is necessarily restricted because conditions do not admit of choice or variety of food. These conditions exist in Conditions when Vit2mine Deflciency is times of famine, or great food shortage, or even may be the result of poverty, also in

Lilkely 
Deflclency Unlikely if Usual Diet is Talsen

prisons, army camps, on ship-board, in Arctic regions and, one must add, in infancy.

The consequences to children are serious, whether we consider simply arrested growth and general malnutrition, or the diseases like scurvy and beri-beri, which result from marked and prolonged deficiencies. But it is not likely that, except in conditions like those mentioned, either children or adults who take the average or usual diet are likely to receive such small quantities of the vitamines as definitely to interfere either with healthy growth or normal nutrition.

A glance over the list of foodstuffs known to contain the different vitamines shows how abundant vitamines are in most common foods. This may be one of the reasons why in the evolution of the diet of the human race certain foods have held their place.

It seems therefore perfectly evident that unless the diet given is a very one-sided one, children receive in their usual food a liberal supply of all these essential food constituents. This will be certain to be the case if the regular diet includes milk, green vegetables, fruits and cereals.

Amount Necessary not Known, Probably Not Large
There are two very striking things brought out in the investigation of vitamines by the observation on animals: One is the very small 
amounts which are apparently required to produce their effects and the other is the specificity of their action. Until these substances have been isolated we shall not know the amounts required for normal nutrition. Apparently the amount of any one of them is not large.

Chick, Drummond and their associates at the Lister Institute have shown how much of different foods is required to protect laboratory animals against beri-beri and also against scurvy, when the diet contained no other source of the vitamine in question. They determined, for example, how much of orange juice, cabbage, tomato and many other foods was needed to prevent scurvy; and how much of potato, yeast, egg and many other foods was needed to prevent beri-beri.

While this establishes much that is important with regard to the relative value of certain foods, it gives us no idea as to the actual amounts of vitamine required by human beings. All the evidence goes to show that the vitamine requirement is affected by many conditions. It undoubtedly varies widely even in animals. Laboratory animals in confinement might be expected to show effects of deficiencies in diet sooner than those living under natural conditions. It has often been 
observed that men who were much exposed and doing hard work were affected by scurvy sooner than others, although all had the same diet. If the human diet is poor in other respects the effects of the absence of the antiscorbutic or any other vitamine are more quickly apparent.

How much of the different vitamines is needed for health we do not yet know. It is clearly not a definite amount for all human beings of the same age, sex and weight, but like our other food requirements the vitamine

Rspecially Important for Growth

Infancy the Period of Most Danger need no doubt varies with many conditions.

The special importance of vitamines for growth makes it imperative that the diet of children should contain the articles already enumerated which are rich in these factors. The requirements of adults are for maintenance merely and undoubtedly are much less than the requirements of children. This is especially true of vitamine A.

It is during the period of infancy that children are likely to suffer most; first, since infants are the most susceptible of human beings to all adverse conditions; secondly infancy is the period of most rapid growth and anything which may affect growth produces its most marked effects at this time; finally, 
the diet of infancy is necessarily a restricted one.

It is not only the infant who is artificially fed who may suffer from vitamine deficiency. The mother must take them in with her food if she is to give them out in her milk. This is true of any of the vitamines, but is especially important in the case of vitamine $\mathrm{A}$, the need of which seems especially marked in infancy.

With infants who are fed upon cow's milk we are rather more likely to see evidences of vitamine deficiency in the winter or early spring months than in summer and fall.

Proprietary infant foods are dangerous not so much from what they contain as from what they lack. They may be deficient in all three of the vitamines. Cereals have practically no vitamine $\mathrm{A}$ or vitamine $\mathrm{C}$, and the dangers of deficiency are likely to exist just in proportion to the extent to which they form a part of the diet.

The specificity of action of these substances is quite as great as that of antitoxin in diphtheria or thyroid extract in cretinism. The different vitamines seem entirely independent of each other in their activity. They are Action of Each Vitamine is Speciflic in no way interchangeable; they seem to have no relation to one another. We cannot supply a deficiency in vitamine $\mathrm{B}$ by giving more 
of vitamine A, nor can we protect against scurvy by the most liberal allowance of vitamine B. Each one has a perfectly definite function in nutrition; which, from evidence now in our possession, can be performed by it but by nothing else. If no vitamine deficiency exists in the diet, it does not seem probable that symptoms of malnutrition will be improved by giving vitamines in excess; it would be surprising if it were so, and we lack evidence that such is the case.

Another practical question is whether if the diet is low in its vitamine content, i.e., a condition of relative deficiency exists, there

Symptoms Due to Relative Deficiency may occur, perhaps not frank scurvy, beriberi, or kerato-malacia, but milder and less definite symptoms, such as failure to make normal progress in growth, malnutrition, and general evidence of ill health. This is something difficult to establish. On a priori grounds it seems not improbable. It must be remembered, however, that symptoms such as those mentioned may be due to a great variety of causes other than vitamine deficiency. In the absence of definite means of diagnosis the only evidence of their dependence upon vitamine deficiency is the therapeutic test, viz., prompt and decided improvement which follows when foods known to be especially rich 
in the different vitamines are added to the diet, such as orange juice or yeast or cod liver oil.

In this connection one is reminded of the patent medicine advertisement which ran somewhat as follows: "If you are cured you haven't got the disease. The remedy never fails."

From our experience with deficiency diets in animals positive results should certainly be seen in a few weeks. Definite results in man can only be established by careful clinical observations. It should first be evident from an analysis of the diet that a defieiency probably exists. The changes made should be as carefully planned as are laboratory experiments with rats or guinea pigs. Otherwise the results reported to follow are likely to depend upon either the faith or the skepticism of the observer.

Some suggestive observations regarding the use of antiscorbutic vitamine have been made by Hess and others, in which the weight

Marked Benefit Only when Deficiency Exists curve of infants showed a prompt rise on the addition of orange juice to the daily diet; but in many or most of these cases the diet was known to be, or at least strongly suspected to be, poor in this factor.

Some results which may be significant have 
also been seen to follow the use of cod liver oil in certain conditions of malnutrition in infancy, particularly in premature infants. I have myself seen the weight curve of some premature infants who had made no gain for many days show an immediate rise by no other change than the addition of five drops of cod liver oil to the daily food. It continued while the oil was administered and ceased when it was withdrawn. This amount is too small to change the energy value of the food. The effect noted looks like a specific action. It is certainly suggestive.

Vitamine B has been urged upon the pro-

Results from Yeast Disappointing

fession in the form of yeast as being especially important for children who are not making the normal gain in weight, who suffer habitually from poor appetite and chronic constipation, etc. In the discussion at the American Pædiatric Society meeting in June, 1921, the practically unanimous opinion expressed was one of complete disappointment in results obtained and ineredulity regarding the specific advantages claimed.

However, in view of the important part which we now know to be played by vitamines in nutrition, it behooves the physician in all cases of malnutrition, particularly when the explanation is not obvious, to investigate 
carefully the character of the food and its preparation to discover any errors which might result in a vitamine deficiency. Especially is this necessary in the case of chronic invalids, or of delicate children whose diet has become greatly restricted from necessity or from caprice, and particularly in the case of infants whose diet is always a restricted one. But until we have some more eertain means of diagnosis than we now possess the Benofit from Administra. tion when No Deficlency Ex1sts, Very indiscriminate use of vitamines in other circumstances than the above, for what is often referred to as "general results," is not likely to be beneficial; it has no rational basis; it should be discouraged; it is hardly scientific therapeutics.

It is most unfortunate that the popular interest in vitamines which is the result of so much recent publicity as has been given to this whole subject, should be exploited commercially. Just now vitamines are in fashion and as much capital as possible is being made of this fact. The medical profession at all events should not be carried along in the popular current. Important and indispensable though vitamines are, we must not lose sight of the fact that there are many other dietary factors equally important.

The physician can fall into no greater

\section{Commercial Exploita. tion Unfor- tunato}


error than to assume that vitamine deficiency is the chief cause of all chronic nutritive disorders; just as not very long ago these were all referred to auto-intoxication and at present a certain group would have us believe that they are due to some disturbance of the glands of internal secretion. The use of vitamines without definite indications will be popular for a period but like other fads it will pass. With time and further investigation their true place will be determined.

What vitamine Investigation

Has Taught

Our knowledge of vitamines has taught the necessity of a variety of food and the danger which follows when conditions make a variety impossible. It has taught us also the incomparable value of certain foods, particularly of milk, not only in infancy, but during the entire period of growth; also the importance in the diet of children of the green or leafy vegetables. The chief objections to some like cabbage, lettuce and celery, when used in a raw state is the difficulty of making children masticate them properly.

Our knowledge of vitamines has greatly helped to put the whole subject of nutrition upon a scientific basis. The experimental method has been substituted for the empirical one in determining the value of the different 
foods. Formerly we might know that certain foods were desirable or necessary; now we are able in very many cases to say why such is the case, and to determine their precise value in nutrition. What was once little more than a suspicion has become definite knowledge.

The discovery of the rôle of vitamines represents another milestone passed on the road of scientific progress. It has furnished the key to many problems which were before obscure or altogether insoluble. As in bacteriology and immunology it is the work of the laboratory which has made advance possible.

The part contributed by the rat-one of man's worst enemies-is a very large and important one. For this contribution we should perhaps in the future treat him with more consideration.

Until confirmed by clinical experience there is however some danger in relying too much upon the results of laboratory observations upon animals of different species whose physiological needs may be different from those of human beings.

To sum up the whole discussion: The study of vitamines has taught us several imSummary portant things regarding the nutrition of children: 
That children should eat a variety of food and that especial dangers may follow the habitual use of a very restricted diet.

That milk is the one indispensable food for children. The diet during the entire growth

Milk In. dispersable period should include if possible whole milk, or if skimmed milk is used, it should be supplemented by butter. Of the butter substitutes, those which contain beef fat, mutton fat and peanut oil are better than those in which other vegetable oils or lard are important constituents.

How much milk or butter is required to supply the amount of vitamine A needed we do not know. The need would seem to be greatest during the period when growth is most rapid. From our present knowledge at least a pint of milk a day seems desirable.

That a diet which includes no milk whatever should contain ample amounts of the green or leafy vegetables.

Cereals, particularly those from whole grains and potato, are important and adequate sources of vitamine B.

Fruits have other uses than as laxatives and as sources of mineral salts; they should form a regular part of the diet.

When fresh fruits are not available dried fruits may be given, but they are distinctly in- 
ferior to canned tomatoes as sources of the antiscorbutic vitamine.

Cabbage is such a rich source of all the vitamines that it should form a larger part of the diet than is usually the case, especially since it is cheap and in winter often almost Value of the only green vegetable available. Unless Cabbage thoroughly masticated raw cabbage is difficult of digestion for young children. Cabbage when boiled for one-half hour undoubtedly retains enough of the antiscorbutic factor for the needs of the body. Its other vitamines are practically uninjured.

In normal peace conditions the results of vitamine deficiencies are most often seen in infancy; very rarely in older children, and then only in extreme poverty, in chronic disease or in rare cases of very delicate ehildren whose diet has become much restricted.

If the daily diet contains milk, cereals, potato, green vegetables, some fruit, one need not fear a vitamine deficiency.

While these articles are especially rich in vitamines, most of our common foods contain them. 


\section{CHAPTER V}

\section{Lecture Five}

\section{Practical Measures for Improving the Nutrition of Children}

THE practical importance of normal nutrition to the child is very great, as it not only affects his childhood but its consequences reach forward into adult life. We have come so far short of realising what is possible of accomplishment, as shown by the low standard of health and nutrition which we have permitted to exist in our country among children, that it has seemed desirable in this concluding lecture to consider briefly some of the means by which the present situation could be improved, applying at many points facts brought out in previous lectures.

Is it possible, is it practicable, so to change conditions which affect the nutrition and growth of the children of this country as to bring about a material improvement? If it is possible it should certainly be attempted, to this end using all means now available and 208 
developing new and better ones to supplement those we have.

The greatest agencies for promoting reform along any line are publicity and education. This is particularly true of all health matters. The public must first understand and appreciate the need and then be taught the remedy and how to apply it.

In this effort to raise the standard of health in children we have to combat not only the ignorance of the ignorant, but using Chester ton's striking phrase, the "ignorance of the educated." People may be intelligent about almost everything else, but grossly ignorant regarding all the essential rules of healthy living. They may be wise in all other practi cal matters, but unspeakably foolish with respect to their children, especially when the subject involves discipline and training.

To improve the nutrition of our children is no easy task, nor will the ideal be reached in one generation, but great improvement in conditions can be brought about in a comparatively short time by well organised intelligent effort.

Children may fail to attain normal physical development from many causes, some of which like a bad inheritance or premature birth reach far back and the consequences of

Causes of Malnutri. tion and Poor Physical Devel. opmont 
which can never be wholly overcome, no matter what the subsequent life history of the individual. Other causes are previous acute or chronic illness of a serious nature. In still other children normal nutrition may be interfered with by certain physical defects, such as carious teeth, large or diseased tonsils or adenoids. Failure in nutrition also may be

- the first and for some time the only obvious symptom of the development of some serious disease like tuberculosis, nephritis, cardiac disease or grave anæmia. In the great majority of cases, however, children are below normal with respect to their nutrition or fail to make normal progress in health and growth as a result of improper or insufficient food and faulty hygiene.

To begin with the food. This may be abundant but lacking in the essential elements for growth; what these are has already been considered: An adequate supply of high grade protein, largely from animal sources; a liberal amount of fat; an ample supply of mineral salts for growth of bone; and finally the essential vitamines. All these constituents will be supplied in ample amount if milk, cereals, green vegetables and fruit in reasonable quantities form a part of the regular diet; but they are not furnished in a diet 
common in many homes, in which the principal articles are coffee, white bread, meat, potato and sweets. The cost of such a diet equals and often exceeds the more valuable one. Insufficient food may be the result of economic conditions-witness the numbers of children in our cities who go to school with no other breakfast than bread and coffee, and whose principal lunch is sweets from the pusheart.

Examples of bad food habits are, eating at all hours rather than at regular hours; the consumption of sweets and trash between meals, and rapid eating with little masticaBad Food Habits and Fauity tion of food. Faulty hygiene includes overcrowding, lack of fresh air in sleeping-rooms or school-rooms or lack of opportunity for out-door play, late hours, in consequence of which the child never gets a proper allowance of sleep, and seldom an opportunity for a rest in the middle of the day after the age of three or four years. Overactivity in the form of work or sometimes in play consumes so much of the energy value of the food that little or none is left for growth. By referring to the chart on page 74 it will be observed that if the allowance for activity is greater than the average, it must be at the expense of growth unless the amount of food taken is propor- 
tionately increased; since the requirements for basal metabolism and the loss in excreta cannot be reduced. Even habitually bad posture is a factor of some importance; as is also chronic constipation from which most of these children suffer in consequence of lack of regularity in habit. There are a great many other minor causes which might be mentioned, but the above include the chief ones.

When is a child to be considered under-

Weight for Height

The Aver. age and the Normal not the Same nourished? When is one to be considered well nourished, one might well ask. By far the best guide is weight in relation to height. I do not think it makes any essential differerence whether we use the standing or the sitting height. The standing height without shoes is most generally used.

The average is not the normal either in weight or height. The average is a line; the normal is a zone. Neither weight for age nor height for age is of much value in determining the question of nutrition. Both are subject to wide variations from such causes as race, family inheritance, etc., so wide indeed as to make these of little interest. Certain deviations from the average even of weight for height are compatible with good health and also with normal nutrition. How wide the variation from the average must be, to be 
placed in the abnormal group is an arbitrary question and not all observers agree. The great majority, however, have considered that if any child under twelve years old is less than 10 per cent or more below or 20 per cent above average weight for height, he may be placed in the normal group, so far as his nutrition is concerned. For those over twelve years, since growth during the adolescent period is more irregular than at an earlier age, a slightly wider deviation from the average weight for height may be included in the normal group.

But not every child whose weight is proper for his height is to be considered normal. Sometimes long continued bad feeding or underfeeding may result in children, as in laboratory animals, in a great stunting in size as well as in weight. The child may then show a proper relation of weight to height but be far below the normal in both. Age, therefore, must be taken into account. Of two children of the same height but of different ages the older should be the heavier. Again, there are quite a group of children who are not as much as ten per cent below normal weight who are not in perfect health and who may require attention because of teeth, tonsils, glandular enlargements, pos- 


\section{4}

FOOD, HEALTH AND GROWTH

ture, etc., but they can hardly be classed as cases of malnutrition.

Fallure to Gain Normally

The other important evidence of improper nutrition is failure to gain normally in weight. Observations must extend over a considerable period before this can be determined. Few children, even those in the best of health, after infancy gain regularly every month. There are often periods of two or three months in which very little progress is recorded, when no cause can be found sufficient to explain it. There are also certain seasonal variations. The gain both in height and in weight is usually greater from June to December than from December to June. But a stationary weight for a prolonged period or steady loss at any time is a warning which should never be disregarded. Regular periodical weighings, usually once a month for the average child, will make possible the early recognition of such conditions as those mentioned and the taking of proper steps for their correction.

Nervous

Manifes.

Children who are much below weight for tations height usually exhibit other symptoms. Nervously two types are met with: One, the dull, listless type, not infrequently considered subnormal mentally, lacking in energy and ambition, easily fatigued, disinclined to exertion, with poorly developed muscles and 
flabby tissues; the other type, ambitious, often excitable, usually hard to manage, energetio, in fact overactive, never still, sleepless, frequently with good muscular development but almost no subcutaneous fat.

If we take the best figures now available, at least 20 per cent of our American school children show evidence of malnutrition by the standard previously laid down; if we add to this number the proportion of those of pre-school age (not infants) and of those who leave school and go to work before they are fully grown, we obtain a total of something between eight and ten millions of children in the United States who are not getting the square deal. In by far the largest number, fully four-fifths probably, this is a remediable condition and there is no reason for its continuance except ignorance and indifference.

The treatment of this situation must include both preventive and remedial measures, and of the two the former is vastly more important. If preventive measures could be generally applied a great improvement would result, not only in the health of the children but in that of the adults of the country.

Prevention must begin with the application of the principles of eugenics, with suitable 
prenatal care, with maternal nursing and the best infant feeding and hygiene. These we will pass over, not because we think them unimportant or unrelated to health conditions at a later period, for the state of nutrition at each period of life has a very close relation to the succeeding one, but the period of infancy has been widely studied and is, comparatively at least, well understood. It is with the older child that we are now specially concerned.

It is during the period immediately after infancy that the child perhaps has been most neglected. His hours of feeding, the character of his food and its preparation are in too many cases identical with those of the rest of the family. He is still a very susceptible individual growing rapidly and easily disturbed by adverse conditions.

How is he to be reached? Thus far there have been no special methods proposed for reaching this class. At present nothing better offers than the use of the same methods and essentially the same agencies as those which have been shown to be successful in the case of infants. What has been done for the infants has been accomplished chiefly by the education of the mother through home visits of the nurse and attendance at the milk 
station or clinic. There is no reason why the same agencies might not accomplish quite as much in teaching the mother the physical needs of her children from infancy to school age.

At the milk stations and clinies for infants, weekly attendance is aimed at and bi-weekly attendance is essential to secure proper supervision of a baby. The greatest motive for return visits is the interest awakened in the mother in the baby's weight. This is something tangible, something she can understand and appreciate. If her baby is gaining regularly, she is happy and satisfied. If not gaining or if losing, she is disturbed, usually enough to make her ready to change hours, food or habits to secure improvement.

Continuous observation upon the weight, and opportunity for frequent advice with regard to minor symptoms, which are insured by weekly or bi-weekly attendance, make it possible to prevent to a very great degree serious disturbances of digestion and nutrition during the first two years.

In early childhood visits need not be made so frequently; monthly or bi-monthly attendance may be quite sufficient. But the endeavour should be made to keep up the same interest in growth and weight. At least 
twice a year every child should have a general examination by a physician.

Records are of course indispensable and

Records Essential

A Complete Medical Examination on School Entrance may be continued on cards similar to those used for the first year. In an ideal system each child on entering school should be able to present to the teacher and school physician a complete record of the essential facts of his life history so far as physical conditions are concerned. From this time on his health record should be a part of his school record. Consider for a moment what an advantage it would be if such a record were available for every child.

The medical examination on school entrance, especially, should be a thorough one. It should certainly include as a minimum the weight, height and chest measurement, tests of hearing and vision, examination of teeth, tonsils and adenoids, the heart, lungs, glands, feet and spine. For this the child should be stripped and the examination made in the presence of the parent. His school hours, work, exercise, athletics, etc., could all be adjusted on the basis of known facts. There would be no unpleasant surprises in the discovery of uncorrected defects, for all these would have been known and most of them remedied before school life was begun. 
It would be most desirable to have such an examination repeated at the beginning of each school year. With funds now available or likely to be available for several years I fear this will be impossible. A thorough semiannual examination should however be made of every child whose school work falls much below the average and this should include mental tests.

It has been argued by some that the vigourous campaign to reduce infant mortality has merely had the effect of bringing about the survival of the unfit, and that these children are carried through the first year only to succumb to other adverse conditions in later childhood. The facts do not bear out this contention. Vital statistics show that with a reduction in infant mortality there has come about an even greater reduction in the mortality for the periods one to two years and two to five years. In New York City two three-year periods show the following comparison:

$$
\text { 1890-1899 }
$$

1917-1919

Deaths under 1 year were 26 per cent of all deaths-14.4 per cent of all

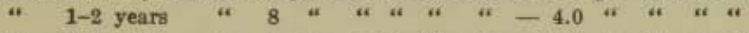

" 2-5 years " 7 " 4 " 4 " $\quad-8.6$ " 4 "

The fall in the mortality rate has been a gradual and steady one for each of these age periods during the entire twenty-seven years. 
There can be no escape from the conclusion that improved health in one period invariably improves the health of the period which succeeds it. Healthier infants mean healthier boys and girls, and healthier boys and girls mean a stronger, more vigourous and healthier generation of men and women.

We have already alluded to the fact that what has been accomplished in the improvement of the health of the infant and the young child has been the result very largely of the education of the parents, particularly the mother. This education forms a distinct and very important part of the field of public health.

Prevent

It is coming to be realised that the most effective way to prevent disease is to promote health. In the campaign against tuberculosis, for example, all have come to recognise that cleanliness, abatement of the spitting nuisance, proper food, exercise, and most of all fresh air, have accomplished far more than isolation and medicinal treatment of those suffering from the disease. In the world-wide campaign against hookworm which is being carried on by the International Health Board it has been found that while the infected individuals in the population can be readily cured, 
little oan be accomplished in stamping out the disease except through education.

It makes no difference then what the particular phase of the health problem is that we are seeking to solve, whether it is cardiac disease, hookworm, tuberculosis or simply malnutrition, it all comes back to the education of the individual in matters of personal hygiene. To promote health is not quite the same as to prevent disease although it invariably has that effect. It is upon the promotion of health that the emphasis in public health work is now very properly coming to be placed.

With reference to their children parents must not only be taught the extreme susceptibility of the very young to all kinds of infection, and the importance of keeping all sick persons from coming in contact with them, but emphasis should be placed upon the means by which children may be kept well. Again, that the function of the young child is to grow and that this occurs when proper food, fresh air and sleep are furnished. A small child is a very delicately constructed bit of machinery, easily injured and even put completely out of order by improper handling. The economic side must also be im- 
pressed, that though meat is cheaper than medicine, milk is much cheaper than meat,

miness

More Ex. pensive than Health and that illness is much more expensive than health.

Again, our foreign population does not appreciate the fact that in a climate like that of our Eastern States, children need a different diet from that required for example in Southern Europe, and that the modern American way of feeding children is really an improvement upon the methods which they have followed in their former homes, even though they have the authority of centuries of usage. But even our native-born American is quite as impervious to modern health teaching. Dr. Biggs, the pioneer in health education in this country, has often said that he could teach the foreign population of New York to adopt a health measure more readily than the native American, and often much more readily than the medical profession. The foreigner has a respect for authority-or at least he once had-which a citizen of free ! America does not possess.

\section{Hosith} Reform: from Fright not Lasting

In times of great emergency, as when an epidemic of cholera or plague threatens, people will do almost anything they are told. They will avoid stimulants, boil their milk and drinking water, practise personal cleanli- 
ness and even clean up their dirty homes. But the influence of this is very transient; when the scare is over they quickly lapse into their former habits.

When a child is dangerously ill there is nothing the average parent will not sacrifice to save him. But to save him day by day by giving him proper food and training him to form proper health habits, is something the importance of which most parents do not yet see.

We have not been very intelligent with respect to our health teaching in the past. For the most part we have been endeavouring to teach adults to reform, to change their habits of eating, drinking, bathing, sleep and exer$\underset{\text { Feach }}{\text { Fard }}$ cise. But adults do not like to reform. It has Adult: been difficult, almost impossible to influence them to change the habits which they have practised all their lives. Their prejudices are hard to remove.

It may well be said of most of the health knowledge of adults, not that they are so ignorant but in the words of Artemus Ward, "they know so many things that ain't so." It is pretty clear that we have wasted most of our energies because we have begun wrong. As it is much easier to form than to reform, it becomes perfectly evident that 
if we are really going to change the health habits of people we must teach the children. Workers in the health field are beginning to appreciate the fact that the health education of children is the great opportunity of the future, as yet scarcely touched. It is

Ohlldhood is the Time becoming more and more clear that we have begun too late with our health education. Childhood is the time before habits have been formed and prejudices established. The twig is so easily bent in the right direction.

The health education of the child should be begun at an early age and in the home. As a matter of fact this is what is always the case, although the kind of education given may be of a most undesirable sort. But it will be improved when mothers are better taught and when they can be made to realise its value. However, even under what may be called favourable conditions, the health teaching of the home leaves very much to be desired. In the homes of the wealthy, intelligent nurses and educated governesses sometimes give very good health instruction and training; but too frequently this is entirely neutralised by the example of parents and their indulgence of the children. The mother who takes entire care of her children, even though intelligent in other matters, has usually, with 
her other domestic duties, very little time, has seldom the knowledge and still less frequently realises the importance of the early instruction in health matters. Comparatively few children in our modern homes have been properly trained or taught in matters relating to their health. Some other instruction than that which a child receives in his home must be given, or each generation will go on for an indefinite time repeating the mistakes of the preceding one.

Clearly the school is the place where it can be done. That systematic instruction in In School Better than in Most health should form part of the school curricHomes ulum and that education in matters of health is quite as important as instruction in the "three R's" are ideas which are only beginning to dawn upon the minds of educators.

The school in many particulars offers advantages over the home as a place for health instruction. The child goes to school expecting to be taught. What his teachers tell him or what he learns from a printed page has in his eyes an authority which home teaching does not possess. Besides, during the school age the child has already in most instances begun to rebel against the prohibitions of the home in which most of the health teaching of the home consists. In the health 
teaching of the past no effort has been made to make health attractive; too often I fear we

Foalth

Made

Repulsive have succeeded only in making it repulsive. A continued repetition of "don't's" and "you mustn'ts"' has very little influence with average boys or girls, whether it relates to their speech, their posture, their manners or their health.

Another advantage of the school is the opportunity it affords for the stimulus of emulation and for group instruction. It is much easier to get a group of thirty or forty children in a school room to do things than to influence a single child to do them. Children at this age are greatly influenced by the opinions and the conduct of their fellows. Once proper health ideas and traditions can become established in a school, a public opinion is created which makes possible a widely varied kind of health teaching. In the six or eight years of school life the child may be made to understand the simplest rules of personal health and the broader aspeets of public health.

Patiure of Former School Teaching

But, some one says, have not our schools been teaching physiology and hygiene for a generation or more? In the advanced grades and in the high-school, yes; but how? These subjects have almost without exception 
been made a matter of text-book instruction and recitation. Children were taught, for instance, the number of bones in the body, the composition of the gastric juice; they learned that in the lungs the body gives off $\mathrm{CO}_{2}$ and takes up oxygen; but that those things had any relation to the kind of food they should eat or to the necessity of keeping the windows of their sleeping-rooms open, was seldom even suggested.

The teaching of these subjects influenced the health habits of the pupils no more than their study of botany. They were not linked up with practical life. A new and more vitalised method of teaching must be devised if results are to be obtained.

A wide, general interest has been awakened in the last few years in physical education, and this is regarded by many school authorities as the solution of the problem of health in the schools. Physical training has been made Will Physical Education and Training Accomplish compulsory in some of our states. Liberal the Result? appropriations have been made by both state and local authorities and the physical director is in many places one of the highest paid school instructors. All this has been emphasised very largely as a result of the revelations of the draft which revealed such a deplorable condition of physical development 
among our young men, nearly one-third of whom were found physically unfit for military service. Whether the problem of the health, nutrition and physical development of our children is going to be solved along the lines of physical education as now conducted seems very doubtful.

The fundamental error appears to me to be the belief that all or at least most of the evils and failures which have been so obvious can be overcome or prevented by exercise, or ex-

Danger of Too Much Emphasis Being Placed on Field Day ercises and physical training. Attention is too often concentrated upon the gymnasium and the showing made on field day. How far this is from solving the health problem the following incident related to me by a health worker in another state will indicate: The girl who was taking a leading part in field day was in such a poor state of health that she was obliged to omit all her school work for many days and so exhausted was she after going through her part that she was excused from her studies and was allowed to remain the rest of the day in bed.

The ambition of school heads to make a good showing on field day, especially at interscholastic meets, and the natural desire of all children to take part in such events and to excel in them is all very well. It has its ad- 
vantages; but encouraging these things is very different from promoting the health and best physical development of the school as a whole.

The fundamental mistake made is that exercise and physical training are too often looked upon as ends, not as a means to an end. By entirely ignoring the question of the nutrition of the pupils, and the effect upon it of physical exercises prescribed and actually performed, the so-called physical education may result in a positive harm instead of benefit to the individual, as in the instance above cited. Periods of rest, not hours of exercise in the gymnasium, are what very many of these children need most.

It seems quite evident that the problem of the nutrition of school children is not going to be solved by physical edueation as now conceived and administered in the great majority of our schools. Instruction in physical education is not health teaching in the sense that we have in mind. In some states the program for physical education includes much more than I have suggested.

Physical education should certainly include the formation of proper health habits. In theory this view is held by most teachers of physical education, but how little it is 
emphasised in practice is indicated by the syllabus of one state which devotes 285 pages to a detailed description of exercises and but a single paragraph to food habits.

Health teaching should be begun in the first

Barly Health Teaching
Value of Different Methods of Education grade at school entrance, and continued through all the grades of the elementary school. The idea should be grasped at the outset that the aim of this teaching is to get children to do things. We must not seek, at this age, to impart information about health, or to teach them to recite the rules of health, but to form what we cannot better describe than good health habits.

Lectures and health talks accomplish very little with children of any age and nothing at all with young children. Such talks when made a part of the regular school curriculum are likely soon to degenerate into advice as to how to prevent taking cold, admonitions to wear rubbers, keep out of draughts, avoid children who are coughing and sneezing, etc. They are a bore both to teacher and pupil.

To determine the value of different means of teaching health to children the following experiment was tried upon a large group: First, the children were given a talk upon health, impressing its value and importance. 
Later they were taken to a health exhibit where they were shown with full explanations various charts, diagrams, etc. Another day they were shown a health film at a moving picture theatre. After an interval the children were required to write compositions upon what they had learned about health. Only one or two mentioned the health talk; a few the health exhibit, while nearly all described fully what they had seen in the picture film.

Such results are most instructive. They show that we must teach health as we teach other things successfully, by the use of methods which appeal to the child, by things he can understand.

Since our aim with young children is the formation of habits, the problem becomes one, first, of selecting the most important, and then of devising means to secure their constant repetition until they become automatic.

The habits stressed by the Child Health Organisation are as follows:

A full bath more than once a week

Brushing the teeth at least once every day

Sleeping long hours with windows open

Drinking as much milk as possible, but no coffee or tea

Eating some vegetables or fruit every day 
Drinking at least four glasses of water a day Playing part of every day out of doors

A bowel movement every morning

These are very simple things, but if regularly practised by all children they would certainly bring about a very marked improvement in their physical condition. To the physician these habits are known as the laws of health; to the children they are taught and practised as the "Rules of the Game."

How to get them done by children, not for a few days or weeks, but regularly and continually during school life-this is the problem.

We must not then make work of our heaith teaching in the school, but seek to make it play; we can get children to do almost anything if it is made play. We should aim to get into their minds that health too is a game, with its rules like other games; a game that one can win or lose according as he obeys the rules. The play motive is altogether the most successful one up to the age of ten or eleven. Unless the child is interested, it is hopeless to attempt to influence him; so we begin if we can with something which is dramatic and which will catch the child's interest, like ChoCho the Health Clown, the Jolly Jester, the Health Fairy, or some of the other dramatic 
characters, first developed by the Child Health Organisation, who introduce health teaching under the guise of amusement or entertainment. Those who see in the modern movement for the health education only amusement for an hour, have not grasped the point. These things are only the beginnings, the first lessons in health-kindergarten lesHow to Awaken sons if you will; but they are based upon sound psychology-that before you can influence, you must interest.

If one is skeptical regarding the effect of such measures let him watch and see how much real interest can be aroused, how children are impressed and how well they remember what they are taught in this way. Health teaching can be correlated with instruction in reading, writing and arithmetic without taking extra time in the curriculum.

When a little older, children love organisation; at a certain age, usually about twelve or thirteen years, they like nothing so much as to belong to a club, to wear badges or a The Club Motive uniform. Hence the response which has come from the Modern Health Crusade movement, and the success which has attended the formation of various types of health clubs or health leagues, in which records are kept of the daily performance of certain "Health 
Chores" like the Rules of the Game mentioned, and where inspections are made daily by the officers to see how well the chores have been done.

All these movements are attempts to capitalise certain instincts of the child, and when well administered they can be made of very great value. The only difficulty is that after a time children almost inevitably lose interest, and the continued repetition of the same performances may become something of a bore. Something more must be devised to maintain their interest if the health habits we are seeking to have children form are to become habitual with them.

Right here is the opportunity for a teacher with tact and imagination to utilise any spe-

What a Teacher without Special Training but with Enthusiasm and Insight can Accom. plish cial interest of the child to carry the health lesson. The following incident illustrates this point :

Miss M. had been appointed a special teacher of an open-air class in one of the public schools of a large city. She became very much interested in the health of her boys and girls, but she thought: "How can I teach them health? I have never had any special training in the subject." One day she had an opportunity to talk to an expert on health education who told her that she needed no tech- 
nical knowledge to teach the simple laws of health; that any teacher could interest her pupils in learning to drink milk, eat green vegetables and have plenty of fresh air and sleep, if she went about it in the right way. She was told of various devices for arousing the children's interest but she was not satisfied. Her city street boys were not of the type to be interested in fairies. She had become enthusiastic, however, over the idea of dramatising health education and at last she stumbled on the magic word; it was "'Sport." Her boys were inveterate readers of the sporting page and, as it happened, horse racing was the particular excitement at this time. Miss M. also took to reading the sporting page. To her surprise she found it to be very stimulating literature. The time came for Man o' War's great race. Miss M. saw her chance and took it. She discussed with the boys what the difference was between a race horse and an ordinary horse, and explained the wonderful care he received; how his coat was washed and brushed every day, his mane combed, his food carefully measured Importance of Health Rules in Care of so that he took neither too little nor too much and how it was given at regular hours; how he was given plenty of water at proper times but never when he was hot; how he was exer- 
cised regularly every day out of doors and had a nice quiet place to sleep, etc. The inference was obvious.

The boys would now come to school ahead of time every day to discuss Man o' War with Miss M.; on the day of the race they came a whole hour before opening. The next day they were asked to write about it. Their compositions showed that the point had been driven home, they were fairly bursting with the inevitable connection between cause and effect. Man o' War had to win because he had followed the "rules of the game." One little boy wrote: "Gee, if you could have seen Man o' War coming around the curve with his coat a-shining in the sun you would know he just couldn't help winning."

It was not hard after this for Miss M. to get her pupils to practise the health rules.

Special training and equipment are useful but not essential. The one thing which is indispensable is a person with tact and enthusiasm. Of such material as Miss M. will the health teachers of the future be made.

The dramatic instinct of children can be utilised in the production of little health plays, like those of Eleanor Griffith. With encouragement and a little help from the teachers, children themselves have written some 
very creditable plays. Milk is most often the subject and the different constituents of the milk are the different characters. The villain of a play is often tea or coffee while milk is the heroine.

The exhibition of good posters in the schoolroom and poster contests among the children may be a means of teaching health as well as drawing. The contests may be between the boys and the girls, between different rooms in a large school, or the competition may be a more general one between all the schools of a city or county. Such a competition with prizes was recently held in New York; with a little newspaper publicity much interest was aroused and some very excellent health posters produced. All the posters were exhibited for several days in one of the rooms of the Metropolitan Museum of Art and the prize posters displayed in a prominent shopwindow.

Health rhymes of the sort which appeal to children are another way of teaching the same lesson. The following by Mrs. Frederick Peterson are excellent examples:

Health Lessons in Catchy Rhymes

There was an old man with a tooth That ached till he said, it's the truth, I neglected 'em young, and now I am stung. How I wish I had brushed 'em in youth! 
There was a boy in our town whose mother was not wise.

Coffee and tea he used to get and grew up undersize.

But when he failed the football team because his size was small,

He cut out both and took to milk and grew up very tall.

The health lessons stressed in such verses are not easily forgotten by children. Why should they not be taught them as well as Mother Goose rhymes? When accompanied by appropriate pictures they form an attractive decoration for the room of the kindergarten or the primary class.

The remarkable success of Mrs. Peterson's Child Health Alphabet (nearly two and a quarter million copies of which have already been distributed) is the most conspicuous example of the need of such literature for small children and its value as a means of teaching them.

Of all the methods proposed for maintaining an interest in health matters in children of all ages, none has been so generally useful

Interest in as that which centers about the weight and height. It is no exaggeration to say that the scales have saved the lives of more infants than any device of medical or surgical treatment. 
And right here may I digress and say a word with reference to tables giving standards of height and weight which have been a subject of so much recent discussion as to discredit in some quarters their value? The differences between nearly all the tables now in use are more apparent than real and are owing chiefly to the difference in the manner of presentation.

By many who have discussed this subject the main point has apparently been missed. The chief purpose of weighing children in school is not to collect anthropometric statistics, but to interest children in health. The actual relationship between weight and height of a child at the beginning of observation is of much less importance than his rate of progress. It is with the latter that health teaching is most vitally connected.

It is of course necessary that scales should be in the schools, and that weights be taken regularly during the school year, usually once The Child's
Own Record a month. The weights for the children of a single room may be entered upon a large chart hung in a conspicuous place. Opposite the initial weight the average weight for the height is recorded so that the child can see where he stands and what progress he is making each month. 
Various other devices are used with the younger children. In one primary classroom I saw a large sheet of paper upnn which was drawn the ladder of health, the different rungs of which are marked from the bottom " going up," "'almost there," "'on the level," " over the top," each child making his own entry after the weighing. The device in another room was a row of small pasteboard clocks, one made by each child, on which was shown by the minute hand the existing weight, and by the hour hand the normal average weight for the child's height and age. The minute hand is moved up or down as he gains or loses at the monthly weighing. These are kindergarten methods, truly, but they accomplish the result aimed at-they gain and hold the child's interest at a certain age.

One must see one of these monthly weighings properly conducted to appreciate their significance. They are made important, often solemn, occasions, and the interest of the children is often intense. The scales are placed at the point of the weight taken the previous month and when a child steps upon the platform eager eyes watch whether the bar will rise or fall, indicating a gain or loss for the month. When the weighing is finished 
one teacher addresses hei children somewhat as follows: "Now will every child in the room who is up to normal weight for height stand up." "Children, I could tell it by your looks; by your bright eyes and rosy cheeks, by the work you did in school this month, by the way you play at recess, etc., etc."

All of course are delighted.

"Now, will every child who gained in weight last month stand."

More words of commendation follow, then the teacher says to a group-

"Now won't you tell us how you did it."

Many hands go up as each wishes to relate his own personal experience. It is not necessary to eall attention to those who did not gain or who are below normal weight.

A common cause of under-weight is that the child has no appetite and will not eat simple nourishing food. The mother says, "he must have some breakfast before school, Bad rood so I give him coffee and a roll, or griddle Habits cakes with syrup which he will eat, rather than have him go to school with no breakfast at all." To change things in the home is difficult; in some homes it is impossible, but in the school it can be done. The child with such habits finds in school that he is at the foot of the class in health. To gain he will 
now go to bed at a reasonable hour, eat his cereal and drink his milk and soon he often finds he likes them.

When a child is found at the monthly weighing to be much under-weight or not gaining he is anxious to know why. He wants to be be Healthy in the healthy group. Now is the opportunity to stress the health rules. Advice to a child who wants to know is never wasted effort. He is ready to submit to a medical examination, have teeth extracted or tonsils and adenoids removed, if these seem to be the cause. But the influence of this does not stop at the school door; as these health records go home to the mother on the monthly report card, her interest is awakened and with little difficulty her coöperation is secured; in fact, the child's zeal makes this almost inevitable.

The home is reached through the child and many a mother may now learn for the first time what is a suitable diet for a school child and what habits are indispensable for health and growth.

When a child has learned that to get up to his normal weight or to gain weight, he must

Conditions Necessary to Gaining be in bed before nine o'clock and not play in the street till ten or eleven; that he must drink milk, not tea and coffee; eat regular meals, not fill his stomach with sweets and 
other trash between meals, must eat a variety of food-cereals, vegetables, fruit, etc., and not make his entire meal of one thing no matter how fond he may be of it-does any one suppose that such habits formed in childhood will not make a lasting impression upon his life?

Too much emphasis cannot be placed upon the fact that the essentials of personal health are such simple things as those mentioned, and that even the untrained teacher, once she is interested, can carry them into effect. Emulation and competition are powerful motives in childhood, and while they are often unduly stimulated, they are very valuable incentives to children to do much that is desirEmulation a Strong able.

In a school atmosphere like the one described-and this is not a fancy sketch, many such exist-such a public opinion as to the desirability of health exists that nothing can resist it. Children are taught health songs, to produce health plays, to make health posters, to devise health games and health charts. One must see it to appreciate the interest the little children take in these things, and the fun they get out of it; the pride they take in being up to weight and their delight at the regular monthly gain. One is touched too by the con- 
scientious efforts of those who are below to gain and to bring their weight up to normal. One little fellow of seven years I saw who was nine pounds below weight and who had formerly had coffee three times a day but who was bravely drinking his milk and eating his oatmeal to be in the healthy group, and getting to like them too. Children are taught to think health, to live health, not to recite it.

Much of this is looked upon at first with doubt by parents, askance by school boards, and with suspicion by physicians; but once they witness the results achieved in improved physical condition and better school work they are compelled to admit its effectiveness and its value.

Morbid

Ideas not

a Result

Health Teaching for Older Children

Children do not by these methods become self-conscious regarding their health; nothing is suggested as to disease, bacteria, the dangers of infection, etc. Health as a thing to be gained, to be kept and to be enjoyed; health as contributing to success in athletic games-these are things which are kept before their minds.

Older children can understand also many of the more important problems in public health. For instance, the enormous loss of life and property in epidemics; the connection between them and faulty hygiene and 
sanitation; the fact that they may be spread by unhealthy persons who handle food, or through a contaminated milk or water sup. ply, or by mosquitoes, flies, rats, lice and other vermin, and that many of these diseases can be communicated from one person to another, and why quarantine is necessary in such diseases. They can also be taught to appreciate the value of clean streets, the necessity of proper disposal of sewage and garbage. How diphtheria, smallpox and yellow fever have been conquered, and the results of the campaign against tuberculosis and typhoid fever, should be known to every one, and there is no reason why this might not be given in schools. Some of our best modern books on hygiene like Winslow's "Healthy Living", give this information in readable form.

These health stories must be graphically told by one who has the gift of writing for children and most of all they must be accurate as to fact and told without exaggeration. They must be better than literature which was put into our schools regarding the injurious effects of alcohol. I am reminded in this connection of the remark of a boy who was gazing out of a sleeping ear window at a vivid sky at sunrise. "Why, 
Mother"' he exclaimed, "it's just like the picture of the inside of the drunkard's stomach in my school reader."

To older children health instruction is best

Health Taught In. cideatally to Other Subjects given not as a subject by itself but incidentally, correlating it with other subjects of the school curriculum. For instance, with history and economics, study the failure of the French to build a Panama Canal and the success of the United States when Gorgas had shown how malarial fever could be stamped out; or the cleaning up of Cuba by Leonard Wood and the consequent control of yellow fever, which previously had been brought from Cuba to the ports of New Orleans, Mobile and Savannah every few years, causing epidemics with thousands of deaths and costing millions of dollars by paralysing business in these cities which were sometimes quarantined for months.

In mathematics let the children solve problems like this: Calculate the cost of erecting and maintaining a water filtration plant for a city, and compare this with an annual occurrence of one hundred cases of typhoid fever each year, with an average disability of eight weeks for each case, without taking account of loss of life.

In debate let them discuss such a question 
as the following: "Resolved that our city or town should furnish half a pint of milk a day at morning recess to every child in the public schools." Think what an opportunity to teach those who take part in such a debate the uses and value of milk! And what a chance to educate the school superintendent if he could be induced to act as one of the judges in such a debate!

In drawing have the children make posters illustrating some health rule, such as an early bed hour, sleeping with windows open, drinking milk, not tea or coffee, etc.

In English composition tell the story of any great health achievement like Jenner's discovery and then let the children write an account of it.

In biography why should not children in school learn as much of the life and work of John Harvey as of Galileo; of Louis Pasteur as of Napoleon; of Lister as of Gladstone; of Robert Koch as of Bismarck; of Walter Reed as of Andrew Carnegie? Appraised in terms of their value to the human race, is not the influence of the first group mentioned quite as important as the second?

These are only a few suggestions of how the teaching of health might be made real 
The General Public Has no Background of Health Education to older children in the schools without taking any time from other studies. Why is it that it is so difficult to get popular support for advanced public health measures? I believe it is chiefly because the great majority of our people today have no background of knowledge regarding these important matters. The boys and girls in our schools today will very soon form our voting population. If health teaching is made a regular part of school instruction it will not be so hard to secure necessary health legislation, or to get appropriations voted for adequate health protection of the community.

Very little in the way of apparatus or equipment is needed for such health teaching as we have suggested. The one thing which is essential to success is a teacher with some enthusiasm for health; without this the monthly weighing becomes a perfunctory performance of no interest to the pupils and but one more piece of drudgery put on the shoulders of the already overworked and often undernourished teacher. Its results are merely statistics which are required by the principal or school superintendent.

One of the by-products of the plan we have described has often been the discovery by the teacher herself that she is far below weight, 
and that the tea and coffee with which she seeks to stimulate her jaded nerves, the sweets she consumes because she has no appetite for plain food, and the evenings which she spends Effect on the Health of the in seeking diversion from the deadly routine of school work, may have something to do with it. The substitution of a quart of milk a day for her tea and coffee, eating simple food at regular hours and taking one or two hours more of sleep a night, are often followed in a few weeks by a gain of six or eight pounds in weight; and with this there frequently comes an entirely new outlook upon life and a different attitude toward her work.

Who is to teach the teacher? Where is she to get the inspiration and the knowledge which will enable her to take the initiative in maintaining and improving the health of her pupils? Our greatest need today in this educational health program is trained people to teach the teachers; not simply to give them the facts of health, but the enthusiasm, which is needed to make these things vital in the life of the child. This ought to be given in teachers' institutes, in our colleges and highschools from which our teachers are recruited, and most of all there should be in our normal schools up-to-date courses upon health 
education which every teacher should be required to take.

It is impossible here to describe in detail how, once the spirit of health teaching exists in a school, this teaching can be correlated

How Health Teaching may be Correlated with other school work. It should be closely linked up with the Domestic Science Department and the work of the physical director. All this can be done without imposing extra burdens upon the teacher or the school curriculum. For suggestions along these lines I would refer to two pamphlets prepared by the Child Health Organisation and issued by the Department of Education in Washington; one by Robert G. Leavitt of the Trenton Normal School on "The Health of the Teacher'" and the other by J. Mace Andress and Mabel Bragg entitled "Suggestions for Teaching Health in the Elementary Schools." These are full of practical hints and should be in the hands of every teacher.

While the teacher alone with only the help we have mentioned can do a great deal, she cannot do it all. She should have the coöperation of a school nurse and a school physician, and in every large town she might have them, if parents appreciated their value.

In an ideal plan, medical school inspection should form an important part of such a pro- 
gram as we have outlined, and should be closely linked up with other health teaching. So also should the hot school lunch, which should be looked upon not merely as a means An Ideal Program of improving the nutrition of the children, important though this may be, but as having great educational value. It offers a unique opportunity to teach children all through their school life food values, food costs, what foods are necessary for growth and what are undesirable. It has proven of the greatest value in teaching children to eat proper foods and to connect the child's interest in his weight with the selection of nutritious food.

The school nurse is needed to take up details with children who are especially in need of help. She can go into the home and secure the coöperation of the mother. The school physician is needed to discover existing disease and to see that physical defects are removed, which may be the cause of the failure to make progress. Then, too, time must be found in the school curriculum for the regular weighing and the accompanying health teaching. They should not be done out of school hours as if they were no real part of the school program.

That education in health should form an 
integral part of our public school education, it seems to me is a position which is unassail-

Health

Instruction an Essential Part of Pub. lic School Education
Corrective Measures able. Next to moral training, more important in its relation to life than anything else, is health. The basis of adult health is proper nutrition during growth. To insure this is one of the great problems before the world today. It can come only through an aroused and enlightened public opinion. But the school is the place where the foundations for it must be laid.

If the general plan of preventive measures just outlined is followed, the need for remedial measures will be greatly reduced. But it may be a considerable period before these preventive measures are adopted even in enlightened and progressive communities. Time will be required to educate public opinion up to the point of demanding them. Yet no matter what preventive measures have been adopted, there will always be a certain number of children whose nutrition is below what it should be. At the present time this group is quite a large one. Among the wellto-do a child with malnutrition should be under the care of a private physician, but he seldom is except where the parents are unusually intelligent in health matters. Among those of moderate means and among the poor 
such a child seldom sees a physician unless really ill. In some communities organised effort has been made to solve the problem of malnutrition, or at least to help in solving it, by the formation of Nutrition Classes.

It is possible here only to outline the organisation of these classes, the methods of operation and to indicate the results which they have accomplished or may accomplish. The purpose of the nutrition class is to help by intensive effort, largely educational, the group of children who by observations upon weight and growth have been found to be so far below the normal average standard that they are in need of special attention. In New York and in other cities such classes have multiplied rapidly, especially during the last two years. The movement is the outcome of the interest in the nutrition of children which has been awakened largely by observations upon weight made in general school surveys. It is certainly an important health movement and if rightly organised and administered it may do for older children what the milk station and the consultation have done for infants.

Classes have been organised in connection with schools, settlements, hospitals, out-patient clinics, church houses and in many other 
places. They have been conducted by physicians, dietitians, trained nurses, social workers, teachers and others, some of them well qualified, and some with no qualifications at all except a general desire to assist in solving a difficult problem.

Without some medical assistance a good

Organisation and Administration nutrition class is impossible. Before children are admitted to such a class they should receive a thorough medical examination to determine whether they are suffering from any serious disease, especially tuberculosis, to which failure to make normal progress is due; also whether there are defects which hamper growth, like bad teeth, tonsils, adenoids, etc. For there is little hope of material improvement if there are faulty organic conditions which are unrelieved. The assistance of the physician is necessary not only for the recognition of these conditions but their correction.

The next step is a careful investigation into the child's diet and his habits; much can be learned from the child himself; but a knowledge of home conditions is indispensable. So that there is necessary a threefold history, medical, personal and sociological. Unless all these matters are thoroughly considered at the outset and definite 
and accurate information obtained regarding them, little that is permanent will be accomplished. For very often the causal factor of greatest importance will otherwise be overlooked. It may be largely poverty that is the chief cause- the child does not get enough food or the right kind of food for the simple reason that there is not money in the house to buy it. Coöperation with relief organisations may therefore be necessary as the first step. In a much larger number of cases the great causes, ignorance and indifference, must be overcome.

One must seek to awaken in the child and also in the mother a desire for improvement. Much the same methods of arousing interest may be used as those already mentioned in discussing general health teaching in the schools, viz., regular weekly weighings and the stimulus which comes from the emulation of being one of a group. Close individual attention is necessary in the beginning until each child is well understood.

One of the great difficulties to overcome in nutrition classes is to secure regular attendance for a period long enough to get results. On this account the school seems to be the most desirable place to conduct them. Here in ideal conditions the coöperation of 
the school physician, the school nurse and the instructor in domestic science may be of great assistance. They should all be members of the staff of such an organised class as we have in mind. School work need not be interrupted; although in most cases it must be modified to allow time for extra rest periods which most of these children require. Openair classes in school are of great assistance.

The common practice of many physicians of advising removal from school for every child whose general condition is much below par, is by no means the best thing for most of these children. Control of energies and regularity of habits are often better secured in the school than in the home.

What is absolutely necessary is a proper adjustment of study, exercise and rest. In the school all these can be organised and regularly carried out. In the home it is often a difficult matter. To be sure, the child is in school or under its control only five or six hours out of the twenty-four and what goes on during the other eighteen hours is also very important.

The plan suggested by Dr. Emerson of having the child keep for several successive days of every month a record of exactly what he 
does during each hour when not in school, is most helpful. Only in this way can one be sure that directions given are actually being carried out. The offering of small prizes for those making most rapid progress is often used as an additional stimulus.

When a child has reached normal weight for height and his faulty habits and physical defects have been corrected, he may "graduate" from the class. Graduation is accompanied by some ceremony and the graduate is given a certificate signed by the person in charge of the class and sometimes stamped with an impressive red seal.

A comparison is sometimes made between the results in very marked cases of malnutriResults tion by attendance upon such a nutrition class as we have described, and those obtained by sending children for a few weeks or even longer period to country homes. With the latter much more rapid improvement usually occurs. A child in two months may gain ten or fifteen pounds. But this improvement in the great majority of cases is lost almost as rapidly when the child returns to his home, to his former diet and his old habits. Something more must be done for these children than to make them gain weight. Unless the acquisition of the extra 
pounds has been accompanied by some education in health the results are very transient. The educational process is slow; it takes time, great patiense and much ingenuity to get and to hold the interest of the children, but nothing else produces lasting results.

Nutrition classes, such as we have been

Essentials for Success considering, need no elaborate equipment; but they do require for success a well trained, enthusiastic, resourceful personnel. They should be conducted by those who understand children and have a genius for influencing them; who have also the basic knowledge of the foods, diet and hygiene which are necessary for children. The coöperation of the home must be secured and careful records of progress must be kept. A class should always have the supervision and assistance of a competent physician.

All this means that not a great deal of this can be done by volunteer workers; by far the greater part must be done by a paid staff. For intensive work classes cannot be large; and for permanent results attendance must be continued for a long period, sometimes one or two years. Good nutrition classes are therefore necessarily expensive and it is impossible for most communities to cover the 
field with anything approaching thoroughness.

Such classes for those suffering from malnutrition are to be regarded as curative or corrective measures. Since it is more important and easier to keep well than to get well, the greater emphasis should be placed upon preventive measures. If proper health teaching has been done through the schools Prevention More Important than Corrective the necessity for nutrition classes will be Measures greatly diminished.

As this work of health education in the schools develops it becomes more and more clear that children can be interested and taught to practise proper health habits through class-room teaching which can be correlated with the regular studies and without taking time from them. The one thing essential is a teacher with the health point of view. What some such teachers, even without special training, have accomplished shows what is possible.

One cannot believe that ideas of health and the way to gain it can be put into the child's mind during his school years by such methods as we have been considering, without their making a permanent impression.

If what we are striving for is a better gen- 
eration of children we must begin by developing a better generation of parents. The glarHow Better ing defects at present are in the home. The Parents boys and girls now in school will be the parents of the next generation; we should see to it that they have a better preparation for their responsibilities than their parents had. What is there which prevents it?

The greatest obstacle in the way of improving the health of children is not poverty; it is ignorance and indifference. Dr. Osler put it right when addressing a public health meeting in Baltimore. He said: "We have a disease in this city more widely prevalent than tuberculosis, more fatal than cancer, one that causes many more deaths every year than the intestinal diseases of children." The audience, the physicians as well as others, wondered what the Doctor had in mind-when after continuing in the same strain for some minutes he announced that "the disease is Baltimore apathy." I fear this disease is not confined to Baltimore.

The foregoing discussion may be summed up in the following propositions which have been adopted as the creed of the Child Health Organisation: 
Every health movement which is to bring permanent results must have an educational basis.

It makes no difference what the particular phase of the health problem is that we are seeking to solve-whether it is cardiac disease, hookworm, tuberculosis or simply malnutrition among children-it all eomes back to the education of the individual in matters of personal hygiene.

To change the health ideas and the health habits of adults is difficult and the attempt very largely a failure.

Health education of the future must be directed to the children.

If all children are to be reached this education must be given in the schools.

In the past most of the health instruction of children has succeeded only in making health repulsive.

The aim of the Child Health Organisation is to make the teaching of health interesting and its practice attractive.

To initiate such a program as we have outlined must be the work of the physician; to carry it out is the task of the school authorities; it can succeed only when backed by an intelligent public opinion. 


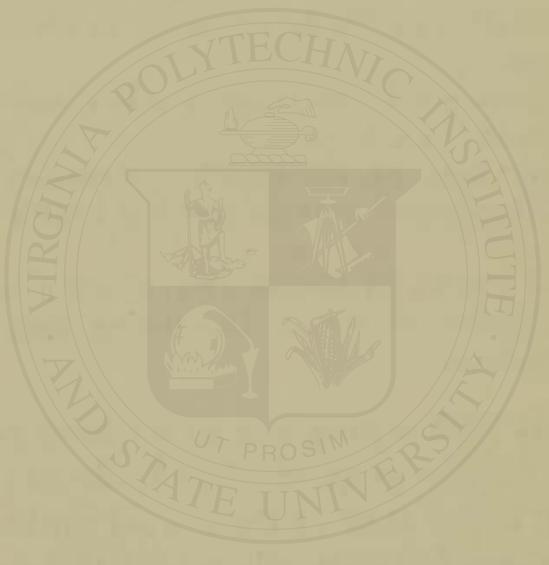




\section{APPENDIX}

THE CALORIC VALUE OF COMMON ARTICLES OF FOOD

Based ehiefly on the original tables of Atwater and Bryant and upon the calculations of Locke; partly ealeulated from original observations made in the laboratory of the Babies' Hospital. 


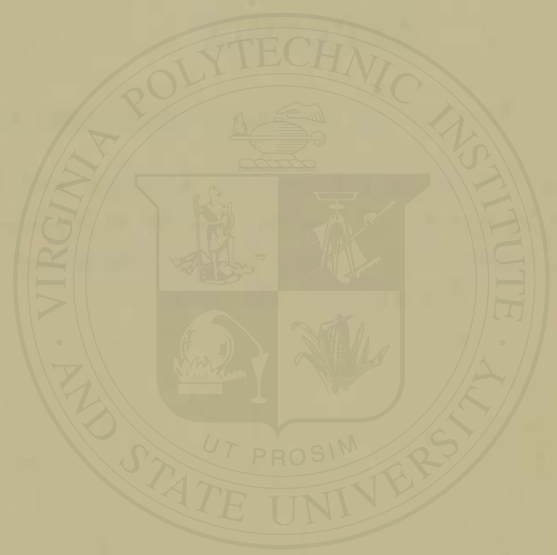




\begin{tabular}{|c|c|c|c|c|c|c|}
\hline & \multirow[b]{2}{*}{ Quantity } & \multirow[b]{2}{*}{$\begin{array}{l}\text { Weight } \\
\text { grams }\end{array}$} & \multicolumn{4}{|c|}{ CALORIES } \\
\hline & & & Fat & $\begin{array}{l}\text { Carbo- } \\
\text { hydrate }\end{array}$ & Protein & Total \\
\hline Meats & & & & & & \\
\hline Beef, roast, very lean.... & $1 \mathrm{or}^{*}$ & 20 & 3.0 & ....... & 19.0 & 22 \\
\hline Beef, round, fat removed, & $10 z$. & 20 & 14.3 & $\cdots \ldots \ldots$ & 22.7 & 37 \\
\hline Beefsteak, tenderloin .... & $1 \mathrm{oz}$ & 20 & 37.8 & $\cdots \cdots \cdots$ & 19.2 & 57 \\
\hline & $1 \mathrm{oz}$. & 20 & 23.7 & ........ & 16.3 & 40 \\
\hline Lamb chop, tenderloin only & $10 z$. & 20 & 23.7 & $\cdots \cdots \cdots$ & 16.3 & 40 \\
\hline Chicken, roast............ & $1 \mathrm{oz}$. & 20 & 8.1 & 1.7 & 26.2 & 36 \\
\hline Turkey, roast........... & $10 z$. & 20 & 34.0 & n...... & 23.0 & 57 \\
\hline Beef juice.............. & 108. & 30 & 6.2 & $\cdots \cdots \cdots$ & 1.8 & 8 \\
\hline Gravy, thick,............. & $10 \%$. & 30 & 44.0 & 12.0 & 6.0 & 62 \\
\hline $\begin{array}{l}\text { Bacon, beechnut, cooked } \\
\text { dry (raw slice, } 13 \text { grams) }\end{array}$ & 1 slice & 3.5 & 20.0 & $\cdots \cdots \cdots$ & 5.0 & 25 \\
\hline Fish & & & & & & \\
\hline Bluefish...$\ldots \ldots \ldots \ldots$ & $10 z$. & 20 & 8.6 & & 21.4 & 30 \\
\hline Cod,$\ldots \ldots \ldots \ldots \ldots$ & $1 \mathrm{oz}$. & 20 & 0.6 & 1.4 & 18.0 & 20 \\
\hline Trout, brook ............. & $10 z$. & 20 & 4.4 & 1.2 & 17.4 & 23 \\
\hline $\begin{array}{l}\text { Shellfish } \\
\text { Clams, long }\end{array}$ & & & & & & \\
\hline $\begin{array}{l}\text { Clams, long } \ldots \ldots \ldots \ldots \\
\text { Oysters, medium size........ }\end{array}$ & $\begin{array}{l}6 \\
6\end{array}$ & $\begin{array}{r}150 \\
85\end{array}$ & $\begin{array}{r}14.0 \\
9.5\end{array}$ & $\begin{array}{l}12.2 \\
12.9\end{array}$ & $\begin{array}{l}52.8 \\
21.6\end{array}$ & $\begin{array}{l}79 \\
44\end{array}$ \\
\hline Soups & & & & & & \\
\hline Consomme, canned....... & $4 \mathrm{oz}$ & 120 & & 2.0 & 12.0 & 14 \\
\hline $\begin{array}{l}\text { Pea, cream soup........... } \\
\text { Other cream soups (aver- }\end{array}$ & 4 or & 125 & 78.6 & 57.6 & 25.8 & 162 \\
\hline age of five) $\ldots \ldots \ldots \ldots$ & $40 \%$ & 125 & 83.1 & 29.7 & 13.2 & 126 \\
\hline Vegetable soup . ......... & $4 \mathrm{or}$ & 125 & 2.0 & 23.0 & 18.0 & 43 \\
\hline Tomato soup $\ldots \ldots \ldots \ldots \ldots$ & $4 \mathrm{oz}$ & 125 & 8.9 & 27.7 & 12.4 & 49 \\
\hline Dairy Products and Eggs & & & & & & \\
\hline $\begin{array}{l}\text { Milk, whole, } 3.5 \% \text { fat... } \\
\text { Skimmed milk, fat-free. }\end{array}$ & $1 \mathrm{oz}$ & 31 & 9.8 & $\begin{array}{l}5.9 \\
5.8\end{array}$ & 4.3 & 20 \\
\hline $\begin{array}{l}\text { Skimmed milk, fat-free. } \\
\text { Buttermilk, }\end{array}$ & $10 z$. & 32 & $\because \cdots$ & 5.8 & $\begin{array}{l}4.2 \\
4.0\end{array}$ & $\begin{array}{r}10 \\
9\end{array}$ \\
\hline & $10 z$. & $\begin{array}{l}82 \\
30\end{array}$ & $\begin{array}{r}0 \\
55.9\end{array}$ & $\begin{array}{l}5.0 \\
2.9\end{array}$ & $\begin{array}{l}7.0 \\
3.2\end{array}$ & 62 \\
\hline Cream, heavy, $40 \%$ fat... & $10 \%$. & 80 & 111.5 & 2.5 & 2.0 & 116 \\
\hline Condensed milk, sweetened & $10 z$ & 36 & 28.2 & 81.5 & 13.3 & 123 \\
\hline Butter,$\ldots \ldots \ldots \ldots \ldots$ & 1 level tsp. & 5 & 39.7 & ......... & 0.3 & 40 \\
\hline $\begin{array}{c}\text { Egg, whole } \\
\text { (wt. with sheil, } 58 \\
\text { grams.) }\end{array}$ & & 52 & 55.0 & .......... & 30.0 & 85 \\
\hline Egg, yolk.............. & 1 & 18 & 54.0 & & 12.0 & 65 \\
\hline Egg, white..$\ldots \ldots \ldots \ldots \ldots$ & $\overline{1}$ & 34 & 1.0 & ......... & 18.0 & 20 \\
\hline Vegetables & & & & & & \\
\hline Baked beans, home-made. & $10 \pi \cdot \cdots$ & 33 & 26.4 & 29.8 & 9.8 & $\begin{array}{l}66 \\
82\end{array}$ \\
\hline Lima beans, whole........ & $10 z$ & 20 & 1.3 & 24.2 & 6.5 & $\frac{32}{7}$ \\
\hline String beans ............. & $1 \mathrm{oz}$. & 30 & 3.0 & 3.0 & 1.0 & 14 \\
\hline Beets $\ldots . \cdots \cdots \ldots \ldots \ldots \ldots$ & 102. & $\begin{array}{l}35 \\
30\end{array}$ & 0.3 & $\begin{array}{r}10.5 \\
7.2\end{array}$ & $\begin{array}{l}3.2 \\
2.0\end{array}$ & 10 \\
\hline 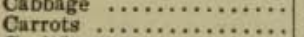 & $\begin{array}{l}10 z \\
1 \mathrm{oz} .\end{array}$ & $\begin{array}{l}30 \\
33\end{array}$ & $\begin{array}{l}0.8 \\
0.5\end{array}$ & $\begin{array}{l}7.2 \\
4.7\end{array}$ & $\begin{array}{l}2.0 \\
0.8\end{array}$ & 6 \\
\hline Cuuliflower ............ & $1 \mathrm{oz}$. & 20 & 0.8 & 3.8 & 1.4 & 6 \\
\hline
\end{tabular}

- Cut in small pieces and measured by volume; $1 \mathrm{oz}$, approximately 1 round tablespoonful.

$* 1$ oz. by volume approximately 1 round tablespoonful. 


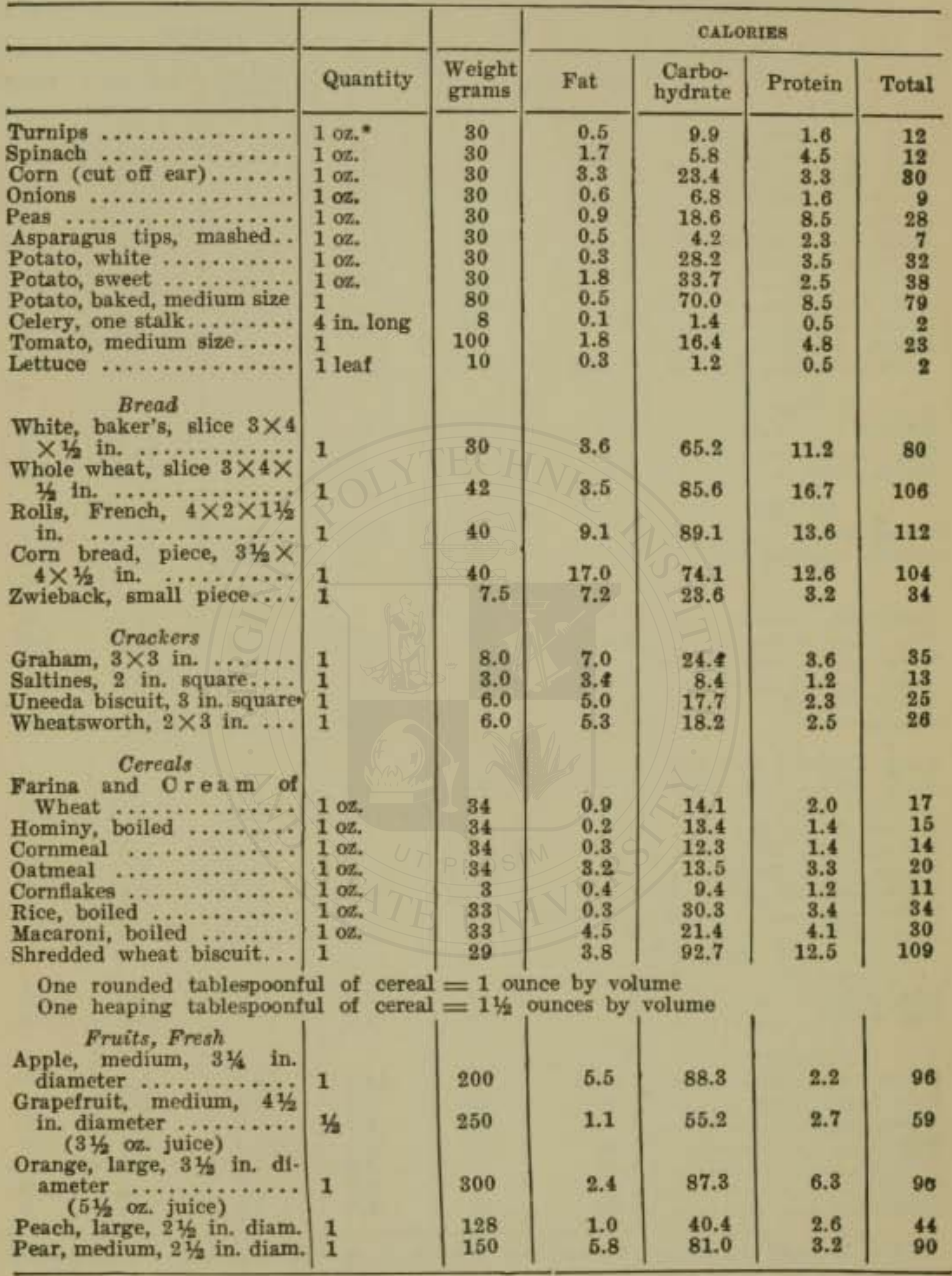

* 1 oz. by volume $=1$ round tablespoonful. 


\begin{tabular}{|c|c|c|c|c|c|c|}
\hline & \multirow[b]{2}{*}{ Quantity } & \multirow[b]{2}{*}{$\begin{array}{l}\text { Weight } \\
\text { grams } \\
\end{array}$} & \multicolumn{4}{|c|}{ CALOHIES } \\
\hline & & & Fat & $\begin{array}{c}\text { Carbo- } \\
\text { hydrate }\end{array}$ & Protein & Total \\
\hline $\begin{array}{l}\text { Strawberries, me di u m, } \\
1 \text { in. diameter } \\
\text { (11/2 oz, mashed })\end{array}$ & 6 & 50 & 2.8 & 15.2 & 2.0 & 20 \\
\hline $\begin{array}{l}\text { Banana, average, } 7 \text { in. } \\
\text { long ( } 100 \text { grams peeled })\end{array}$ & 1 & 160 & 6.0 & 92.8 & 5.2 & 104 \\
\hline Orange juice...$\cdots \cdots \cdots$ & $1 \mathrm{oz}$. & 30 & 0.6 & 14.4 & 1.0 & 16 \\
\hline $\begin{array}{l}\text { Fruits, Dried } \\
\text { Apricots, large .......... }\end{array}$ & & 40 & & & & \\
\hline $\begin{array}{l}\text { Apricots, large } \ldots \ldots \ldots \ldots \\
\text { Dates, large ............. }\end{array}$ & $\begin{array}{l}5 \\
5\end{array}$ & $\begin{array}{l}40 \\
42\end{array}$ & $\begin{array}{l}3.7 \\
9.7\end{array}$ & $\begin{array}{l}102.5 \\
120.0\end{array}$ & $\begin{array}{l}7.8 \\
3.3\end{array}$ & $\begin{array}{l}114 \\
133\end{array}$ \\
\hline Figs, lange ................. & 5 & 100 & 2.6 & 296.3 & 17.1 & 316 \\
\hline Prunes, large ........... & 5 & 100 & & 254.6 & 7.4 & 262 \\
\hline Raisins, large $\ldots \ldots \ldots \ldots$ & 5 & 12 & 3.5 & 35.2 & 1.3 & 40 \\
\hline Fruits, Cooked & & & & & & \\
\hline Apple sauce...$\ldots \ldots \ldots$ & $10 z$. & 35 & 1.7 & 35.8 & 0.5 & 38 \\
\hline Prune pulp $\ldots \ldots \ldots \ldots \ldots$ & $10 z$. & 35 & & 38.2 & 1.8 & 40 \\
\hline $\begin{array}{l}\text { Marmalade, orange } \ldots \ldots \ldots \\
\text { Jelly, currant ........... }\end{array}$ & $10 z$. & 35 & 0.3 & 103.9 & 0.8 & 105 \\
\hline $\begin{array}{l}\text { Jelly, currant } \ldots \ldots \ldots \ldots \\
\text { Apple, baked, large ....... }\end{array}$ & $10 z$ & $\begin{array}{r}35 \\
190\end{array}$ & $\cdots \cdots m_{4}$ & 111.5 & 1.5 & 113 \\
\hline $\begin{array}{l}\text { Apple, baked, large } . . .7 \% \\
\text { Peaches, canned, large, } 2 \text { is }\end{array}$ & & 120 & 5.4 & 120.1 & 2.5 & 128 \\
\hline in. ................. & 2 halves & 120 & 1.1 & 46.6 & 3.3 & 51 \\
\hline 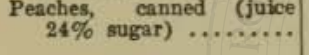 & $1 \mathrm{oz}$. & 33 & & 33.0 & & 33 \\
\hline $\begin{array}{l}\text { Cakes, Pastries, Puddings } \\
\text { Oookie, } 8 \text { in. diameter... }\end{array}$ & & & & & & \\
\hline Gingerbread, $1 \times 2 \times 3$ in. & 1 piece & $\begin{array}{r}9.0 \\
60.0\end{array}$ & 50.3 & $\begin{array}{r}31.0 \\
156.4\end{array}$ & $\begin{array}{r}2.9 \\
14.3\end{array}$ & $\begin{array}{r}42 \\
221\end{array}$ \\
\hline $\begin{array}{l}\text { Sponge cake, } 2 \times 3 \frac{1 / 2}{1 / 2} \times 1 / 2 \\
\text { in. } \ldots \ldots \ldots \ldots \ldots \ldots \ldots \ldots\end{array}$ & 1 piece & 23.0 & 22.9 & 62.2 & 6.0 & 91 \\
\hline Lady finger, 4 in. long ... & 1 & 20.0 & 9.2 & 57.8 & 7.0 & 74 \\
\hline Apple pie, 16 pie..... & 1 piece & 126.0 & 114.9 & 221.1 & 16.0 & 352 \\
\hline Custard pie, 16 pie ...... & 1 piece & 133.0 & 77.8 & 142.2 & 23.0 & 243 \\
\hline Bread pudding...$\ldots \ldots$ & $1 \mathrm{oz}$ & $\ldots \ldots$ & 13.2 & 47.2 & 7.6 & 68 \\
\hline $\begin{array}{l}\text { Rice pudding } \\
\text { Baked custard }(8 \ldots \ldots \text { oz. milk, }\end{array}$ & 102. & $\ldots \ldots$ & 15.7 & 35.4 & 8.9 & 60 \\
\hline $\begin{array}{c}1 \text { egg, } 1 \text { oz, sugar) } \ldots . . \\
\text { Junket ( } 8 \text { oz milk, } 1 \text { oz. }\end{array}$ & $1 \propto z$. & $\cdots$ & 17.0 & 13.5 & 6.5 & 37 \\
\hline sugar) $\ldots . . . \cdots \ldots \ldots . . .$. & $1 \propto z$. & & 9.7 & 13.8 & 4.5 & 28 \\
\hline Apple tapioca $\ldots \ldots \ldots \ldots$ & 108. & & 0.6 & 35.1 & 0.3 & 36 \\
\hline Chocolate cornstarch ..... & $10 \%$. & $\ldots \ldots$ & 24.4 & 38.0 & 6.6 & 69 \\
\hline Ice cream * ............ & $1 \mathrm{oz}$. & $\ldots \ldots$ & 28.5 & 22.0 & 6.5 & 57 \\
\hline Orange ice,$\ldots \ldots \ldots \ldots$ & $10 z$. & & 0.5 & 91.8 & 1.7 & 94 \\
\hline Tapioca pudding $\ldots \ldots \ldots$ & $10 z$ & $\cdots \cdots$ & 18.2 & 29.2 & 7.6 & 55 \\
\hline 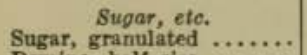 & 1 level tsp. & 6 & & 25 & $\cdots \cdots \cdots$ & 25 \\
\hline Domino, half size ........ & & 6 & $\ldots \ldots$ & 25 & $\ldots \ldots \ldots$ & 25 \\
\hline Domino, cube.....$\ldots \ldots$. & & 7 & $\ldots \ldots \ldots$ & 29 & ...... & 29 \\
\hline Honey, 20 c. c. . ........ & 1 tbsp. & 30 & $\ldots \ldots \ldots$ & 100 & 1.0 & 101 \\
\hline Maple syrup, 20 c.c. ..... & 1 thsp. & 30 & n....... & 88 & $\cdots \cdots \cdots$ & 88 \\
\hline Karo eorn syrup, 20 c.c. . & 1 tbsp. & 30 & $\ldots \ldots$ & 95 & $\cdots \cdots \cdots$ & 95 \\
\hline Ice cream soda...$\ldots \ldots$. & 1 & $\ldots \ldots$ & 94.7 & 161.9 & 21.4 & 278 \\
\hline
\end{tabular}

- Made with egg. 


\begin{tabular}{|c|c|c|c|c|c|c|}
\hline & \multirow[b]{2}{*}{ Quantity } & \multirow[b]{2}{*}{$\begin{array}{l}\text { Weight } \\
\text { grams }\end{array}$} & \multicolumn{4}{|c|}{ CALORIEB } \\
\hline & & & Fat & $\begin{array}{l}\text { Carbo- } \\
\text { hydrate }\end{array}$ & Protein & Total \\
\hline 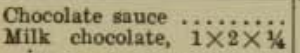 & 108. & $\cdots \cdots$ & 36.0 & 112.0 & 4.0 & 152 \\
\hline Fudge, $1 \times 1 \times 1 \times 3$ in. $\ldots \ldots$ & $\begin{array}{l}1 \text { piece } \\
1 \text { piece }\end{array}$ & $\begin{array}{l}10 \\
28\end{array}$ & $\begin{array}{l}29.0 \\
20.2\end{array}$ & $\begin{array}{l}26.0 \\
46.5\end{array}$ & $\begin{array}{l}8.0 \\
8.3\end{array}$ & $\begin{array}{l}58 \\
70\end{array}$ \\
\hline 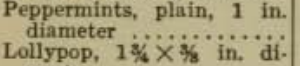 & 1 & 7 & 0.3 & 26.7 & 0 & 27 \\
\hline ameter...$\ldots \ldots \ldots \ldots$ & 1 & 27 & 0 & 107.0 & 0 & 107 \\
\hline 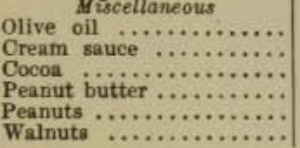 & $\begin{array}{l}1 \text { ot. } \\
1 \text { oz. } \\
1 \text { tsp. } \\
1 \text { tsp. } \\
10 \\
1\end{array}$ & $\begin{array}{l}25 \\
30 \\
2.5 \\
9 \\
20 \\
4\end{array}$ & $\begin{array}{l}235 \\
43 \\
6.8 \\
39.0 \\
54 \\
25.3\end{array}$ & $\begin{array}{r}0 \\
12.8 \\
3.9 \\
6.3 \\
15.0 \\
2.4\end{array}$ & $\begin{aligned} 0 \\
5.2 \\
2.3 \\
10.7 \\
16.0 \\
\mathbf{8 . 3}\end{aligned}$ & $\begin{array}{r}235 \\
61 \\
13 \\
56 \\
85 \\
31\end{array}$ \\
\hline
\end{tabular}




\section{INDEX}

Accessory food factors (see Vitamines).

Activity, ealoric requirements for, 55 .

inereased ealoric requirements during, 67.

Adolescence, food requirements during, 66.

food needs greater during, 76 . American ehildren, size of, 20.

Amino-acids, essential for growth, 89.

Antiscorbutic foods, 177, 183.

Antiscorbutic vitamine (see Vitamine C).

Ayers, on school retardation, 23.

Balanced ration, importance of, 147.

Benediet and Talbot, basal requirements, 50 .

Beri-beri, 152, 172.

Blanton, on German children with malnutrition, 30 .

Bloch, eye disease in infants from defieiency of fat, 163.

Bones, salts needed for, 139 .

Bryant, school survey, 25.

Cabbage, 207.

Calcium, milk important source, 138.

California ehildren, size, 21.

Caloric requirements, basal, 50 .

for growth, 54.

for aetivity, 55 .

estimate of, 60 .

complete daily schedule, 73 .
Calorie, definition, 47 .

Calories, for basal metabolism, 50. growth allowanee, 54. activity allowance, 55 . excreta allowance, 60 . total requirements, 60 . per kilo, 65. eomplete sehedules per kilo, 67 . eomplete sehedules, daily requirements, 73 . taken by 100 healthy children, 78.

table giving suggested total daily, 84 . distribution of in diet, 139.

Camerer, total ealories, 61, 65. protein intake, 100.

fat intake, 117.

distribution of ealories, 146.

Candy, consumption of, 124.

Carbohydrate, funetions of, 120. requirement, 120 .

intake of infants, 123. of older children, 124. of adults, 126.

tendency to overfeed with, 124. proportion taken as sugar, 128. and dental earies, 131. amount recommended, 132.

Carbohydrates, effect of excess of, $37,129,131$. economical, 121.

Chiek and Hume, observations on vitamine C, 182.

amount of vitamine required for protection, 197.

Child Health Organisation, ereed of, 260. 
Club motive, use of in health instruction, 233.

Condensed milk, effects of, 130 .

Cow's milk, low in iron, 137.

Jzerny and Keller, Mehinährschaden, 165.

Deficiency diseases, 44.

Dental caries and earbohydrates, 131.

Detroit, sehool survey, 27.

Draft, results of, 7 .

Education, of parents, 10, 260. importance of, in nutrition problem, 209.

disease prevented by, 220 .

of adults, diffieult, 223 .

Eijkman, early observations on beri-beri, 173.

Energy, definition, 87.

Excreta, calories lost in, 58.

Fat, requirement, 107.

function of, 108.

effect of, on mineral metabolism, 111.

starvation and susceptibility to infeetions, 112.

intake of nursing infant, 115. of artifieially-fed infants, 116. of older ehildren, 116. of adoleseent boys, 118.

symptoms due to excess of, 118. amount recommended, 120 .

Fat-soluble vitamine (see Vitamine A).

Food, influence of, on growth, 17 . of Japanese ehildren, 18. requirements, 47 .

valued by vitamine content, 191 .

Foods, injured by preservation and storage, 192.

infant, deficieney in vitamines, 199.

Funk, observations on beri-beri, 152.
Gephart, observations at St. Paul's School, 62, 100, 117, 125.

Gillett, ealorie intake, 60 . protein intake, 99.

Gillett and Sherman, ealorie intake, 66 .

Government, expenditure for Department of Animal Industry, 14.

appropriation for Children's Bureau, 15.

Growth, determined by food, 18.

of Japanese children, 19.

effeets of prolonged underfeeding on, 42.

ealoric requirements for, 52 .

estimated calories needed for, 54.

amino-acids necessary for, 89 . protein allowance for, 92 .

Growth rate, 52.

Habits, bad, a eause of malnutrition, 211.

formation, essential to health, 231.

Hart, Steenboek and Ellis, vitamine content of cow's milk, 187.

Health, eompetition in, 242.

municipal appropriations for, 15.

Health education, preventing disease by, 220 .

in home, 224.

in school, 225.

by older methods, 226 .

successful and unsuccessful methods in, 230.

play motive in, 232.

elub motive in, 233.

of older ehildren, 244.

of teacher, 248.

eorrelated with other sehool sub. jects, 246, 250.

Health habits, 231. 
Health literature for ehildren, 238. Milk, importance of during plays, 236.

posters, 237.

rhymes, 237.

Hess, on antiscorbutic vitamine, 201.

Hill, observations in Germany, 57.

Hopkins, early observations on vitamines, 152.

Holst, seurvy in animals, 158.

Infancy, period of susceptibility to vitamine deficiency, 198.

Infeetion, resistance to, dependent upon nutrition, 33 .

susceptibility of delicate children to, 35.

Iron, deficiency of, in cow's milk, 137.

Japanese ehildren, food of, 18. growth of, 19.

Jews, Russian, growth of, in U. S., 20.

Kerato-malacia, 163.

Lard, vitamine A in, 189.

Lusk, estimate for ealoric requirements, 56, 67 .

Malnutrition, extent of, $8,215$. nervous symptoms in, 31, 214. causes of, 209.

evidences of, 214. prevention of, 215.

MeCollum and Davis, on vitamines, 155.

Medical school examinations, 218.

Mehlnährschaden, 165.

Metabolism, definition, 47. basal, 50 .

Milk, an important source of calcium, 138.

effect of heating, on vitamine C, 178 .

growth, 206.

amount required, 206.

Mineral salts, funetions of, 135 .

Mortality, infant, reduction of, $5,219$.

Müller, on ealories lost in $\mathbf{e x}$ ereta, 59.

on protein intake, 100.

on fat intake, 117.

Nervous symptoms, and malnutrition, 31, 214.

Noël and Paton, observations an Vienna children, 43.

Nutrition, factors influeneing, 17. importance of in treatment of disease, 36 .

in ehronic disease, 38 .

in organic disease, 39 .

in ehronic nervous disease, 41.

practical measures for improving, 208.

weight-height relationship, index to, 212.

Nutrition classes, 253.

Orange juice, amount needed to protect against seurvy, 182.

Osborne and Mendel, effect of different proteins on growth of rats, 93 .

of salts, on growth of rats, 93.

of vitamine B, on growth of rats, 170 .

low-fat diet, 109.

early observations on vitamines, 154.

Oxidation, effect of, on vitamines, 185.

Packer and Moehlman, sehool survey by, 27.

Parents, education of, 10, 260.

Paton and Watson, observations on rickets, 168 . 
Physical education and training not health teaching, 227 .

Play motive, use of in health instruetion, 232.

Porter, observations on growth and school progress, 24.

Pre-school child, neglect of, 6. ways of reaching, 216.

Preventive medicine, opposition to, 12.

Protein intake of healthy children, 101.

Proteins, composition of, 88. adult requirement, 90 . animal, preferable for growth, 90,92 .

animal vs. vegetable, 91, 106.

growth allowance, 92 .

effect of different, on growth of rats, 93.

in woman's milk, 94 .

in eow's milk, 96 .

in condensed milk, 97.

amount needed by infants taking cow's milk, 98 .

amount for older ehildren, 99. amount per kilo, 103. vegetable, of lower grade, 106.

Rickets, causes of, 167 .

Ross, on kerato-malacia, 164.

School retardation, 22.

Seurvy, a defieiency disease, 157.

time required to produce, 180.

Smith, Theobald, observations on seurvy in animals, 158.

St. Paul's Sehool, calories taken by boys in, 62 .

Stunted children, 213.

Tigerstedt, on total calories, 62 .

Underfeeding, effects of, 3 . arrest of growth in, 42 .
Vegetables, importance of, 170, $176,204$.

Vitamine A, 157.

sourees of, 159 .

symptoms due to deficiency of, 161,163 .

Vitamine B, 157. sources of, 169.

symptoms due to deficiency of, 171.

Vitamine C, 159.

not needed by certain animals, 175.

sources of, 176 .

injured by heat, 176, 179 .

small amount of in milk, 178. amount needed for protection against seurvy, 181.

Vitamines, 149.

early observations of Hopkins on, 152.

effeet of oxidation on, 185 .

solubility of, 186.

effeet of food upon amount of, in cow's milk, 187.

in woman's milk, 187.

in diet of nursing mother, 187. deficiency of, when likely, 195.

requirements, conditions affecting, 197.

deficiency of, in infancy, 198. specific action of, 199.

symptoms due to relative defieiency of, 200.

commercial exploitation of, 203.

use not indieated when no defieiency, 203.

Von Gröer, infants on fat-free diet, 110.

War edema, 165.

Washington, survey of school children in, 26.

Water-soluble vitamine (see Vitamine B). 
Weighing, how used in health edu- Whole wheat flour, advantages and eation, 240.

Weight-height relationship, an index to nutrition, 212 .

Weight records, value and purpose of, 238.

White wheat flour, advantages and disadvantages of, 192.

disadvantages of, 193.

Xerophthalmia, 162.

Yeast, vitamines in, 155. in malnutrition, 202. 


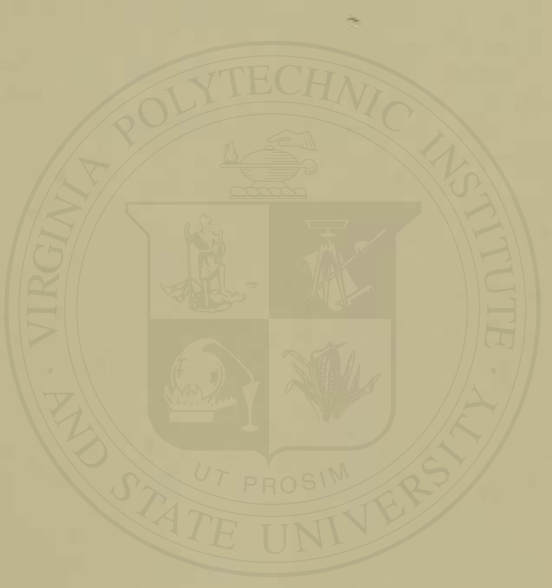




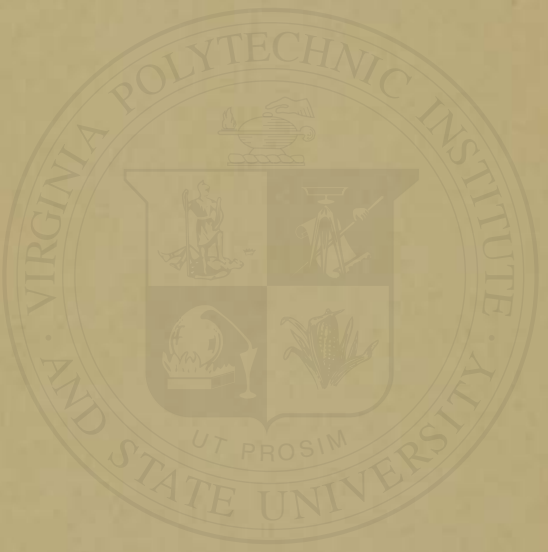




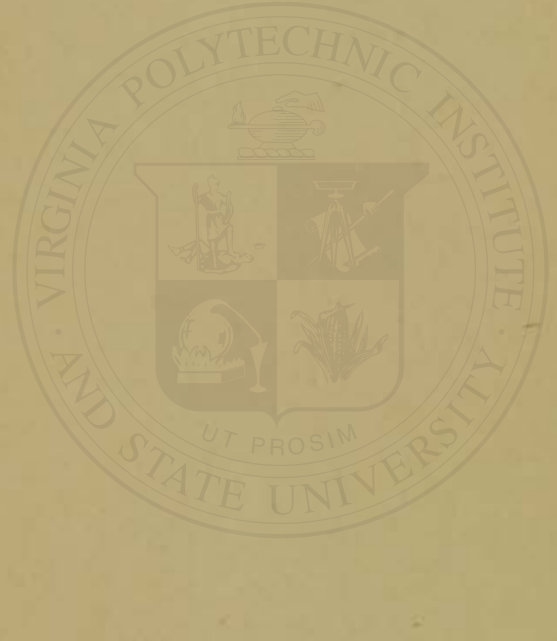




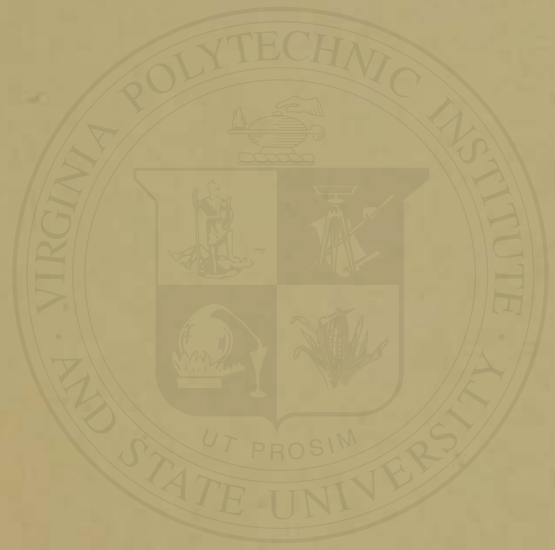


